NBER WORKING PAPER SERIES

\title{
ON THE MEASUREMENT OF UPSTREAMNESS AND DOWNSTREAMNESS IN GLOBAL VALUE CHAINS
}

\author{
Pol Antràs \\ Davin Chor \\ Working Paper 24185 \\ http://www.nber.org/papers/w24185 \\ NATIONAL BUREAU OF ECONOMIC RESEARCH \\ 1050 Massachusetts Avenue \\ Cambridge, MA 02138 \\ January 2018
}

We are grateful to Lorenzo Caliendo, Thibault Fally, Gene Grossman, Lili Yan Ing, and John Romalis for helpful comments, as well as to Jiacheng (Jack) Feng for extremely valuable research assistance. Antràs acknowledges support from the NSF (proposal \#1628852). Chor acknowledges support from the Global Production Networks Center at the National University of Singapore (GPN@NUS). The views expressed herein are those of the authors and do not necessarily reflect the views of the National Bureau of Economic Research.

NBER working papers are circulated for discussion and comment purposes. They have not been peer-reviewed or been subject to the review by the NBER Board of Directors that accompanies official NBER publications.

(C) 2018 by Pol Antràs and Davin Chor. All rights reserved. Short sections of text, not to exceed two paragraphs, may be quoted without explicit permission provided that full credit, including () notice, is given to the source. 
On the Measurement of Upstreamness and Downstreamness in Global Value Chains

Pol Antràs and Davin Chor

NBER Working Paper No. 24185

January 2018

JEL No. D5,F1,F2

\begin{abstract}
$\underline{\text { ABSTRACT }}$
This paper offers four contributions to the empirical literature on global value chains (GVCs). First, we provide a succinct overview of several measures developed to capture the upstreamness or downstreamness of industries and countries in GVCs. Second, we employ data from the World Input-Output Database (WIOD) to document the empirical evolution of these measures over the period 1995-2011; in doing so, we highlight salient patterns related to countries' GVC positioning - as well as some puzzling correlations - that emerge from the data. Third, we develop a theoretical framework - which builds on Caliendo and Parro's (2015) variant of the Eaton and Kortum (2002) model - that provides a structural interpretation of all the entries of the WIOD in a given year. Fourth, we resort to a calibrated version of the model to perform counterfactual exercises that: (i) sharpen our understanding of the independent effect of several factors in explaining the observed empirical patterns in the period 1995-2011; and (ii) provide guidance for how future changes in the world economy are likely to shape the positioning of countries in GVCs.
\end{abstract}

\author{
Pol Antràs \\ Department of Economics \\ Harvard University \\ 1805 Cambridge Street \\ Littauer Center 207 \\ Cambridge, MA 02138 \\ and NBER \\ pantras@fas.harvard.edu \\ Davin Chor \\ Department of Economics \\ National University of Singapore \\ 1 Arts Link \\ Singapore 117570 \\ davinchor@nus.edu.sg
}

A data appendix is available at http://www.nber.org/data-appendix/w24185 


\section{Introduction}

In 2017, international trade economists celebrated the two hundredth anniversary of the birth of their field, as marked by the publication of David Ricardo's Principles of Political Economy and Taxation. This treatise is widely recognized to contain the first lucid exposition of the concept of comparative advantage. Although the notion of comparative advantage is as relevant today as it was two hundred years ago, the nature of international trade flows has dramatically changed in recent decades. Technological, institutional and political developments in the last 30 years have led to a sharp disintegration of production processes across borders, as firms found it more and more profitable to organize production on a global scale. Countries are no longer exchanging "cloth for wine", to quote Ricardo's famous example. Instead, world production is now structured into global value chains (GVCs, hereafter) in which firms source parts, components or services from producers in several countries, and in turn sell their output to firms and consumers worldwide.

By dramatically altering the international organization of production, the rise of GVCs has placed the specialization of countries within GVCs at center stage. Where in GVCs are different countries specializing? What are the determinants of a country's positioning in GVCs? What are the real income implications of moving up or down GVCs? Although we still lack definitive answers to these questions, a recent body of work in international trade has contributed to our understanding by developing measures of the positioning of countries and industries in GVCs (see Fally, 2012, Antràs et al., 2012, Antràs and Chor, 2013, Fally and Hillberry, 2015, Alfaro et al., 2017, Miller and Temurshoev, 2017, Wang et al., 2017). ${ }^{1}$ The intellectual foundation and computation of these measures is based on Input-Output (I-O) analysis. The application of Input-Output techniques by trade economists has in turn been reciprocated by an increased interest by Input-Output practitioners on the global dimension of inter-industry linkages. Indeed, a big contributing factor to the popularization of the literature on GVC positioning has been the construction and widespread availability of global Input-Output tables, which provide a detailed picture of inter-industry commodity flows both within and across countries.

A key limitation of existing approaches to measuring the positioning of countries in GVCs is that they lack a theoretical foundation within the realm of modern general equilibrium models of international trade. With information on the various entries of a global Input-Output table, a researcher can compute the implied upstreamness or downstreamness of specific industries and countries. But without knowledge of what shapes these I-O entries, a researcher cannot tease out the primitive determinants of GVC positioning or elucidate how changes in the economic environment (e.g., changes in trade costs) are likely to affect the specialization of countries within GVCs. To be clear, we do not mean to imply that the literature on GVCs has been atheoretical in nature. On the contrary, in recent years, various theoretical frameworks have been developed highlighting the implications of the rise of GVCs for the workings and implications of general equilibrium models

\footnotetext{
${ }^{1}$ These contributions relate to a parallel body of work, starting with the seminal piece of Johnson and Noguera (2012), that has been concerned with tracing the value-added content of trade flows and the participation of various countries in GVCs (see Koopman et al., 2014, Johnson, 2014, Timmer et al., 2014, de Gortari, 2017).
} 
of international trade. ${ }^{2}$ Nevertheless, the vast majority of theoretical models developed to date are too stylized to easily map to global Input-Output tables. ${ }^{3}$

This paper makes four contributions to the literature on GVCs. First, we provide a succinct overview of various measures developed in the literature to capture the upstreamness or downstreamness of industries and countries in GVCs. Second, we employ data from the World InputOutput Database (WIOD) to document the empirical evolution of these measures over the period 1995-2011. Third, we develop a theoretical framework - which builds on Caliendo and Parro (2015) - that provides a structural interpretation of all the entries of the WIOD in a given year. Fourth, we then resort to a calibrated version of the model to perform counterfactual exercises that: (i) sharpen our understanding of the independent effect of several factors in explaining the observed empirical patterns between 1995-2011; and (ii) provide guidance for how future changes in the world economy are likely to shape the positioning of countries in GVCs.

The key measures of upstreamness explored in this paper are introduced in Section 2. These measures envision a world in which production in GVCs features some element of sequentiality. ${ }^{4}$ We first consider a measure of distance or upstreamness of a production sector from final demand which was developed independently by Fally (2012) and Antràs and Chor (2013), and consolidated in Antràs et al. (2012). This measure (which we label $U$ ) aggregates information on the extent to which an industry in a given country produces goods that are sold directly to final consumers or that are sold to other sectors that themselves sell disproportionately to final consumers. A relatively upstream sector is thus one that sells a small share of its output to final consumers, and instead sells disproportionately to other sectors that themselves sell relatively little to final consumers. A second related measure, originally proposed by Fally (2012), captures the distance or downstreamness of a given sector from the economy's primary factors of production (or sources of value-added). According to this measure (which we denote by $D$ ), an industry in a given country will appear to be downstream if its production process uses little value-added relative to intermediate inputs, and particularly so when it purchases intermediate inputs from industries that themselves use intermediate inputs intensively. In addition, we also discuss simpler versions of these two measures of GVC positioning: the first reduces the measure in Antràs et al. (2012) to simply the share of a country-industry's output that is sold directly to final consumers (denoted by $F / G O$ ), while the second reduces the Fally (2012) measure of distance from value-added to simply

\footnotetext{
${ }^{2}$ See, among others, Harms et al. (2012), Baldwin and Venables (2013), Costinot et al. (2013), Antràs and Chor (2013), Fally and Hillberry (2015), Kikuchi et al. (2017), and Tyazhelnikov (2017). This literature is in turn inspired by earlier contributions to modeling multi-stage production, such as Dixit and Grossman (1982), Sanyal and Jones (1982), Kremer (1993), Yi (2003, 2010), and Kohler (2004).

${ }^{3}$ Two recent exceptions are the work of Antràs and de Gortari (2017) and de Gortari (2017), who develop multicountry models that emphasize the sequential nature of trade flows in GVCs. Their frameworks provide a structural interpretation of global Input-Output tables, but the calibration of those models requires a much more cumbersome estimation procedure than is required for the model developed in this paper.

${ }^{4}$ Baldwin and Venables (2013) famously introduced the term 'snakes' to refer to purely sequential value chains, in which each production stage obtains its inputs from a unique upstream stage. They distinguished 'snakes' from 'spiders', which are flatter GVCs in which each production stage sources from several upstream suppliers simultaneously. The measures of GVC positioning that we review in Section 2 are defined in a general way, so that they can be computed for production processes that have both 'snake'-like as well as 'spider'-like features.
} 
the share of a country-industry's payments accounted for by payments to primary factors (denoted by $V A / G O)$.

Although these measures were initially developed at the industry-level with national InputOutput tables in mind, we show that it is straightforward to define them and compute them at the country-industry level with data from global Input-Output tables, as in the recent work of Fally and Hillberry (2015) and Miller and Temurshoev (2017). Similarly, taking weighted averages of these indices across sectors, one can easily compute the average upstreamness or downstreamness of specific countries in GVCs, which we will adopt as summary measures of countries' GVC positioning.

With these definitions in hand, in Section 3 we use data from the WIOD to compute these measures for the period 1995-2011. We unveil two systematic and somewhat surprising facts. First, countries that appear to be upstream according to their production-staging distance from final demand $(U)$ are at the same time recorded to be downstream according to their production-staging distance from primary factors $(D)$. This puzzling finding is also observed when working with the simpler $F / G O$ and $V A / G O$ measures. More specifically, countries that sell a disproportionate share of their output directly to final consumers (thus appearing to be downstream in GVCs according to $U$ ) tend to also feature high value-added over gross output ratios, reflecting a limited amount of intermediate inputs embodied in their production (thus appearing to be upstream in GVCs according to $D$ ). Our second main empirical finding relates to the evolution of these measures. Not only is the puzzling positive correlation between $U$ and $D$ (and between $F / G O$ and $V A / G O$ ) present in all the years in our sample, but it actually appears to have intensified between 1995-2011. While we first illustrate these results using the GVC measures aggregated at the country level, we further show that these positive correlations (as well as their increase over time) are also observed in the GVC measures as originally computed at the country-industry level.

In Section 4, we provide a tentative investigation of the possible causes behind these salient and puzzling facts from the data. We first explore the role of trade costs. Note that in a closed economy, value-added coincides with final consumption as a national accounting identity; thus, in a crosssection of closed economies that differ in their value-added intensity in production, one would expect to record a perfect positive correlation between $F / G O$ and $V A / G O$. This suggests that the observed positive correlation between these indices (and between $U$ and $D$ ) might reflect the persistence of large trade barriers across countries. When applying the Head and Ries (2001) approach to back out implied trade costs, we indeed find these costs to be substantially high, even towards the end of our sample. Nevertheless, we also find that average trade barriers fell significantly in the period 1995-2011 (especially prior to the Global Financial Crisis), while the positive correlation between the various pairs of country-level GVC measures actually intensified. This suggests that other mechanisms must have been in play to explain the puzzling facts unveiled in Section 3. As a second candidate explanation, we provide evidence for the importance of compositional effects related to the differential (and growing) importance of services. Intuitively, service sectors feature short production chain lengths, with both a high ratio of sales to final consumers and little use of intermediate inputs in production. The cross-country variation in our measures of upstreamness 
(as well as the positive correlation among $U$ and $D$ ) thus partly reflects variation in the importance of service sectors in the production structure of different countries. ${ }^{5}$

In order to better elucidate the quantitative importance of these alternative explanations, and also to be able to interpret the data in a structural manner, we turn in Section 5 to develop a theoretical model. We begin by reviewing Caliendo and Parro's (2015) extension of the Eaton and Kortum (2002) Ricardian model of trade. In its closed economy version, the Cobb-Douglas structure of the demand and production sides of this model are closely related to the framework in Acemoglu et al. (2012). As is well known, the demand and technological Cobb-Douglas parameters of that model can easily be recovered from expenditure shares reported in national Input-Output tables. In the type of open-economy equilibrium corresponding to a global Input-Output table, cross-country and cross-industry expenditure shares are less straightforward to map structurally to a model because they are the outcome of competition across potential sources, and are thus shaped by differences in productivity and trade costs across countries. Caliendo and Parro (2015) showed, however, that a variant of the Eaton and Kortum (2002) framework could be used to interpret structurally the share of purchases of a given type of industry good originating from different source countries.

We develop in Section 5 an extension of the Caliendo and Parro (2015) model that features a more flexible formulation of trade costs, in order to be able to fully match all entries of a World Input-Output Table (WIOT) that relate to trade in intermediate inputs and trade in goods/services designated for final consumption. In its original form, the Caliendo and Parro (2015) model does not allow these "trade shares" to vary depending on the identity of the purchasing entity, that is, depending on whether they are sold to final consumers or to different industries as inputs. Instead, the model (implicitly) imposes certain restrictions on these entries that need not (and typically do not) hold in the actual data. Given our objective of providing a structural interpretation of the GVC measures described in Section 2, it is instead desirable to correctly match both the intermediate-use and final-use trade shares, since the implied values of upstreamness and downstreamness will clearly depend on the extent to which a sector's output is sold to final consumers or to other industries. ${ }^{6}$ For the extension we develop, we further show - in line with Dekle et al. (2008) and Caliendo and Parro (2015) - that in order to perform various counterfactuals, all that is required are: (i) initial trade shares available from a WIOT; (ii) demand and technological Cobb-Douglas parameters easily recoverable from the same WIOT; and (iii) a vector of sectoral parameters shaping the elasticity of trade flows (across source countries) to trade barriers.

\footnotetext{
${ }^{5}$ In the ongoing revision of his 2012 working paper, Fally studies the role of the growth of the service sector in explaining the downward trend in $D$ observed in U.S. Input-Output Tables in the period 1947 to 2002.

${ }^{6}$ A recent paper by Alexander (2017) extends the Caliendo and Parro (2015) framework by allowing trade shares to vary depending on whether goods are sold to final consumers or to other industries, but imposes a common trade share for all intermediate input purchasing industries. Readers familiar with the construction of WIOTs will be aware that proportionality assumptions are commonly adopted that would imply identical trade shares for all input purchasing industries. In practice though, the World Input-Output Database (WIOD) used in this paper introduces minor adjustments that generate some variation in input trade shares in the data. Following the lead of de Gortari (2017), we hypothesize that future WIOTs will make better use of firm-level import and export data to generate even larger departures from such proportionality assumptions.
} 
In Section 6, we leverage this result to undertake several counterfactual exercises. We first attempt to trace the relative contribution of trade cost reductions and the growing share of final consumption of services for explaining the puzzling increase in the key correlations between $F / G O$ and $V A / G O$ (and between $U$ and $D$ ) over the 1995-2011 period. Our quantitative results confirm that declining trade costs tend only to aggravate the high-correlation puzzle. On the other hand, we find that changes in final consumption shares did contribute - but only modestly - to the observed increase in the correlation between these GVC measures. We next use our model to shed light on the potential future evolution of the positioning of industries and countries in GVCs. We do so by experimenting with possible scenarios involving different trade cost reductions, as well as further increases in the share of countries' spending on services. Interestingly, we find that a trade cost reduction that is disproportionately larger for services than for goods industries can induce a further increase in the correlation between $F / G O$ and $V A / G O$ (and between $U$ and $D$ ); this is because a change in trade costs of this nature would tend to reinforce initial patterns of specialization for countries with comparative advantage in services.

The rest of the paper is structured as follows. In Section 2, we review the empirical measures of GVC positioning. In Section 3, we compute these measures using data from the WIOD for the period 1995-2011 and discuss several patterns that emerge. In Section 4, we explore two possible explanations for these patterns. In Section 5, we turn to a theoretical model to interpret the data structurally, and in Section 6, we use the framework to perform counterfactual exercises. Finally, in Section 7, we offer some concluding comments. (The Appendix contains some technical details of our model.)

\section{An Overview of Four Measures of GVC Positioning}

In this section, we develop the main measures of GVC positioning we will work with throughout the paper. $^{7}$ Our unit of analysis is a country-industry pair such as Electrical and Optical Equipment in Australia. The goal is to devise measures of the extent to which a country-industry is relatively upstream or downstream in global value chains. These measures are built with the type of data available from global Input-Output tables. We shall refer to a world Input-Output table as a WIOT, and Figure 1 provides a schematic version of one such WIOT.

The WIOT in Figure 1 considers a world economy with $J$ countries (indexed by $i$ or $j$ ) and $S$ sectors (indexed by $r$ or $s$ ). In its top left $J \times S$ by $J \times S$ block, the WIOT contains information on intermediate purchases by industry $s$ in country $j$ from sector $r$ in country $i$. We denote these intermediate input flows by $Z_{i j}^{r s}$. To the right of this block, the WIOT contains an additional $J \times S$ by $J$ block with information on the final-use expenditure in each country $j$ on goods originating from sector $r$ in country $i$. We denote these final consumption flows by $F_{i j}^{r}$. The sum of the $(J \times S)+J$ terms in each row of a WIOT represents the total use of output of sector $r$ from country $i$, and naturally coincides with gross output in that sector and country (denoted by $Y_{i}^{r}$ ).

\footnotetext{
${ }^{7}$ See Johnson (2017) for a recent complementary overview of these and other measures of GVC activity.
} 


\begin{tabular}{|c|c|c|c|c|c|c|c|c|c|c|c|c|c|}
\hline & & & \multicolumn{7}{|c|}{ Input use \& value added } & \multicolumn{3}{|c|}{ Final use } & \multirow[t]{2}{*}{ Total use } \\
\hline & & & \multicolumn{3}{|c|}{ Country 1} & $\cdots$ & \multicolumn{3}{|c|}{ Country $J$} & Country 1 & $\cdots$ & Country $J$ & \\
\hline & & & Industry 1 & $\cdots$ & Industry $S$ & $\cdots$ & Industry 1 & $\cdots$ & Industry $S$ & & & & \\
\hline \multirow{3}{*}{ Intermediate } & \multirow{3}{*}{ Country 1} & Industry 1 & $Z_{11}^{11}$ & $\cdots$ & $Z_{11}^{1 S}$ & $\cdots$ & $Z_{1 J}^{11}$ & $\cdots$ & $Z_{1 J}^{1 S}$ & $F_{11}^{1}$ & $\cdots$ & $F_{1 J}^{1}$ & $Y_{1}^{1}$ \\
\hline & & $\ldots$ & $\cdots$ & $Z_{11}^{r s}$ & $\cdots$ & $\cdots$ & $\cdots$ & $Z_{1 J}^{r s}$ & $\cdots$ & $\cdots$ & $\cdots$ & $\cdots$ & $\cdots$ \\
\hline & & Industry $S$ & $Z_{11}^{S 1}$ & $\cdots$ & $Z_{11}^{S S}$ & $\cdots$ & $Z_{1 J}^{S 1}$ & $\cdots$ & $Z_{1 J}^{S S}$ & $F_{11}^{S}$ & $\cdots$ & $F_{1 . J}^{S}$ & $Y_{1}^{S}$ \\
\hline \multirow[t]{2}{*}{ inputs } & $\cdots$ & $\cdots$ & $\cdots$ & $\cdots$ & $\cdots$ & $Z_{i j}^{r s}$ & $\cdots$ & $\cdots$ & $\cdots$ & $\cdots$ & $F_{i j}^{r}$ & $\cdots$ & $Y_{i}^{r}$ \\
\hline & & Industry 1 & $Z_{J 1}^{11}$ & $\cdots$ & $Z_{J 1}^{1 S}$ & $\cdots$ & $Z_{J J}^{11}$ & $\cdots$ & $Z_{J J}^{1 S}$ & $F_{J 1}^{1}$ & $\cdots$ & $F_{J J}^{1}$ & $Y_{J}^{1}$ \\
\hline \multirow[t]{2}{*}{ supplied } & Country $J$ & $\ldots$ & $\cdots$ & $Z_{J 1}^{r s}$ & $\cdots$ & $\cdots$ & $\cdots$ & $Z_{J J}^{r s}$ & $\cdots$ & $\cdots$ & $\cdots$ & $\cdots$ & $\cdots$ \\
\hline & & Industry $S$ & $Z_{J 1}^{S 1}$ & $\cdots$ & $Z_{J 1}^{S S}$ & $\cdots$ & $Z_{J J}^{S 1}$ & $\cdots$ & $Z_{J J}^{S S}$ & $F_{J 1}^{S}$ & $\cdots$ & $F_{J J}^{S}$ & $Y_{J}^{S}$ \\
\hline \multicolumn{3}{|c|}{ Value added } & $V A_{1}^{1}$ & $\cdots$ & $V A_{1}^{S}$ & $V A_{j}^{s}$ & $V A_{J}^{1}$ & $\cdots$ & $V A_{J}^{S}$ & & & & \\
\hline \multicolumn{3}{|c|}{ Gross output } & $Y_{1}^{1}$ & $\cdots$ & $Y_{1}^{S}$ & $Y_{j}^{s}$ & $Y_{J}^{1}$ & $\cdots$ & $Y_{J}^{S}$ & $\cdots$ & & & \\
\hline
\end{tabular}

Figure 1: The Structure of a World Input-Output Table

More formally, we have

$$
Y_{i}^{r}=\sum_{s=1}^{S} \sum_{j=1}^{J} Z_{i j}^{r s}+\sum_{j=1}^{J} F_{i j}^{r}=\sum_{s=1}^{S} \sum_{j=1}^{J} Z_{i j}^{r s}+F_{i}^{r},
$$

where we will hereafter denote the total final use of output originating from sector $r$ in country $i$ by $F_{i}^{r}=\sum_{j=1}^{J} F_{i j}^{r}$.

As illustrated by the two bottom rows of the WIOT, gross output in industry $s$ in country $j$ is also equal to the sum of: (i) all intermediate purchases made from source sectors $r$ in countries $i$; and (ii) country $j$ 's value-added employed in the production of industry $s$ itself (the latter denoted by $\left.V A_{j}^{s}\right)$. More formally:

$$
Y_{j}^{s}=\sum_{r=1}^{S} \sum_{i=1}^{J} Z_{i j}^{r s}+V A_{j}^{s}
$$

As described, the WIOT contains information on linkages in a full production network, where each country-industry could potentially be traversed in a large number of production chains. In this complex setting, the measures of GVC positioning described below will seek to capture the average position of each country-industry in the production chains in which it is involved. The first two measures introduced below will take as a point of reference the sources of final demand at the end of each production chain, and compute the upstreamness of the country-industry relative to final use. The second set of measures will instead capture the downstreamness of each country-industry from where production processes commence, namely from sources of value-added to primary factors.

\subsection{Upstreamness from Final Use}

How upstream or downstream in GVCs is a given sector $r$ from a given country $i$ ? A first possible approach to tackling this question is to consider the extent to which a country-industry pair sells its output for final use to consumers worldwide or instead sells intermediate inputs to other producing sectors in the world economy. The idea is that a sector that sells disproportionately to final consumers would appear to be downstream in value chains, while a sector that sells little to final 
consumers is more likely to be upstream in value chains. Invoking equation (1), a simple measure of this notion of GVC positioning is the ratio $F_{i}^{r} / Y_{i}^{r}$, which equals the share of gross output in sector $r$ in country $i$ that is sold to final consumers. We will refer to this measure as $F / G O$. Note that a lower value of this ratio is associated with a higher upstreamness from final use.

An unappealing feature of the simple measure $F / G O$ is that it does not capture variation in the upstreamness of country-industry pairs that goes beyond the extent to which their output is directly sold to final consumers or to other industries. In order to transition to a more satisfactory measure, let us first define $a_{i j}^{r s}=Z_{i j}^{r s} / Y_{j}^{s}$ as the dollar amount of sector $r$ 's output from country $i$ needed to produce one dollar worth of industry $s$ 's output in country $j$. With this notation, equation (1) becomes:

$$
Y_{i}^{r}=\sum_{s=1}^{S} \sum_{j=1}^{J} a_{i j}^{r s} Y_{j}^{s}+F_{i}^{r}
$$

Iterating this identity, we can express industry $r$ 's output in country $i$ as an infinite sequence of terms which reflect the use of this country-industry's output at different positions in global value chains, starting with its use as a final good/service, as a direct input in the production of final goods/services in all countries and industries, as a direct input of a direct input in the production of final goods/services in all countries and industries, and so on:

$$
Y_{i}^{r}=F_{i}^{r}+\sum_{s=1}^{S} \sum_{j=1}^{J} a_{i j}^{r s} F_{j}^{s}+\sum_{s=1}^{S} \sum_{j=1}^{J} \sum_{t=1}^{S} \sum_{k=1}^{J} a_{i j}^{r s} a_{j k}^{s t} F_{k}^{t}+\ldots
$$

Building on this identity, Antràs and Chor (2013) suggested computing the (weighted) average position of a country-industry's output in global value chains by multiplying each of the terms in (4) by its respective production-staging distance from final use plus one, and dividing by $Y_{i}^{r}$, or:

$$
U_{i}^{r}=1 \times \frac{F_{i}^{r}}{Y_{i}^{r}}+2 \times \frac{\sum_{s=1}^{S} \sum_{j=1}^{J} a_{i j}^{r s} F_{j}^{s}}{Y_{i}^{r}}+3 \times \frac{\sum_{s=1}^{S} \sum_{j=1}^{J} \sum_{t=1}^{S} \sum_{k=1}^{J} a_{i j}^{r s} a_{j k}^{s t} F_{k}^{t}}{Y_{i}^{r}}+\ldots
$$

It is clear that $U_{i}^{r} \geq 1$, and that larger values are associated with relatively higher levels of upstreamness of the output originating from sector $r$ in country $i$.

Although computing (5) might appear to require computing an infinite power series, provided that $\sum_{r=1}^{S} \sum_{i=1}^{J} a_{i j}^{r s}<1$ for all $j$-s pairs (a natural assumption), the numerator of the above measure is actually equal to the $((i-1) \times S+r)$-th element of the $J \times S$ by 1 column matrix $[I-\mathbf{A}]^{-2} \mathbf{F}$; here, $\mathbf{A}$ is a $J \times S$ by $J \times S$ matrix whose $((i-1) \times S+r,(j-1) \times S+s)$-th element is $a_{i j}^{r s}$, while $\mathbf{F}$ is a column matrix with $F_{i}^{r}$ in its $((i-1) \times S+r)$-th row. Using the fact that the stacked column matrix of gross output also satisfies $\mathbf{Y}=[I-\mathbf{A}]^{-1} \mathbf{F}$ - which is easily verified from (3) - the numerator is thus also equal to the $((i-1) \times S+r)$-th element of the $J \times S$ by 1 matrix $[I-\mathbf{A}]^{-1} \mathbf{Y}$, where $\mathbf{Y}$ is a $J \times S$ by 1 column matrix with $Y_{i}^{r}$ in its $((i-1) \times S+r)$-th row. Because a WIOT provides direct information on $\mathbf{A}$ and $\mathbf{Y}$, computing the upstreamness of output 
of each sector $r$ in each country $i$ thus amounts to a straightforward matrix inversion. ${ }^{8}$

Fally (2012) instead proposed a measure of upstreamness (or distance from final use) based on the notion that industries selling a disproportionate share of their output to relatively upstream industries should be relatively upstream themselves. ${ }^{9}$ In particular, he posited the following linear system of equations that implicitly defines upstreamness for each industry $r$ in country $i$ :

$$
\tilde{U}_{i}^{r}=1+\sum_{s=1}^{S} \sum_{j=1}^{J} b_{i j}^{r s} \tilde{U}_{j}^{s},
$$

where note that $b_{i j}^{r s}=Z_{i j}^{r s} / Y_{i}^{r}=a_{i j}^{r s} Y_{j}^{s} / Y_{i}^{r}$ is the share of total output of sector $r$ in country $i$ that is purchased by industry $s$ in country $j$. Again, it is clear that $\tilde{U}_{i}^{r} \geq 1$. Less obviously, one can demonstrate using matrix algebra that $\tilde{U}_{i}^{r}$ and $U_{i}^{r}$ are in fact equivalent; this is the key theoretical result in Antràs et al. (2012).

\subsection{Downstreamness from Primary Factors}

We next turn to alternative measures of GVC positioning based on a country-industry pair's use of intermediate inputs and primary factors of production. These measures are based on the identity in (2), which describes the technology for producing output in industry $s$ in country $j$. Other things equal, it seems plausible that production processes that embody a larger amount of intermediate inputs relative to their use of primary factors of production will be relatively downstream in value chains. Conversely, if an industry relies disproportionately on value-added from primary factors of production, then it would appear that this industry is relatively upstream. In light of equation (2), a simple measure to capture such GVC positioning is the ratio $V A_{j}^{s} / Y_{j}^{s}$, with large values of this measure being associated with higher upstreamness or lower downstreamness. We will refer to this measure as $V A / G O$.

As in the case of the sales-based measure of $F / G O$, a limitation of $V A / G O$ is that it does not take into account potential heterogeneity in the upstreamness of the inputs used in the production process of a country-industry pair. With that in mind, we next develop a more informative measure of downstreamness from primary factors of production. Recall that $b_{i j}^{r s}=Z_{i j}^{r s} / Y_{i}^{r}$ denotes the share of sector $r$ 's output in country $i$ that is used in industry $s$ in country $j$. Then equation (2) can be written as:

$$
Y_{j}^{s}=\sum_{r=1}^{S} \sum_{i=1}^{J} b_{i j}^{r s} Y_{i}^{r}+V A_{j}^{s} .
$$

\footnotetext{
${ }^{8}$ It may be tempting heuristically to view the exercise here as one of projecting the information on production linkages within the WIOT into a stylized linear production chain. We should however caution against this interpretation, since the intention of the GVC measures is not to literally arrange the country-industries in a WIOT into a unique production sequence. To give an example, if the Mining and Quarrying industry in Australia has the next largest $U$ value compared to the Rubber and Plastics industry in China, it does not mean that the former is necessarily being purchased as an input by the latter industry; instead, what this means is that the former industry tends on average to enter production chains at a larger number of stages relative to final demand.

${ }^{9}$ We should stress that although they were developed independently, Fally's (2012) measure chronologically preceded that in Antràs and Chor (2013).
} 
Iterating this identity, we can express:

$$
Y_{j}^{s}=V A_{j}^{s}+\sum_{r=1}^{S} \sum_{i=1}^{J} b_{i j}^{r s} V A_{i}^{r}+\sum_{r=1}^{S} \sum_{i=1}^{J} \sum_{t=1}^{S} \sum_{k=1}^{J} b_{k i}^{t r} b_{i j}^{r s} V A_{k}^{t}+\ldots
$$

Notice that the first term captures the direct use of primary factors in the production of industry $s$ in country $j$. The second term reflects the use of intermediate inputs that are themselves produced directly with primary factors. The third term captures intermediate input purchases produced with inputs produced with primary factors, and so on. The larger are the terms associated with further iterations, the more intensive is that country-industry's use of inputs far removed from primary factors, and thus the more downstream is production relative to these primary factors.

Building on Antràs and Chor (2013), Miller and Temurshoev (2017) propose the following measure of downstreamness of a given country-industry pair from primary factors of production:

$$
D_{j}^{s}=1 \times \frac{V A_{j}^{s}}{Y_{j}^{s}}+2 \times \frac{\sum_{r=1}^{S} \sum_{i=1}^{J} b_{i j}^{r s} V A_{i}^{r}}{Y_{j}^{s}}+3 \times \frac{\sum_{r=1}^{S} \sum_{i=1}^{J} \sum_{t=1}^{S} \sum_{k=1}^{J} b_{k i}^{t r} b_{i j}^{r s} V A_{k}^{t}}{Y_{j}^{s}}+\ldots
$$

As in the case of $U_{i}^{r}$, it is clear that $D_{j}^{s} \geq 1$, with larger values being associated with relatively higher levels of downstreamness of industry $s$ in country $i$. Given the similar structure of $U_{i}^{r}$ in (5) and $D_{j}^{s}$ in (7), it should come as no surprise that one need not approximate the infinite sum in (7) to compute $D_{j}^{s}$. By defining a matrix $\mathbf{B}$ analogous to the matrix $\mathbf{A}$ invoked in the construction of $U_{i}^{r}$ and computing $[I-\mathbf{B}]^{-1} \mathbf{Y}$, the various elements of the numerator of $D_{j}^{s}$ are easily retrieved. Furthermore, there is an analogous foundation for the measure $D_{j}^{s}$ building on the following recursive definition:

$$
\tilde{D}_{j}^{s}=1+\sum_{i=1}^{J} \sum_{r=1}^{S} a_{i j}^{r s} \tilde{D}_{i}^{r}
$$

This system of equations defining downstreamness $\tilde{D}_{j}^{s}$ was first suggested by Fally (2012), who associated it with the average number of production stages embodied in a sector's output. As pointed out by Miller and Temurshoev (2017), $\tilde{D}_{j}^{s}$ in (8) and $D_{j}^{s}$ in (7) are in fact mathematically equivalent. ${ }^{10}$

\subsection{Aggregation}

So far we have developed measures of GVC positioning at the country-industry level, but for some applications a researcher might be interested in the average position of countries in GVCs. An example of such a focus on the country dimension rather than the country-industry dimension is provided by Antràs and de Gortari (2017).

In principle, there are two alternative ways to compute country-level measures of upstream-

\footnotetext{
${ }^{10}$ Miller and Temurshoev (2017) refer to $U_{j}^{s}$ as the "output upstreamness" of sector $s$ in country $j$, and $D_{j}^{s}$ as the "input downstreamness" of the same sector.
} 
ness/downstreamness. First, one can take a WIOT and simply collapse its entries at the countryby-country level. More specifically, one can compute the total purchases of intermediate inputs by country $j$ from country $i$ as $Z_{i j}=\sum_{r=1}^{S} \sum_{S=1}^{S} Z_{i j}^{r s}$, and then generate a left $J \times J$ block matrix with elements $Z_{i j}$. Similarly, a $J \times J$ block matrix of aggregate final-use sales can be computed with entries $F_{i j}=\sum_{r=1}^{S} F_{i j}^{r}$. With this collapsed country-level WIOT, it is then straightforward to compute country-level variants of the measures of upstreamness and downstreamness developed above. A second potential approach maintains the country-industry level dimension of the data and the GVC positioning measures, but instead computes a weighted-average measure of upstreamness/downstreamness at the country level by averaging the industry-level values of those measures within a country.

For the two basic measures $F / G O$ and $V A / G O$, it turns out that these two approaches deliver the exact same country-level positioning numbers when using the shares of a country's gross output accounted for by different industries as weights in the second approach. To see this equivalence result for the $F / G O$ measure, note that:

$$
\sum_{r=1}^{S} \frac{F_{i}^{r}}{Y_{i}^{r}} \times \frac{Y_{i}^{r}}{\sum_{s=1}^{S} Y_{i}^{s}}=\frac{\sum_{r=1}^{S} F_{i}^{r}}{\sum_{s=1}^{S} Y_{i}^{s}}=\frac{F_{i}}{Y_{i}}
$$

where the left-hand side is the gross-output weighted-average of final-use shares, while $F_{i} / Y_{i}$ (in the right-hand side) is the aggregate ratio of final use to gross output in country $i$; the latter is naturally the ratio $F / G O$ that would be computed with a WIOT collapsed at the country level. Similarly, for the measure $V A / G O$, we have:

$$
\sum_{s=1}^{S} \frac{V A_{j}^{s}}{Y_{j}^{s}} \times \frac{Y_{j}^{s}}{\sum_{s=1}^{S} Y_{j}^{s}}=\frac{\sum_{s=1}^{S} V A_{j}^{s}}{\sum_{s=1}^{S} Y_{j}^{s}}=\frac{V A_{j}}{Y_{j}}
$$

where the right-hand side term, $V A_{j} / Y_{j}$, would naturally be the value for the country-level valueadded over gross output ratio resulting from a WIOT collapsed at the country level.

When considering the more involved measures $U$ and $D$, such an equivalence result between the two aggregation approaches no longer holds. In the empirical analysis to be performed in the next section, we have nevertheless found the two approaches to deliver extremely highly correlated country-level indices of GVC positioning (see, in particular, footnote 16). ${ }^{11}$

Finally, one might also be interested in computing a worldwide average measure of GVC positioning. A natural way to do so would be to compute a weighted sum of the respective measures, $F / G O, V A / G O, U$, and $D$, with weights given by gross output in each country. From simple

\footnotetext{
${ }^{11}$ Our numerical results also suggest that the gross-output weighted-average of the country-industry $U$ 's (respectively, $D$ 's) is slightly larger than the country-level $U$ 's (respectively, $D$ 's) computed from a collapsed WIOT. This would be consistent with the matrix inverse used in the computation of these indices being a convex transformation.
} 
inspection of (9) and (10), it is straightforward to see that the worldwide averages for $F / G O$ and $V A / G O$ will coincide with the ratio of aggregate world final consumption to aggregate world gross output and the ratio of aggregate world value-added to aggregate world gross output, respectively. Furthermore, because the world as a whole is a closed economy, the aggregate world value of finaluse expenditures is necessarily equal as an accounting identity to the aggregate payments made to primary factors. Denoting these aggregates with upper bars, we thus have $\bar{F} / \overline{G O}=\overline{V A} / \overline{G O}$ at the level of the world economy. There is a similar though far less obvious relationship connecting the world measures of $U$ and $D$. More specifically, Proposition 1 in Miller and Temurshoev (2017) establishes that the gross-output weighted-average $\bar{U}$ value across countries is in fact exactly equal to the corresponding gross-output weighted-average $\bar{D} \cdot{ }^{12}$

This suggests that one should not interpret these world averages as measures of GVC positioning. Instead, these world averages should be viewed as measures of the complexity of world production patterns, as captured by the extent to which production processes are sliced across industries and countries. When $\bar{U}=\bar{D}$ is large (or $\bar{F} / \overline{G O}=\overline{V A} / \overline{G O}$ is low), GVCs are more complex in the sense that world production uses inputs far removed from final use, but also highly processed inputs far removed from the primary factors that initiated production. Conversely, a world with a low value of $\bar{U}=\bar{D}$ and a high value of $\bar{F} / \overline{G O}=\overline{V A} / \overline{G O}$ is a world with little intermediate input use and short production chains.

\section{The Empirical Evolution of GVC Positioning}

We turn now to the annual World Input-Output Database (WIOD) to compute the four measures of GVC positioning defined in the previous section, and document how these have evolved in recent decades. The WIOD is well-suited for this exercise: It contains detailed information on countryindustry production linkages and final-use expenditures for a large panel of $J=41$ countries (including a rest-of-the-world aggregate), a common set of $S=35$ consistently-defined industries in each country, at an annual frequency, as described in Timmer et al. (2015). We work with the 2013 edition of the WIOD, which covers the years 1995-2011. This is in practice a very large dataset. Looking at the entries that correspond to input purchases across country-industry pairs (i.e., the $Z_{i j}^{r s}$ 's in the schematic in Figure 1), there are already a total of $(35 \times 41)^{2}=2,059,225$ such data points in any single year. Looking at the entries that report the value of each country's purchases for final-use from each country-industry source (i.e., the $F_{i j}^{r}$ 's in Figure 1), this yields an additional $35 \times 41^{2}=58,835$ observations per year. ${ }^{13}$

\footnotetext{
${ }^{12}$ The proof relies on the fact that: (i) $U$ can be computed from the Leontief inverse matrix, $\mathbf{L}=[\mathbf{I}-\mathbf{A}]^{-1} ;$ (ii) $D$ can be computed from the Ghosh inverse matrix, $\mathbf{G}=[\mathbf{I}-\mathbf{B}]^{-1}$; and (iii) the Leontief and Ghosh inverse matrices are closely related to each other. Facts (i) and (ii) were discussed earlier in Section 2, while (iii) is made explicit in Miller and Temurshoev (2017). In particular, define $Y$ to be a square matrix whose diagonal entries are equal to gross output in each industry, and whose non-diagonal entries are all equal to zero. Then, we have: $Y \mathbf{G}=\mathbf{L} Y$.

${ }^{13}$ We have separately verified that similar patterns hold in the recent 2016 release of the WIOD. Relative to the 2013 edition, the 2016 WIOD includes 44 countries and 56 industries from 2000-2014. The increase in the number of industries covered arises mainly from a more detailed breakdown of service industries. We have nevertheless based the analysis in this paper on the 2013 WIOD, in order to trace the evolution of GVCs starting from an earlier year.
} 
In terms of practical implementation, we calculate the four GVC measures for each industry $r$ in each country $i$ in each year, after first performing a "net inventory" correction. For expositional purposes, equation (1) presented earlier had simplified the components of gross output, $Y_{i}^{r}$ : Apart from the value of that output that is purchased for intermediate and final uses (the $Z_{i j}^{r s}$ 's and $F_{i j}^{r}$ 's), gross output in the Input-Output accounts includes an additional third component equal to the net value that is inventorized (which we denote by $N_{i}^{r}$ ). ${ }^{14}$ To fully account for how these net inventories affect the measurement of production staging, one would need to observe the identities of the industries $s$ that undertake this inventorization. However, a breakdown of $N_{i}^{r}$ by the identity of purchasing industries is not available in the WIOD. We therefore follow Antràs et al. (2012) in applying a "net inventory" correction that apportions $N_{i}^{r}$ across purchasing countries and industries, in proportion to the corresponding breakdown seen in the intermediate use entries (i.e., the $Z_{i j}^{r s}$ s). This correction boils down to rescaling each $Z_{i j}^{r s}$ and $F_{i j}^{r}$ term by a multiplicative factor equal to $Y_{i}^{r} /\left(Y_{i}^{r}-N_{i}^{r}\right)$ before we compute the GVC measures at the country-industry level. ${ }^{15}$

To more succinctly illustrate the broad trends in countries' GVC positioning over time, we will find it useful to begin by working with a collapsed version of the World Input-Output Tables (WIOT), in which we aggregate out the industry dimension - by summing over all industry entries for each source-by-destination country pair - to obtain a panel of country-by-country Input-Output tables, as described in Section 2.3. From this collapsed WIOT, one can compute a set of countrylevel measures of $F / G O, V A / G O, U$, and $D$ (with a corresponding net inventory correction based on country-level aggregate inventories) to summarize the GVC positioning of each country, and more easily illustrate how this has evolved over time. ${ }^{16}$

\subsection{The GVC Positioning of Countries Over Time}

Figure 2 provides an overview of how GVCs have evolved for the world economy as a whole. Here, we have taken two of the country-level measures of GVC positioning, namely $F / G O$ and $U$, computed the gross-output weighted-average of each measure (across the 41 countries in the 2013 WIOD), and plotted these over time.

The upper panel reveals that the final-use share in gross output in the world economy $(\bar{F} / \overline{G O})$

${ }^{14}$ The full output identity should thus be:

$$
Y_{i}^{r}=\sum_{s=1}^{S} \sum_{j=1}^{J} Z_{i j}^{r s}+\sum_{j=1}^{J} F_{i j}^{r}+N_{i}^{r} .
$$

\footnotetext{
${ }^{15}$ See Antràs et al. (2012) for a derivation of this correction term and how it arises from proportionality assumptions.

${ }^{16}$ As mentioned in Section 2.3, an alternative approach would be to work directly with the country-industry measures of GVC positioning in a given year, and take weighted-averages of these to obtain their analogues at the country level. As explained in Section 2, the two approaches clearly yield exactly the same country-level values for $F / G O$ and $V A / G O$ if weights equal to gross output in each country-industry are used. While the two approaches are not equivalent for $U$ and $D$, they nevertheless result in highly-correlated GVC measures at the country-level (with a correlation higher than 0.98 , for both $U$ and $D$ ). The trends that we document are thus not sensitive to the approach taken to compute the country-level GVC measures. In practice, the net inventory correction introduces small discrepancies between the country-level GVC measures computed under either approach, but the correlation remains very high.
} 

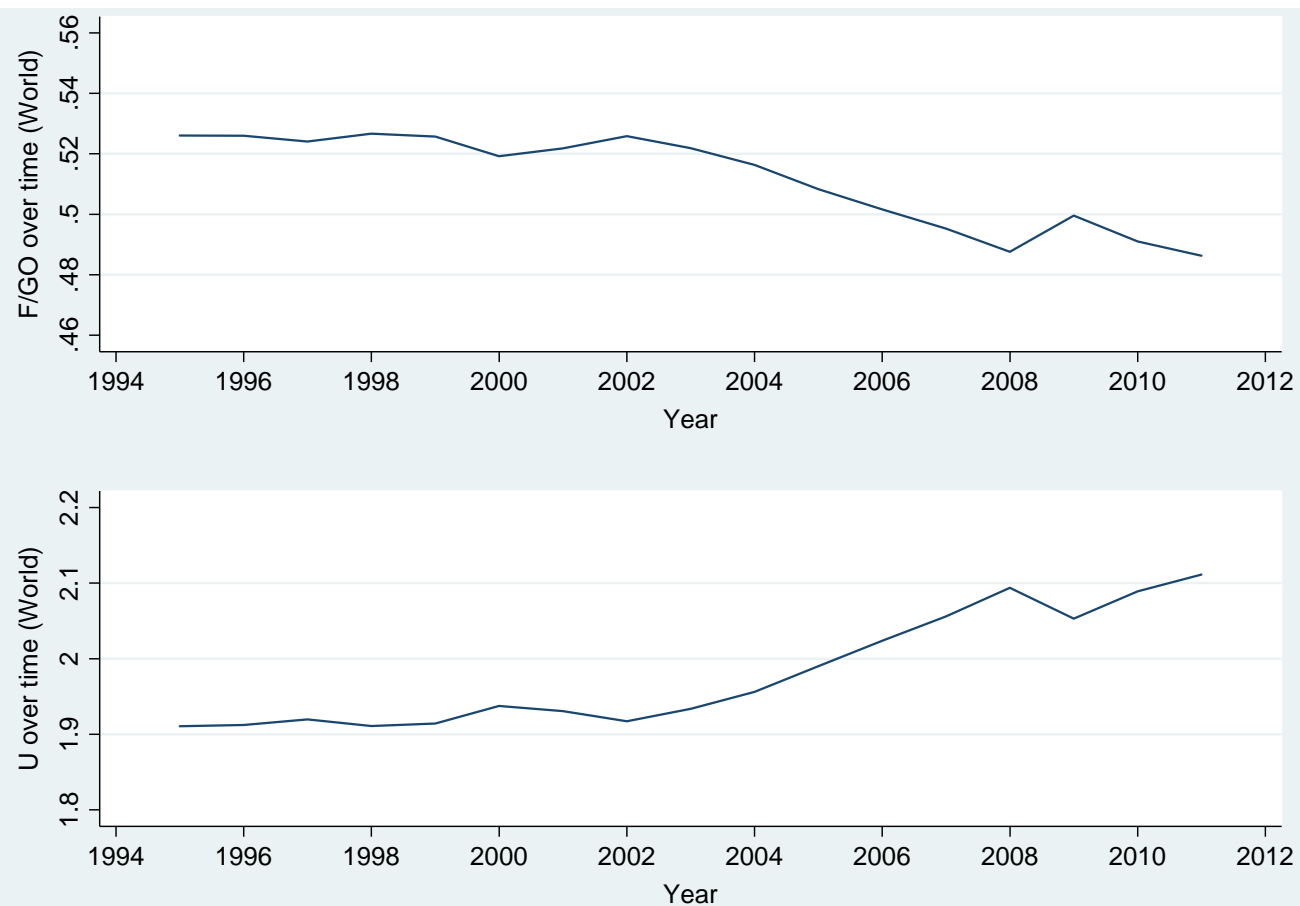

Figure 2: GVC Positioning over Time (World Average)

has been on the decline over this period. While the magnitude of this change was fairly small (from 0.526 in 1995 to 0.486 in 2011), the drop was nevertheless perceptible and steady, particularly after 2002. Put otherwise, production and trade in intermediate inputs has risen relative to that in final goods, which would be consistent with a rise in GVC activity around the world. The lower panel corroborates this interpretation. There, we see that the world average upstreamness $\bar{U}$ has been on the uptick, suggesting that production processes have become fragmented into more stages.

What about the other two measures of GVC positioning? Remember from Section 2.3 that the aggregate world value of final-use expenditures is equal to the aggregate world payments made to primary factors. A plot of $\overline{V A} / \overline{G O}$ over time would thus be identical to the upper panel in Figure 2. As previously discussed, the gross-output weighted-average $U$ value is in fact also equal to the gross-output weighted-average of $D$, and thus a separate figure for the evolution of $\bar{D}$ over time would also be redundant.

In Figure 3, we take a more detailed look at these aggregate patterns, by plotting the respective GVC measures for the countries at the 25th, 50th, and 75th percentiles of the cross-country distribution in each year. Note that the worldwide equivalence between $F / G O$ and $V A / G O$, as well as that between $U$ and $D$, no longer holds for individual countries, so we can now meaningfully examine the evolution of the four separate GVC measures. The plots in the left column of Figure 3 verify that the downward trend in $F / G O$, and the converse upward trend in $U$, both hold across these different percentiles of the cross-country distribution. Viewed from the perspective of these two GVC measures, it appears that countries have been broadly moving more upstream relative to final demand in the nature of the production activities that are conducted. On the other hand, the plots 

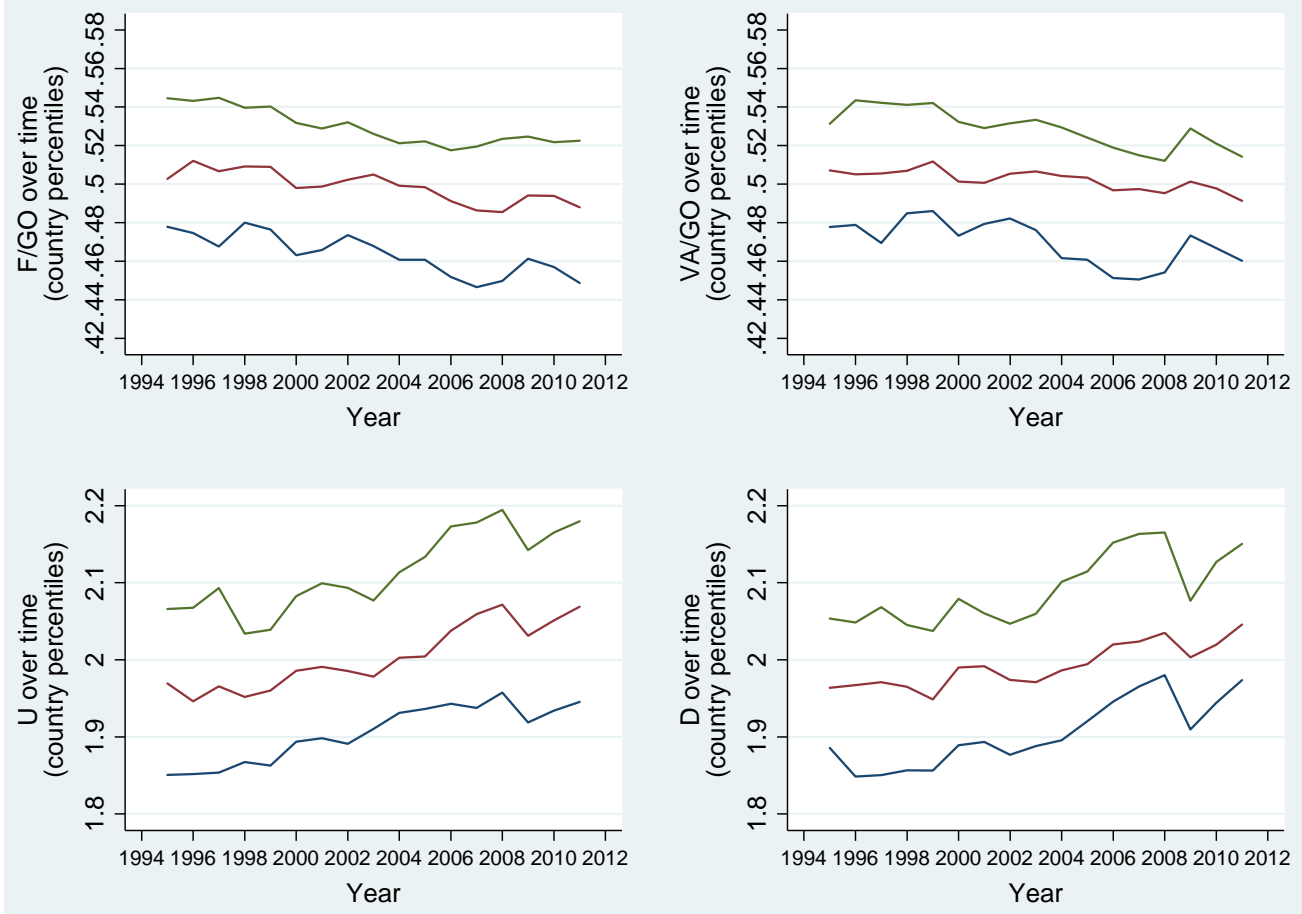

Figure 3: GVC Positioning over Time (25th, 50th, 75th country percentiles)

in the right column indicate that the value-added to gross-output ratio $(V A / G O)$ has been falling over this period, while the measure of production staging relative to sources of value-added $(D)$ has been rising. The distribution of countries' GVC positioning has thus simultaneously become more downstream in relation to primary factors. Taken together, these observations suggest that GVCs have become more complex, as the average global production chain "length" from primary factors to a particular country, and onward from that country to final demand, have both increased.

It is useful to discuss how the above stylized facts relate to the broader empirical literature on GVC positioning. We are admittedly not the first to document the gradual rise in $U$ and $D$ over time: Miller and Temurshoev (2017) have also reported this pattern both across countries and across industries in the 2013 WIOD. In the regression analysis that we present below, we will extend this finding by showing that these trends are present too when examining the within country-industry variation in these GVC measures (see Table 2). In contrast, Fally (2012) has documented a fall over time in the number of production stages from primary factors to industries, i.e., in the $D$ measure, using U.S. Input-Output Tables that span 1947 to 2002. Nevertheless, the bulk of the decline documented by Fally (2012) occurred in the 1980s and early 1990s, prior to the period considered in this paper, and thus prior to the explosion in GVC activity. Furthermore, in the ongoing revision of his work, Fally documents an uptick in $D$ over the period 1997-2007, which is consistent with our findings.

While Figures 2 and 3 point to broad trends that apply across the country sample, these may mask significant movements in individual countries' GVC positioning. A simple rank correlation test nevertheless indicates that each country's position in GVCs vis-à-vis other countries has remained 
remarkably stable. In particular, we obtain Spearman coefficients in excess of 0.75 for each of the country-level GVC measures when comparing their cross-country rank order in 1995 against that in 2011. Table 1 confirms that there is a striking persistence in countries' GVC position over time, even in the tail ends of the rank order. For example, focusing on the left half of the table, China, Luxembourg, and the Czech Republic were among the five most upstream countries relative to final demand in both 1995 and 2011, based on either the country rank by $F / G O$ or $U$. On the other hand, Brazil, Greece, and Cyprus have remained in the five most downstream countries over this period in their proximity to final-use. A similar persistence can also be seen in the right half of Table 1, which reports the rank order of countries in terms of their GVC position relative to primary factors (based on either $V A / G O$ or $D$ ).

\section{[Table 1 here]}

The above discussion has described patterns in the evolution of GVC positioning across countries, in terms of the broad decline in $F / G O$ and $V A / G O$, as well as the accompanying rise in $U$ and $D$ over time. We next establish that these patterns are also borne out when focusing instead on variation within countries - and more specifically, within country-industry - over time. For this, we turn to the more disaggregate GVC measures computed at the country-industry level. To tease out the desired "within"-variation, we run a series of regressions of the following form:

$$
G V C_{j, t}^{s}=\beta_{1} Y e a r_{t}+F E_{j}^{s}+\epsilon_{j, t}^{s}
$$

On the left-hand side, $G V C_{j, t}^{s}$ denotes the GVC measure for industry $s$ in country $j$ during year $t$. We will use each of the four measures $(F / G O, V A / G O, U$, and $D)$ as this dependent variable; summary statistics for these country-industry GVC measures are presented in Appendix Table 1. On the right-hand side, the $F E_{j}^{s}$ 's denote country-industry fixed effects. The variable $Y e a r_{t}$ then seeks to pick up whether there is a simple linear time trend in the evolution of $G V C_{j, t}^{s}$ within country-industry. In more detailed specifications, we will replace $Y_{\text {ear }}$ with a full set of year dummies to trace the year-by-year evolution in the respective GVC measures. We report conservative standard errors that are multi-way clustered by country, industry, and year, to accommodate possible correlation in the $\epsilon_{j, t}^{s}$ 's along each of these dimensions (Cameron et al. 2011).

Table 2 reports the results from this regression exercise. These confirm that the broad patterns documented earlier are present too in the evolution of GVC positioning within country-industry: Both the final-use share in gross output $\left(F / G O_{j, t}^{s}\right.$, Columns 1-2) and the value-added share in gross output ( $V A / G O_{j, t}^{s}$, Columns 3-4) have declined steadily over time. Conversely, upstreamness relative to final demand has been rising $\left(U_{j, t}^{s}\right.$, Columns 5-6), as has been its production-staging distance from primary factors $\left(D_{j, t}^{s}\right.$, Columns 7-8). The estimates in the odd-numbered columns point to a significant linear time trend, this being negative in the case of $F / G O$ and $V A / G O$, while positive in the case of $U$ and $D$. Inspecting more closely the coefficients of the year dummies in the even-numbered columns, most of the movement over time in these GVC measures appears to 
have kicked in starting in $2000 .{ }^{17,18}$

[Table 2 here]

In sum, the decline in $F / G O$ and $V A / G O$, and the rise in $U$ and $D$, appear to be pervasive phenomena. These patterns are clearly visible in how the country-level measures of GVC positioning have moved over time. They also emerge robustly from more formal regressions that exploit within country-industry movements in the GVC measures.

\section{$3.2 \quad$ Puzzling Correlations}

The findings in the previous subsection hint at interesting patterns of co-movement among the GVC positioning measures. We explore this dimension of the data more carefully now, specifically the correlation between $F / G O$ and $V A / G O$ (respectively, $U$ and $D$ ) across countries, and how this correlation has behaved over the period 1995-2011.

As GVCs have grown in importance as a mode of production, one might have imagined that individual countries would have gradually positioned themselves (on average) in particular segments of these GVCs in which they have comparative advantage. For example, one might have expected that countries with comparative advantage in natural resources or basic parts and components would have increasingly specialized in early stages of production processes, and would have consequently experienced a downward shift in $F / G O$ and an increase in $V A / G O$. Conversely, countries with comparative advantage in production stages that are closer to final assembly would have been expected to experience a rise in $F / G O$ and a decline in $V A / G O .{ }^{19}$ If such a scenario had indeed played out, this should have led any positive correlation between $F / G O$ and $V A / G O$ to weaken over time, and perhaps even turn negative.

Figure 4 reveals, however, that the actual patterns in the data are surprisingly at odds with this prior intuition. The upper row in this figure plots the country-level measures of $F / G O$ against $V A / G O$ in 1995 and 2011 respectively. A positive relationship between these two measures stands out in both years, and this relationship actually appears to have tightened around the line of best fit by the end of the period. The plots in the bottom row demonstrate that a similarly strong positive relationship has persisted between the country-level measures of $U$ and $D$. These observations are moreover consistent with what was seen earlier in the country rank lists in Table 1 . We saw there

\footnotetext{
${ }^{17}$ We have found no major differences in the within country-industry time trends when re-running the Table 2 regressions restricting to either goods-producing or service industries. The time trends for each of the GVC measures retain the same sign as in Table 2; statistical significance on the Year $_{t}$ variable is lost in only one case, for the regression involving $F / G O$ for goods industries (results available on request). The goods-producing industries are defined as industries 1-16 in the WIOD, these being industries in agriculture, mining, and manufacturing activities; the service industries are defined as industries 17-35.

${ }^{18}$ In separate unreported results, we have found similar time trends when weighting each observation by the gross output of the country-industry in question. Likewise, the results are robust when adopting a less stringent set of fixed effects, namely when the $F E_{j}^{s}$ 's are replaced with a set of country fixed effects instead.

${ }^{19}$ Costinot et al. (2013) and Antràs and de Gortari (2017) develop models in which countries specialize in equilibrium in particular segments of the global value chain: some countries have comparative advantage in more upstream stages, while others specialize in more downstream stages.
} 

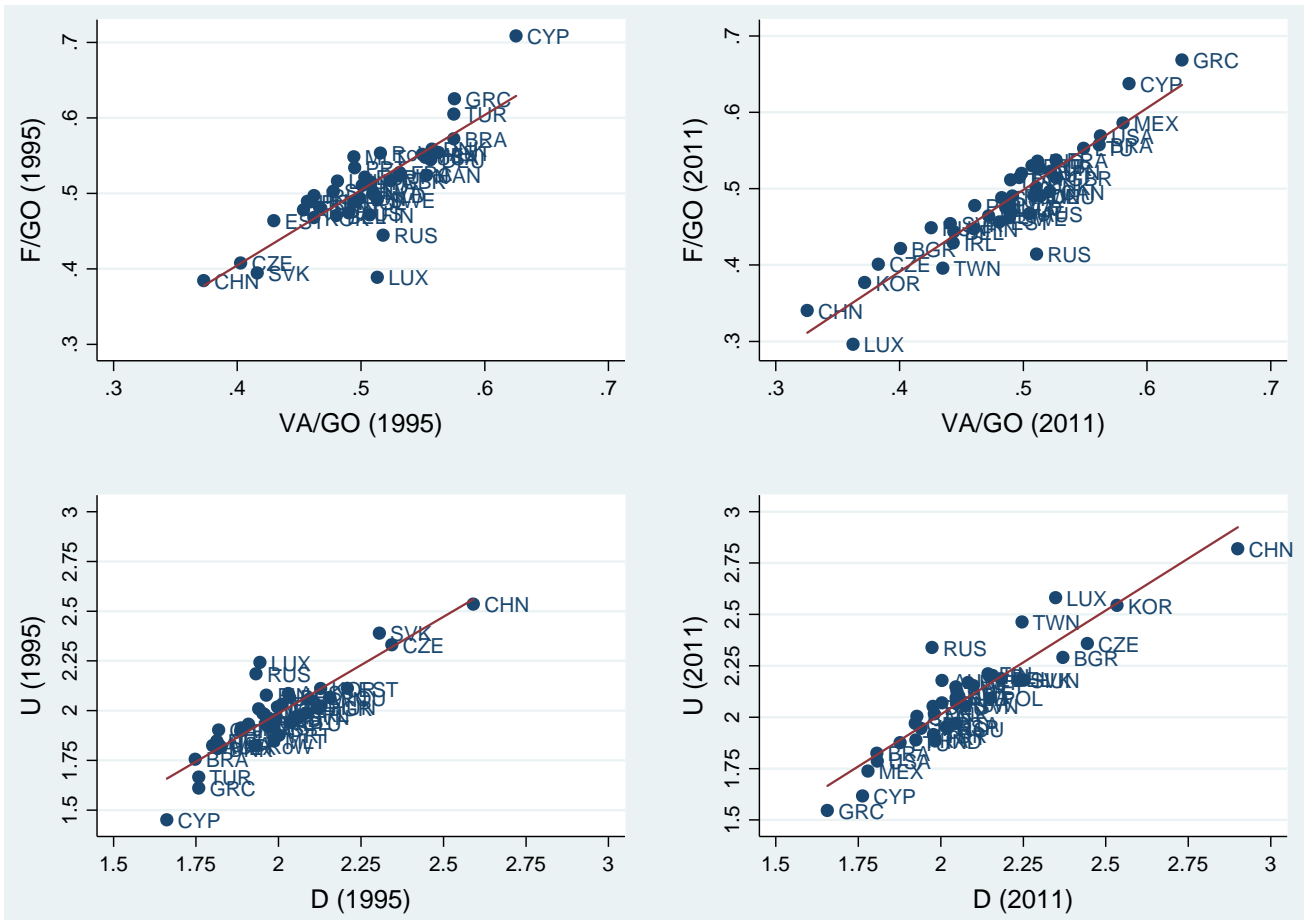

Figure 4: GVC Positioning Measures and their Correlation over time

that countries such as China and Luxembourg were among the bottom-five according to both $F / G O$ and $V A / G O$ across the sample period. Similarly, countries such as Brazil, Greece, and Cyprus were consistently ranked in the top-five of both of these GVC measures. This persistent correlation between $F / G O$ and $V A / G O$ is surprising, as it is a feature that would be more consistent with a world in which trade costs have remained relatively high. Recall in particular from the discussion in the Introduction that in the extreme case of autarky, the cross-country correlation between $F / G O$ and $V A / G O$ would a perfect one. Taken at face value, this suggests that trade costs have perhaps not fallen enough to cause any significant dampening in this positive correlation.

Taking a more detailed look at the annual data, Figure 5 shows that these correlations are not anomalous or specific to 1995 or 2011. The upper panel here plots the pairwise correlation between $F / G O$ and $V A / G O$ at the country level for each year in the sample. The correlation was already strong at the beginning of the period (equal to 0.825 in 1995), and contrary to what we might expect in an age of rising GVC activity, it in fact strengthened gradually over time $(0.925$ by 2011). The bottom panel provides a closely-related illustration. There, we have run a simple bivariate regression of the country-level measures of $F / G O$ against $V A / G O$, separately for each year between 1995-2011. The estimates of the coefficient of $V A / G O$ have been plotted, together with their associated $95 \%$ confidence interval bands. The positive partial correlation between the final-use and the value-added shares of gross output is always precisely estimated, with the slope coefficient itself hovering around 1 in each year. In sum, the positive correlation between $F / G O$ and $V A / G O$ has shown no sign of waning over time.

An analogous set of correlations can be documented between the country-level measures of $U$ 

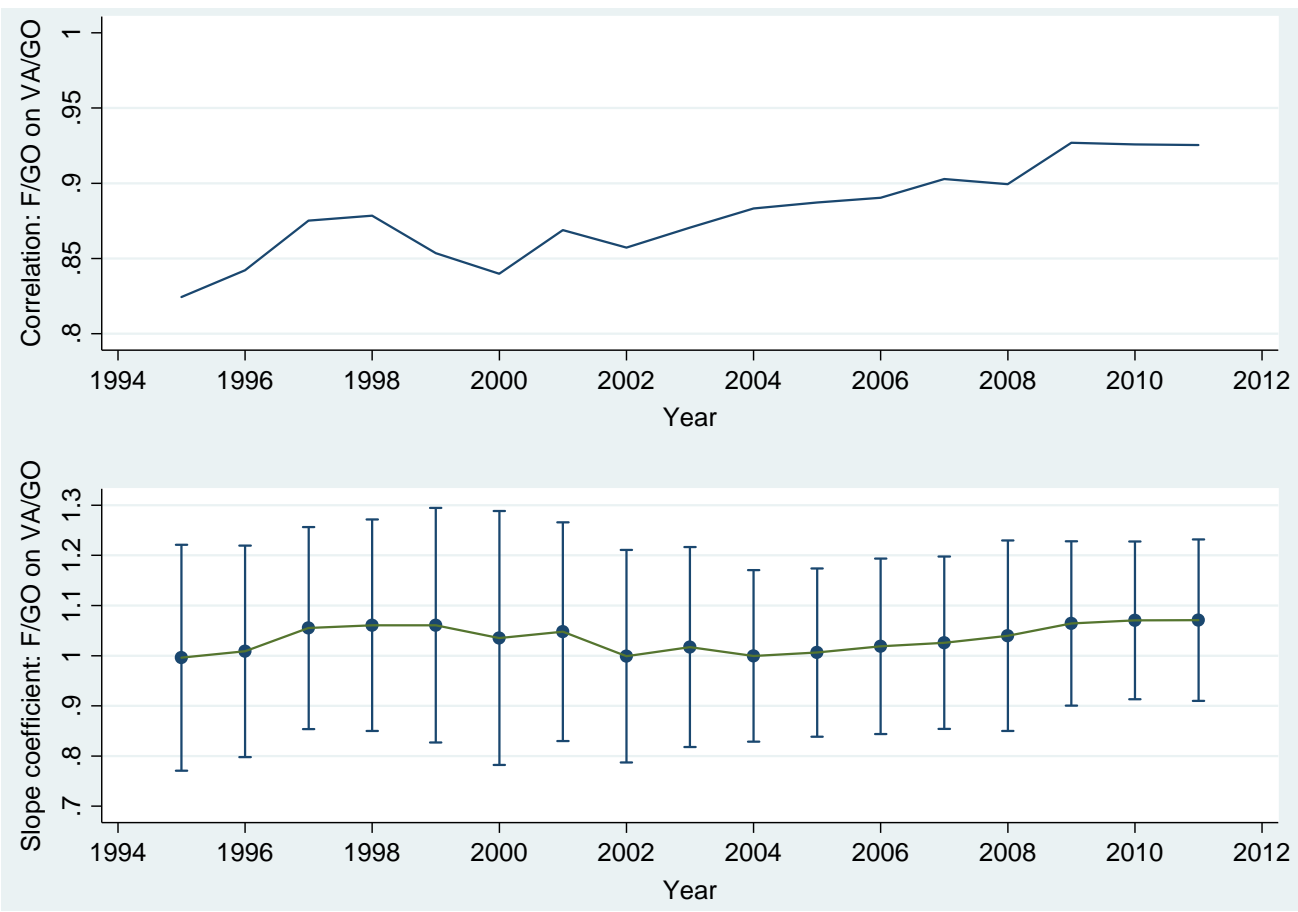

Figure 5: $F U / G O$ and $V A / G O$ over time

and $D$. As seen in Section 2, the definition of $U$ would lead us to expect that it would be inversely correlated with $F / G O$, as the more upstream a country is from sources of final demand, the lower would be the share of country output that goes directly to final-use. Similarly, $D$ exhibits a negative correlation with $V A / G O$, so that the more downstream a country is from primary factors, the lower would be the share of gross output that goes towards direct payments to those factors. ${ }^{20}$ We therefore obtain a positive correlation in Figure 6 between $U$ and $D$ in each year, in line with what was seen earlier for $F / G O$ and $V A / G O$. We find once again that there are no clear signs of a weakening in the positive $U-D$ correlation in more recent years (upper panel), while the bivariate slope coefficient is positive and relatively stable over time (lower panel).

The positive association between $F / G O$ and $V A / G O$, as well as that between $U$ and $D$, are robust features even when we turn to the more detailed country-industry measures of GVC positioning. Toward this end, we have run a series of regressions of the form:

$$
F / G O_{j, t}^{s}=\beta_{1} V A / G O_{j, t}^{s}+F E_{j}+F E^{s}+\epsilon_{j, t}^{s}
$$

to uncover how the country-industry measures of $F / G O$ and $V A / G O$ are correlated in any given year $t$. In the interest of space, we have reported the findings for $t=1995$ and $t=2011$ in Table 3 , but the results for other years are very similar. For each year, the table reports the estimates from three different specifications, namely: (i) a simple bivariate regression with no fixed effects,

\footnotetext{
${ }^{20}$ The correlation between the country-level measures of $F / G O$ and $U$, as well as between the country-level measures of $V A / G O$ and $D$, is indeed negative and lower than -0.96 in any given year.
} 


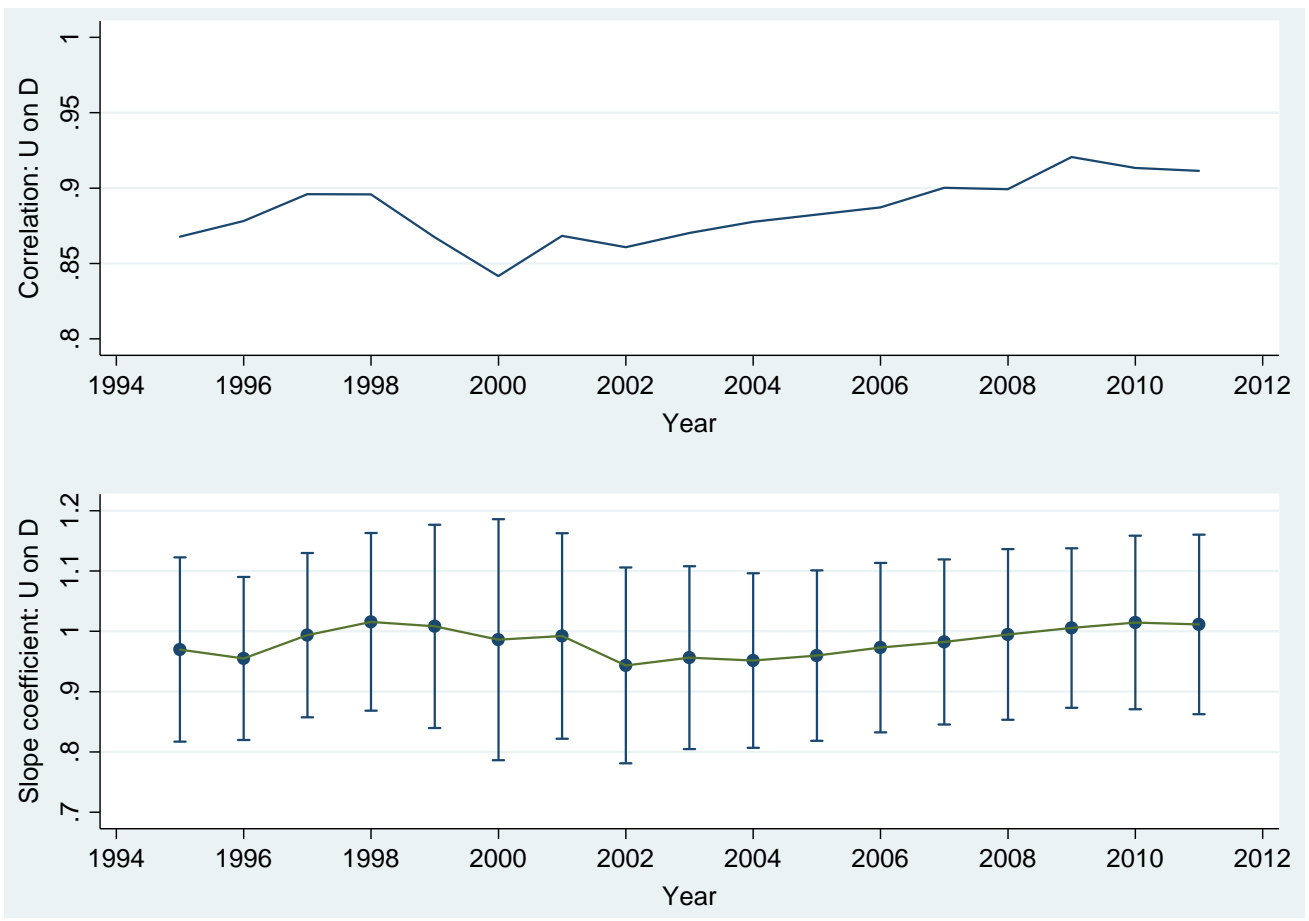

Figure 6: $U$ and $D$ over time

to assess the unconditional cross-sectional correlation between $F / G O$ and $V A / G O$; (ii) a second regression that then controls for country fixed effects $\left(F E_{j}\right)$; and (iii) a last regression that further includes industry fixed effects $\left(F E^{s}\right)$ as in (12) above. These results are presented in the upper row of Table 3, while the bottom row performs the analogous exercise from regressing $U$ against $D$. (The standard errors in the table are two-way clustered, by country and industry.)

\section{[Table 3 here]}

Even in the simple bivariate regressions, we already find a positive association between $F / G O$ and $V A / G O$ (respectively, between $U$ and $D$ ) in the raw cross-section (Columns 1, 4, 7, 10). The $R^{2}$ 's for these regressions range from 0.1-0.2, pointing to a fair bit of unexplained variation in the data, but the highly significant slope coefficient estimates clearly point at a positive correlation. Controlling for country fixed effects (Columns 2, 5, 8, 11), and further for industry fixed effects (Columns 3, 6, 9, 12), successively reduces the magnitude of this slope coefficient, but it always remains statistically significant except in Column 3 for the relationship between $F / G O$ and $V A / G O$ at the start of the sample period. In short, the positive associations between $F / G O$ and $V A / G O$, as well as between $U$ and $D$, are present even when we focus on these different sources of variation in the measures of GVC positioning at the country-industry level. ${ }^{21}$

\footnotetext{
${ }^{21}$ We have verified that the patterns documented in this section are not unduly driven by the small economies in the WIOD sample. In particular, similar time trends are obtained when: (i) dropping Malta, Cyprus, Estonia, Latvia, and Lithuania, these being the five smallest countries by GDP; (ii) using aggregate gross output as regression weights in the cross-country regressions underlying the lower panels in Figures 5 and 6 ; or (iii) weighting the Table 3 regressions by the gross output of the country-industry in question.
} 


\section{Proximate Explanations}

The correlations that we have just documented warrant closer investigation, as their persistence runs counter to what one might expect in an era of global production fragmentation. We take a first look in this section at two proximate explanations that could account (at least qualitatively) for these puzzling correlations, before turning to a model-based investigation in Sections 5 and 6 .

\subsection{Trade Costs}

A first possibility is that trade costs might not in actuality have fallen as much as commonly perceived. If cross-border trade frictions have remained relatively high, this would provide an immediate explanation for the significant and persistent correlation between $F / G O$ and $V A / G O$ (and by extension, between $U$ and $D$ ). One could naturally argue that high cross-border trade costs would in principle discourage rather than facilitate the formation of GVCs. But for the sake of argument, let us for now suspend that concern and instead examine what the data tell us about trade costs over this sample period.

We make use of the Head and Reis (2001) index as a measure of these cross-border trade costs, since this can readily be computed from information that is already contained in the WIOD. The Head-Reis index is usually constructed at the country level to yield a measure of bilateral trade costs. We extend this concept to the country-industry level, to capture trade costs from country $i$ to $j$ in industry $r$, and moreover distinguish between trade costs that are incurred when the good/service from industry $r$ is being used as an intermediate input and when it is destined instead for final-use. Specifically, for each $i \neq j$, we compute:

$$
\begin{aligned}
\tau_{i j}^{r s} & =\left(\frac{Z_{i j}^{r s} Z_{j i}^{r s}}{Z_{i i}^{r s} Z_{j j}^{r s}}\right)^{-\frac{1}{2 \theta}}, \text { and } \\
\tau_{i j}^{r F} & =\left(\frac{F_{i j}^{r} F_{j i}^{r}}{F_{i i}^{r} F_{j j}^{r}}\right)^{-\frac{1}{2 \theta}} .
\end{aligned}
$$

Note that $\tau_{i j}^{r s}$ denotes the trade costs associated with exporting sector- $r$ intermediates from country

$i$ to country $j$ when these are purchased as inputs by industry $s$. On the other hand, $\tau_{i j}^{r F}$ captures the corresponding trade costs incurred when the exports in question are purchased for final-use. From the above formulae, one can see that the Head-Reis index infers the magnitude of cross-border trade costs from the observed values of bilateral trade flows relative to domestic absorption. The $\theta$ that appears in the exponent in (13) and (14) is the familiar trade elasticity with respect to iceberg trade costs, which we assume satisfies $\theta>1$. Intuitively, the greater is the level of cross-border trade relative to domestic absorption, the lower would be the inferred iceberg trade costs; moreover, the greater is the trade elasticity, the lower will be the trade costs required to rationalize a given ratio of cross-border to domestic sales.

As is well-known, the Head-Reis index is an exact way to back out the iceberg trade cost when 
bilateral flows are characterized by a gravity equation with a constant trade elasticity $\theta$, subject to two further assumptions. First, within-country trade costs are uniformly equal to 1 ; in our context, this amounts to normalizing $\tau_{i i}^{r s}=1$ and $\tau_{i i}^{r F}=1$ for all countries $i$ and industry pairs $r$ and $s$. Second, cross-border trade costs are directionally symmetric; in other words, we have $\tau_{i j}^{r s}=\tau_{j i}^{r s}$ and $\tau_{i j}^{r F}=\tau_{j i}^{r F}$ for all industries $r$ and $s$, so that the cost of exporting for intermediate-use (respectively, for final-use) is equal regardless of whether one is exporting from country $i$ to $j$ or from $j$ to $i$. The latter assumption in particular is more restrictive. As we shall see in Section 5, it potentially limits the flexibility of the model there to fully match all entries of a WIOT. That said, absent more direct measures of trade costs, the Head-Reis index provides a convenient empirical handle to assess how trade costs have been moving on average.

To get a sense of aggregate trends, we first use the country-by-country version of the WIOT (i.e., with the industry dimension collapsed out) to calculate the standard Head-Reis index of bilateral trade costs between country pairs. ${ }^{22}$ We adopt a baseline value of $\theta=5$ for the trade elasticity. We take for each year a simple average of the Head-Reis index over all country pairs with $i<j$ (bearing in mind the symmetric nature of the index), and then plot the trends over time in Figure 7. This is done separately for intermediate-use and final-use trade costs. ${ }^{23}$

Several observations emerge from Figure 7. Trade costs remain high in absolute levels, with the average iceberg friction still roughly $300 \%$ in ad valorem equivalent terms even at the end of the sample period. That said, the overall trend between 1995-2011 has been one of declining trade costs, this being especially marked in the first half of the sample period. ${ }^{24}$ Absent other forces, this fall in trade costs is difficult to reconcile with the persistence over time in the positive correlation between $F / G O$ and $V A / G O$ (as well as between $U$ and $D$ ). Interestingly, while trade costs have fallen for both intermediate- and final-use, the average level of trade frictions faced by intermediate inputs has been lower than that for final-use throughout this period. This is consistent with a "tariff escalation" intuition: there is less incentive to impose barriers on trade in intermediates, since a country may end up bearing a portion of these trade costs if the inputs are embodied in final goods/services that the country eventually consumes.

This message of a broad decline in trade costs is reinforced when we examine the Head-Reis indices constructed at the country-industry level, as given by (13) and (14). With these measures, we find that even within narrowly-defined country-industry pairs, there is strong evidence of a downward trend over time in trade costs. More specifically, we regress the log of each Head-Reis

\footnotetext{
${ }^{22}$ Using the notation in Section 2.3 , this is calculated for any country pair $(i, j)$ as: $\left(\left(Z_{i j} Z_{j i}\right) /\left(Z_{i i} Z_{j j}\right)\right)^{-1 / 2 \theta}$ for trade in intermediates and as: $\left(\left(F_{i j} F_{j i}\right) /\left(F_{i i} F_{j j}\right)\right)^{-1 / 2 \theta}$ for final-use trade. Note that the formulae for the Head-Reis indices imply that trade costs are infinite when either the value of trade from $i$ to $j$ or that from $j$ to $i$ is zero. For practical purposes, we therefore add a small constant to all $Z_{i j}^{r s}$ and $F_{i j}^{r}$ entries that are equal to zero, before collapsing the WIOT to a country-by-country set of tables, in order to bound the implied trade costs away from infinity. The constant added $\left(1 e^{-18}\right)$ is less than the smallest positive entry seen in the WIOT in any year.

${ }^{23}$ When plotting Figure 7 , we have dropped the largest $1 \%$ of values for both intermediate-use and final-use trade costs. In practice, this helps to smooth out the time trend in the figure, ensuring that the patterns are not being driven by outliers that correspond to very small trade flows that are most prone to being measured with error.

${ }^{24}$ There appears to be a small rise in trade costs around the onset of the Global Financial Crisis, consistent with the collapse in trade flows experienced during that episode.
} 


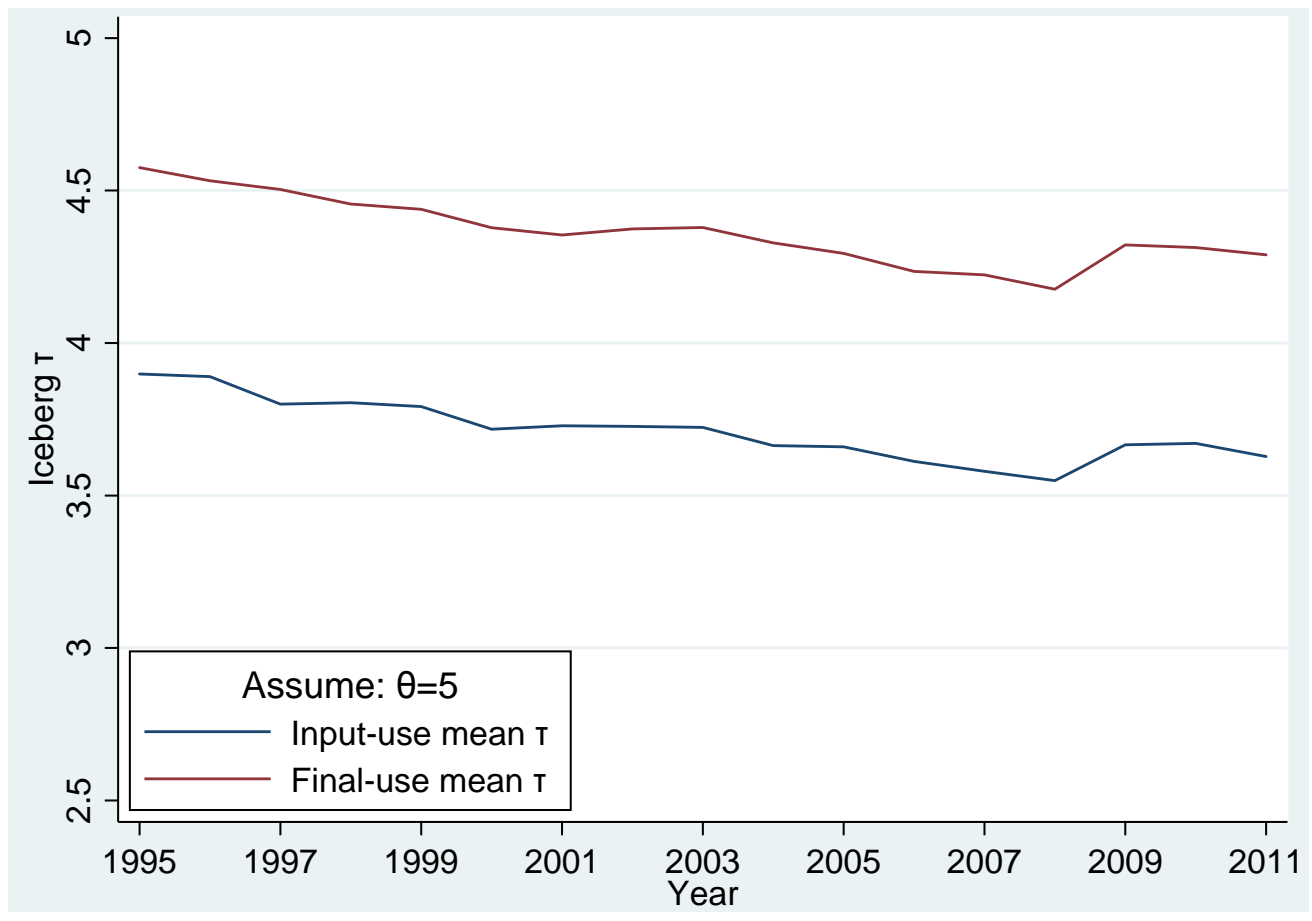

Figure 7: Head-Reis $\tau$ 's (country-level) over time

index against a linear time trend $\left(\right.$ Year $\left._{t}\right)$ and an extensive set of fixed effects, as follows:

$$
\begin{aligned}
& \ln \tau_{i j, t}^{r s}=\beta_{0} \text { Year }_{t}+F E_{i j}^{r s}+\epsilon_{i j, t}^{r s}, \text { and } \\
& \ln \tau_{i j, t}^{r F}=\beta_{0} \text { Year }_{t}+F E_{i j}^{r}+\epsilon_{i j, t}^{r} .
\end{aligned}
$$

In the first regression involving trade costs for intermediate inputs, we include a full set of source country-industry by destination country-industry dummies $\left(F E_{i j}^{r s}\right)$, this being the most comprehensive set of fixed effects that can be used while allowing us to identify the coefficient of the time trend. Similarly, in the second regression explaining trade costs for final-use, we include a full set of source country-industry by destination country dummies $\left(F E_{i j}^{r}\right)$. The above regressions thus seek to isolate what could be called the pure "within" component of the time variation in these trade costs. The findings from estimating (15) and (16) are reported in Tables 4 and 5 respectively, based on Head-Reis indices calculated once again using a common value of $\theta=5$. Given the directional symmetry described earlier, we include in Table 4 only those trade cost observations corresponding to input-use purchases that lie above the main diagonal of the matrix of $Z_{i j}^{r s}$ 's in the WIOT in any given year, while we include in Table 5 only observations for which the country index satisfies $i<j$. Even so, the regression sample is very large, especially in Table 4: For trade costs related to intermediate inputs, we will report results for specifications with close to 17.5 million observations, with more than 1 million fixed effects used!

Turning now to these results, we obtain coefficients on Year $_{t}$ that are negative and highly significant in Column 1 in both Tables 4 and 5. (The standard errors are multi-way clustered 
by source country-industry, destination country-industry, and year in Table 4, while clustered by source country-industry, destination country, and year in Table 5.) For trade in intermediates, the point estimate indicates an average fall in trade costs of about $1.6 \%$ per year. The corresponding fall has been slightly faster for final-use trade costs, namely a $2.1 \%$ decrease per year. A very similar pattern emerges in Column 2, when replacing the linear time trend with a full set of year dummies. Over the course of 1995-2011, the average within-category fall in intermediate input trade costs was a cumulative $25.4 \%$, while the corresponding decline for final-use trade costs was $34.2 \%$.

\section{[Tables 4 and 5 here]}

We have also explored whether there are differences in the manner of these trade cost movements across goods versus service industries, given that this sectoral distinction will play an important part in the next subsection. This is done in the remaining columns of Tables 4 and 5, which look at trade in goods (Columns 3-4) versus trade in services (Columns 5-6). From these columns, it is clear that the decrease in trade costs is a feature shared by both goods and service industries. Separately, we have found similar patterns when allowing for differences across industries in the trade elasticity used to compute the Head-Reis indices, specifically when using the industry-level estimates of $\theta$ from Caliendo and Parro (2015) matched to the WIOD industry categories. ${ }^{25}$ The conclusion of a broad decline in trade costs is also robust to dropping the largest 1\%, $5 \%, 10 \%$, $25 \%$, and even $50 \%$ of the trade cost observations in each table (results available on request), so that the patterns are unlikely to be driven by observations that correspond to small trade flows. ${ }^{26}$

Ceteris paribus, the widespread decrease in cross-border trade costs would in principle have spurred GVC activity, which in turn might lead us to expect that the link between $F / G O$ and $V A / G O$ would have weakened. It is thus difficult to rationalize the persistence in the correlation between $F / G O$ and $V A / G O$ (as well as that between $U$ and $D$ ) on the basis of the observed movements in trade costs alone. We are left to conclude that other forces must have been at play that account for these puzzling correlations between the GVC measures.

\subsection{Composition of Industries: Goods versus Services}

As a second proximate explanation, we explore the possibility of shifts in the underlying composition of industrial activity. This is motivated by the observation from Appendix Table 1, that there are distinct differences between goods and service industries in the nature of their GVC positioning. Goods-producing industries feature on average a lower share of their output going directly to finaluse and are more upstream relative to final demand when compared against service industries, likely reflecting that the manufacturing process for goods can be more easily fragmented into stages involving separate parts and components. At the same time, goods industries also exhibit a lower share of payments to primary value-added and are more downstream relative to primary

\footnotetext{
${ }^{25}$ These industry-level elasticities are for goods-producing sectors, and so we continue to set $\theta=5$ for trade flows involving services in this robustness exercise.

${ }^{26}$ Similar results are obtained when dropping the industries related to transport services, namely Inland Transport (23), Water Transport (24), Air Transport (25), and Other Transport Activities and Travel Agencies (26).
} 

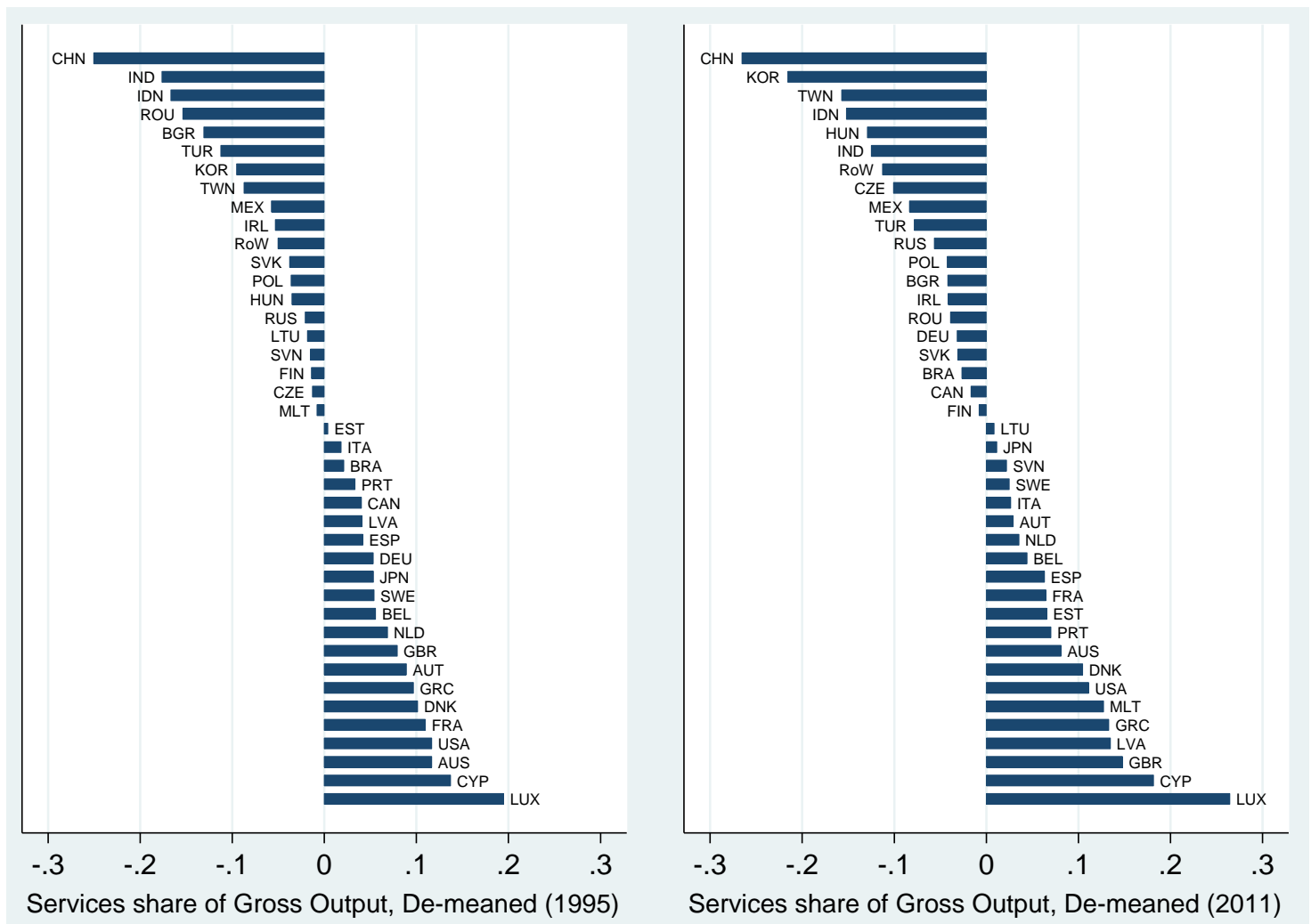

Figure 8: GVC Positioning Measures and their Correlation over time

factors than service industries, presumably because payments to labor comprise a larger share of the production costs in service industries. Goods industries thus appear to be positioned in "longer" production chains - with more stages both upstream and downstream - than service industries.

This raises a potential explanation for the positive correlation between $F / G O$ and $V A / G O$ at the country level: Suppose that countries differ in their comparative advantage across goods versus services. Countries with comparative advantage in services would then feature low final-use and value-added shares in gross output ("short" GVCs), with the converse being true for countries that have comparative advantage in goods-producing industries ("long" GVCs). In the cross-section of countries, this would manifest itself as a positive correlation between $F / G O$ and $V A / G O$ (as well as between $U$ and $D$ ). Pursuing this logic further, a decline in cross-border trade costs of the type documented in Figure 7, applying broadly to both goods and services, would reinforce this preexisting pattern of comparative advantage, and could even strengthen these positive correlations.

To explore whether such a mechanism may have been at play, we examine how patterns of specialization across countries in goods versus services have evolved over time. We do so by looking at the service sector's share of gross output within each country. (Recall from footnote 17 that industries 17-35 in the WIOD are classified as services, while industries 1-16 are goods-producing.) This services share has been on the rise, from an average across countries of $59.5 \%$ in 1995 to $65.6 \%$ in 2011. At the same time, this secular rise in recorded service activity was accompanied by a mild increase in dispersion in the services share across economies. This is illustrated in Figure 8, 
where we have plotted these services shares after demeaning by the cross-country average in each respective year. The figure points to an increase between 1995 and 2011 in the observed spread in the services share: Countries such as Luxembourg, Cyprus, and Great Britain that initially were relatively specialized in services have become even more so, while economies such as China, Korea, and Taiwan have become more skewed towards producing goods. ${ }^{27}$ These compositional shifts in output between goods and services thus appear to be moving in the right direction to help account for the cross-country correlation puzzle among the GVC measures. Admittedly, however, our empirical results so far cannot help us elucidate the extent to which the shifts observed in Figure 8 are directly related to the trade cost reductions documented in Figure 7 . We will return to this point in Section 6, after having developed our quantitative model.

Can the rise of services help to account too for the correlation puzzle at the country-industry level? Figure 9 plots the relationship between $F / G O$ and $V A / G O$, constructed at the countryindustry level, for the goods and services sectors separately; a third subplot illustrates the relationship when pooling across all industries. While the figures are drawn for 2011, the message is similar if one were to look at 1995 instead. A quick comparison of the first two subplots confirms that goods industries tend to feature lower final-use and value-added to gross-output ratios than service industries. The respective lines of best fit (drawn with $95 \%$ confidence interval bands) moreover demonstrate that it is the service industries that are driving the overall positive correlation between $F / G O$ and $V A / G O$; the corresponding correlation when looking at goods industries is in fact weakly negative. Figure 10 performs the analogous exercise for the country-industry measures of $U$ and $D$. In line with Appendix Table 1, the service industries are on average more proximate to final-use, as well as to primary factors, when compared to the goods industries. The raw correlation between $U$ and $D$ is now slightly positive when examining just the industries in the goods sector. But this relationship is particularly marked for the service sector, which ultimately contributes to the strong positive slope seen between $U$ and $D$ when pooling across all industries. Put otherwise, absent the service industries, the correlations between $F / G O$ and $V A / G O$ (as well as between $U$ and $D$ ) would clearly be much weaker.

We round off this subsection by further documenting that there has been a compositional shift away from goods and towards services over the sample period. This is important for translating the positive correlations described above at the country-industry level into a corresponding set of correlations at more aggregate levels (say when aggregating over all industries within a country). More specifically, we show that over time: (i) services have risen as a share of final-use expenditures; and (ii) service inputs have risen as a share of gross-output value.

Focusing first on (i), we calculate the share of industry $s$ in the final-use expenditures of country $j$ as: $\alpha_{j}^{s}=\left(\sum_{i=1}^{N} F_{i j}^{s}\right) /\left(\sum_{i=1}^{N} \sum_{s=1}^{S} F_{i j}^{s}\right)$. Pooling these $\alpha_{j}^{s}$ 's over all years $t$ in the WIOD, we then explore how these shares have evolved over time with the following regression:

$$
\ln \alpha_{j, t}^{s}=\beta_{0} Y e a r_{t}+F E_{j}^{s}+\epsilon_{j, t}^{s} .
$$

\footnotetext{
${ }^{27}$ The coefficient of variation of the service share in gross output rose slightly from 0.159 in 1995 to 0.167 in 2011.
} 

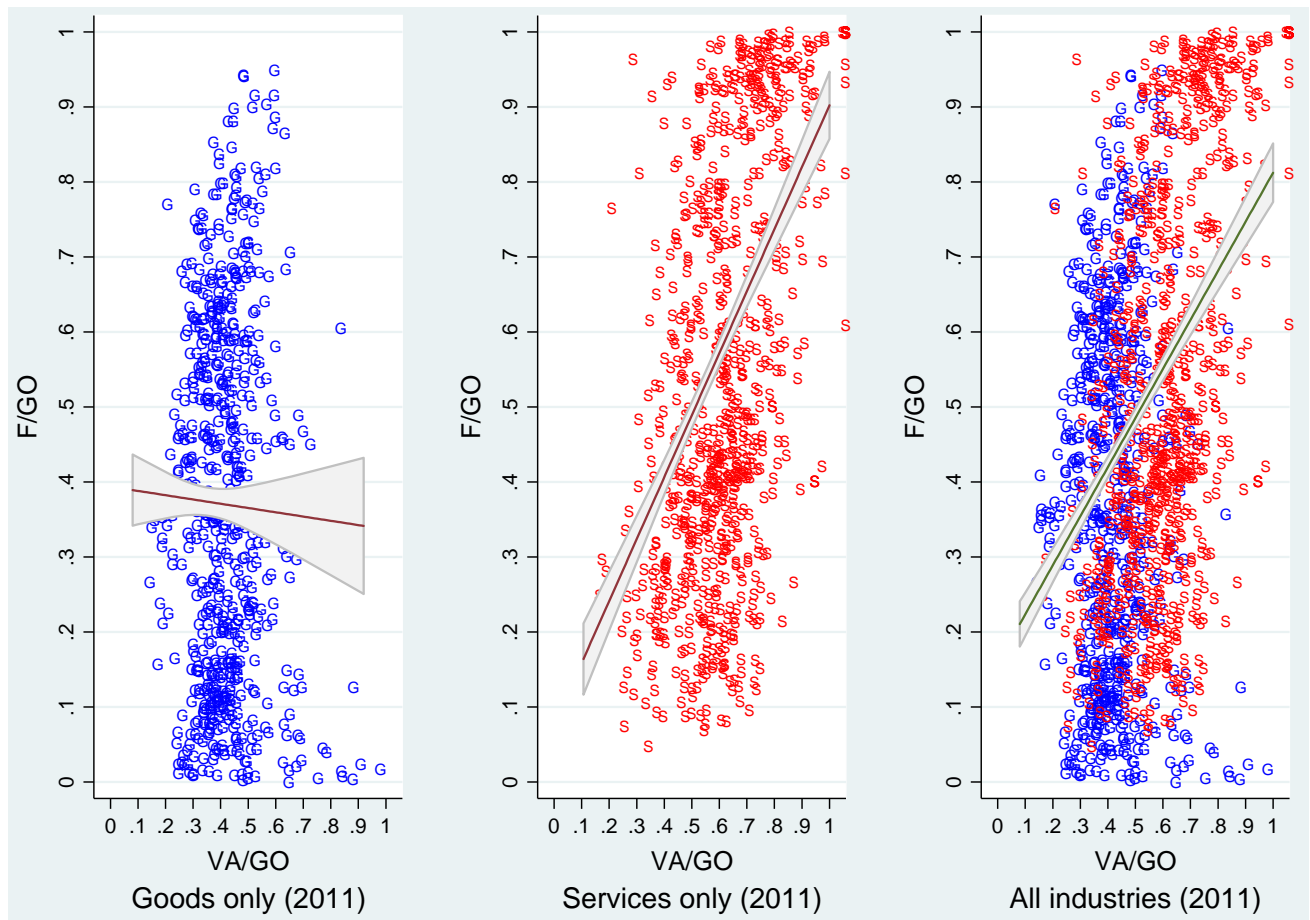

Figure 9: Correlation between $F / G O$ and $V A / G O$ : Goods versus Services

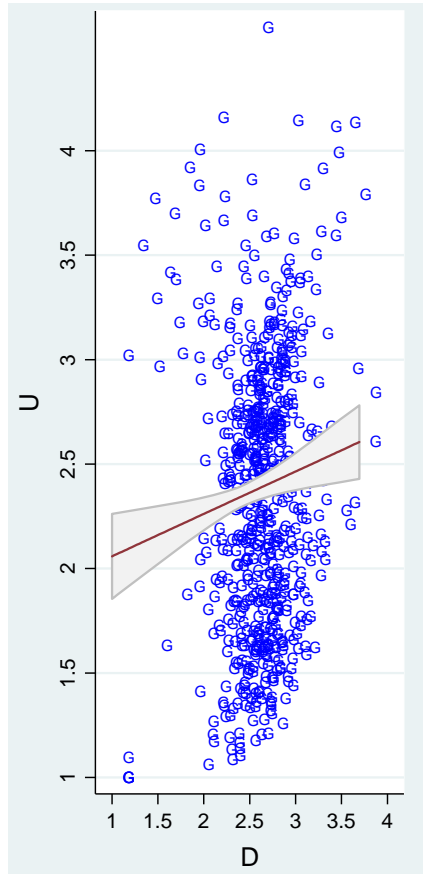

Goods only (2011)

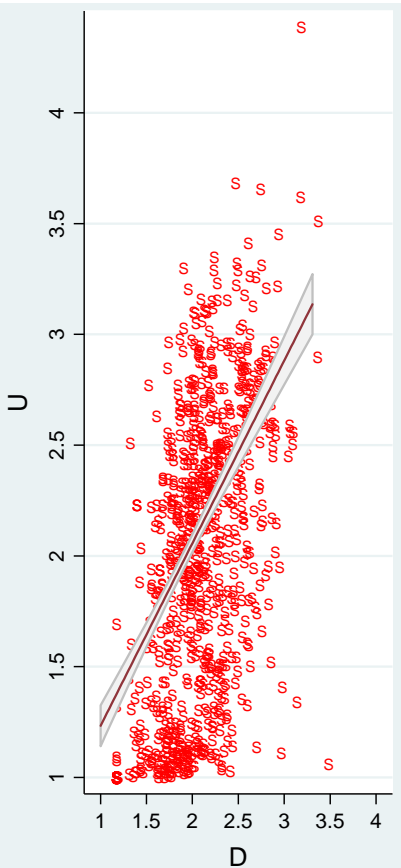

Services only (2011)

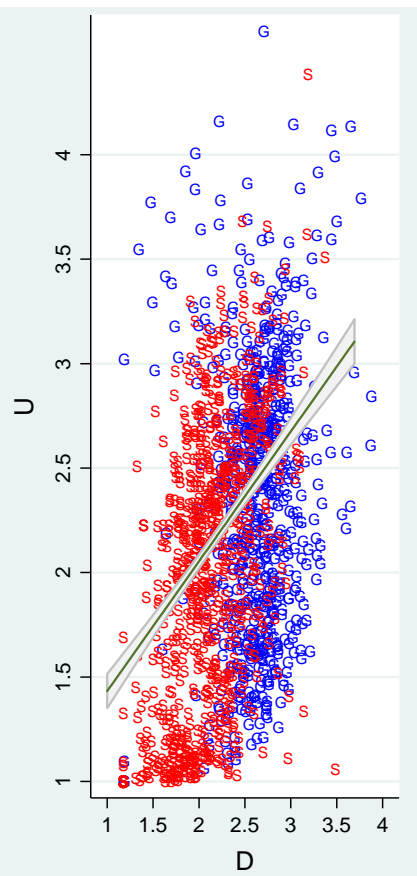

All industries (2011)

Figure 10: Correlation between $U$ and $D$ : Goods versus Services 
As before, the use of the $F E_{j}^{s}$ fixed effects means that we are estimating the $Y$ ear $t$ coefficient off time variation within the industry-by-country bins. Table 6 presents these regression results; multiway clustered standard errors (by country, industry, and year) are reported. Since the $\alpha_{j, t}^{s}$ 's sum up to 1 in any given country and year, any increases over time in the expenditure shares on particular goods or services would need to be offset by decreases in the shares spent on other industries; in line with this, we find no significant time trend on average when pooling across all industries (Columns 1-2). However, a distinct pattern emerges when we separate goods from services and re-run (17): There has been a significant decline in the goods industries' shares in final demand over time (Columns 3-4), and this has been accompanied correspondingly by an increase in the expenditure shares on services (Column 5-6). While the coefficient on the linear time trend in Column 5 is marginally insignificant, the more flexible specification with year dummies in Column 6 uncovers a positive effect over time (albeit one that has tapered off slightly in the last few years).

[Table 6 here]

Turning to (ii), we take a similar look at how the importance of goods versus service inputs has shifted. This is done by computing (once again from the WIOD) the following measures of the share of sector- $r$ inputs in the value of gross output of industry $s$ in country $j$, namely: $\gamma_{j}^{r s}=\left(\sum_{i=1}^{N} Z_{i j}^{r s}\right) /\left(Y_{j}^{s}\right)$. We focus on the variation over time within each $r$-by-s-by- $j$ bin using:

$$
\ln \gamma_{j, t}^{r s}=\beta_{0} Y e a r_{t}+F E_{j}^{r s}+\epsilon_{j, t}^{r s}
$$

where $F E_{j}^{r s}$ denotes a full set of industry-pair by destination country fixed effects. The results in Table 7 highlight the rising importance of services versus goods, this time as an input in production processes. There is no distinct pattern seen in these input purchase shares over time when looking over all inputs (Columns 1 and 2). When separately examining goods and services purchases though, we immediately detect a downward time trend in the purchases of inputs from goods industries (Columns 3 and 4), and a corresponding rise over time in that associated with services (Columns 5 and 6). Comparing the point estimates in Column 5 across Tables 6 and 7, each successive year is associated with an increase in the services input-use share of about $0.97 \%$ per annum, versus an increase in the final-use share of about $0.37 \%$ per annum; the rise in purchases of services has thus been larger in proportional terms for intermediate input-use than for final-use.

\section{[Table 7 here]}

This observed increase in the use of services as an intermediate input warrants some discussion. One interpretation is that production technologies have indeed shifted toward substituting the use of more service for goods inputs. This view would be in line with the "servification" hypothesis, as articulated for example by Baldwin and Ito (2014). An alternative interpretation is that the use of services is now recorded more comprehensively as a result of a rise in outsourcing. Services that previously were performed in-house - ranging from basic janitorial services to more complex 
accounting work - are now increasingly performed by sub-contractors that are independent entities located outside of firm headquarters. Such activity might in the past have been recorded as payments to labor within the firm, but are now picked up instead as payments across establishments and firms with the rise of such outsourcing practices. The observed increase in services purchases may thus be a reflection of such organizational rather than technological change per $s e .^{28}$

Distinguishing between these two hypotheses is an interesting research question, but one that lies beyond the scope of this paper. What should be clear is that the shifting composition of goods versus services industries - with the latter rising in importance in both final expenditures and input purchases - has potential to explain why $F / G O$ and $V A / G O$ (respectively, $U$ and $D$ ) have remained positively correlated at both the country and country-industry levels.

\section{A Structural Interpretation of the Data}

We turn next to develop a theoretical framework that provides a structural interpretation of all the cells in a WIOT, and that hence allows for a basic quantitative assessment of the extent to which trade cost declines and the rising importance of services can help to account for the correlations seen over time between the various GVC measures.

\subsection{A Useful Starting Point}

The Caliendo and Parro (2015) model provides a useful starting point. Consider a world with $J \geq 1$ countries and $S \geq 1$ sectors or industries. This gives rise to a $J \times S$ by $J \times S$ matrix of bilateral country-industry trade shares for trade in intermediate inputs, and a $J \times S$ by $J$ matrix of trade shares for trade designated for final-use.

For the purposes of clarity, let us establish upfront the notation to index the economic variables in the exposition, which deviates from Caliendo and Parro (2015). As in our empirical sections, we use the subscripts $i$ and $j$ to refer throughout to countries; whenever a pair of subscripts is used (e.g., to describe a trade flow variable), the left subscript will denote the source country, while the right subscript will denote the destination country (so $i j$ corresponds to a flow from $i$ to $j$ ). On the

other hand, we use the superscripts $r$ and $s$ to refer to industries; once again, whenever a pair of superscripts is used on a variable, the left superscript will be the identity of the source (i.e., selling) industry, while the right superscript will be the identity of the destination (i.e., buying) industry (so $r s$ is a purchase from industry $r$ by industry $s$ ).

\subsubsection{Model Set-Up and Equilibrium}

Preferences are country-specific and take the form:

$$
u\left(C_{j}\right)=\prod_{s=1}^{S}\left(C_{j}^{s}\right)^{\alpha_{j}^{s}},
$$

\footnotetext{
${ }^{28}$ See Berlingieri (2014) for a related discussion based on the U.S. domestic Input-Output tables.
} 
where $C_{j}^{s}$ denotes consumption of a sector- $s$ aggregate, $C_{j}$ denotes the vector of the $C_{j}^{s}$ 's consumed in country $j, \alpha_{j}^{s}$ is the share of industry $s$ in the expenditure of the country- $j$ representative consumer, and $\sum_{s=1}^{S} \alpha_{j}^{s}=1$.

Within each industry $s$, there is a continuum of varieties indexed by $\omega^{s} \in[0,1]$. Production of each variety is a Cobb-Douglas function of equipped labor, as well as intermediate inputs. More specifically, in country $j$, the production function for each industry- $s$ variety is given by:

$$
y_{j}^{s}\left(\omega^{s}\right)=z_{j}^{s}\left(\omega^{s}\right)\left(l_{j}^{s}\left(\omega^{s}\right)\right)^{1-\sum_{r=1}^{S} \gamma_{j}^{r s}} \prod_{r=1}^{S}\left(\mathcal{M}_{j}^{r s}\left(\omega^{s}\right)\right)^{\gamma_{j}^{r s}} .
$$

Note that $\mathcal{M}_{j}^{r s}\left(\omega^{s}\right)$ is the amount of composite intermediates from industry $r$ used in the production of variety $\omega^{s}$ in country $j$. The exponent $\gamma_{j}^{r s}$ is the (constant) share of production costs spent on intermediate inputs from sector $r$ by each industry- $s$ producer in country $j$. We assume that $0<\gamma_{j}^{r s}<1$, and moreover that $0<\sum_{r=1}^{S} \gamma_{j}^{r s}<1$, so that the equipped labor share (or simply, value-added share) of production costs is strictly positive in all sectors and countries. The productivity shifter $z_{j}^{s}\left(\omega^{s}\right)$ is an i.i.d. draw from a Fréchet distribution with cumulative density function: $\exp \left\{-T_{j}^{s} z^{-\theta^{s}}\right\}$. The scale parameter $T_{j}^{s}$ governs the state of technology of country $j$ in industry $s$, while $\theta^{s}>1$ governs (inversely) the dispersion of productivity in industry $s$ across producers worldwide, thereby shaping comparative advantage.

The country- $j$ composite in industry $s$, which is used both for final consumption $\left(C_{j}^{s}\right)$, as well as to provide inputs to other sectors $r\left(\mathcal{M}_{j}^{s r}\right)$, is a CES aggregate over the set of varieties on the unit interval:

$$
Q_{j}^{s}=\left(\int q_{j}^{s}\left(\omega^{s}\right)^{1-1 / \sigma^{s}} d \omega^{s}\right)^{\sigma^{s} /\left(\sigma^{s}-1\right)},
$$

where $q_{j}^{s}\left(\omega^{s}\right)$ denotes the quantity of variety $\omega^{s}$ that is ultimately purchased, naturally from the lowest-cost source country. Note that the same CES aggregator over varieties applies to the industry- $j$ composite, whether it is being consumed in final demand or being used as an intermediate input; this is a key feature of the model that will be relaxed below.

Consider the decision problem of either the representative consumer or a firm in country $j$, regarding which country to purchase variety $\omega^{s}$ from. As in Eaton and Kortum (2002), this corresponds to choosing the lowest-cost source country across $i \in\{1, \ldots, J\}$, after factoring in the unit production $\operatorname{costs} c_{i}^{s}$ and iceberg trade $\operatorname{costs} \tau_{i j}^{s}$ across all potential source countries $i{ }^{29}$ The solution to this discrete choice problem and the law of large numbers yields an expression for the expenditure share of country $j$ spent on industry- $s$ varieties that come from country $i$ :

$$
\pi_{i j}^{s}=\frac{T_{i}^{s}\left(c_{i}^{s} \tau_{i j}^{s}\right)^{-\theta^{s}}}{\sum_{k=1}^{J} T_{k}^{s}\left(c_{k}^{s} \tau_{k j}^{s}\right)^{-\theta^{s}}} .
$$

In turn, the unit production $\operatorname{cost} c_{j}^{s}$ is obtained as the solution to the cost-minimization problem

\footnotetext{
${ }^{29}$ We ignore tariffs and their implied tariff revenue for simplicity.
} 
faced by each industry-s firm in country $j$, based on the production function (20). This is given by:

$$
c_{j}^{s}=\Upsilon_{j}^{s} w_{j}^{1-\sum_{r=1}^{S} \gamma_{j}^{r s}} \prod_{r=1}^{S}\left(P_{j}^{r}\right)^{\gamma_{j}^{r s}},
$$

where $\Upsilon_{j}^{s}$ is a constant that depends only on the parameters $\gamma_{j}^{r s}$, and $P_{j}^{r}$ is the ideal price index of the industry- $r$ composite being used as an intermediate input in country $j$. Following Eaton and Kortum (2002), the expression for $P_{j}^{r}$ is given explicitly by:

$$
P_{j}^{r}=A^{r}\left[\sum_{i=1}^{J} T_{i}^{r}\left(c_{i}^{r} \tau_{i j}^{r}\right)^{-\theta^{r}}\right]^{-1 / \theta^{r}},
$$

where $A^{r}$ is a constant that depends only on $\sigma^{r}$ and $\theta^{r}{ }^{30}$

Let $X_{i j}^{s}$ denote the expenditure of country $j$ on industry- $s$ varieties from country $i$. This is the sum of country- $j$ expenditures on the industry- $s$ composite from country $i$, over both its use as an intermediate input and for final consumption. In turn, define: (i) $X_{j}^{s}=\sum_{i=1}^{J} X_{i j}^{s}$ as the total expenditure of country $j$ on industry- $s$ varieties; and (ii) $Y_{j}^{s}$ as the value of gross output in industry $s$ produced in country $j$. Having defined these objects, we can close the model by clearing the market for each industry in each country:

$$
X_{j}^{s}=\sum_{r=1}^{S} \gamma_{j}^{s r} \underbrace{\sum_{i=1}^{J} X_{i}^{r} \pi_{j i}^{r}}_{Y_{j}^{r}}+\alpha_{j}^{s}\left(w_{j} L_{j}+D_{j}\right) .
$$

Note that the first term on the right-hand side of (25) is equal to the total purchases of intermediate inputs from industry $s$, where the sum is taken over all industries $r$ that purchase intermediate inputs from $s .{ }^{31} D_{j}$ is the national deficit of country $j$, computed as the sum of all sectoral and final-use imports of a country minus the sectoral and final-use outputs. Then, the second term on the right-hand side is the total purchases by country $j$ on industry $s$ for final consumption.

We finally impose trade balance, equating a country $j$ 's imports to its exports plus its observed deficit $D_{j}$ :

$$
\sum_{s=1}^{S} X_{j}^{s}=\sum_{s=1}^{S} \sum_{i=1}^{J} X_{j}^{s} \pi_{i j}^{s}=\sum_{s=1}^{S} \sum_{i=1}^{J} X_{i}^{s} \pi_{j i}^{s}+D_{j}
$$

One can show that this last equilibrium condition can alternatively be derived from the equality of

\footnotetext{
${ }^{30}$ We assume that $\sigma^{r}<1+\theta^{r}$ for each $r$, in order for the ideal price index over this industry- $r$ CES aggregate to be well-defined.

${ }^{31}$ The manipulation uses the fact that gross output of industry $r$ in country $j$ is equal to the world's total purchases from this country-industry.
} 
(equipped) labor income and total value-added. ${ }^{32}$

The equilibrium of the model is then pinned down by the system of equations: (22), (23), (24), $(25)$, and $(26) .{ }^{33}$

\subsubsection{Mapping the Model to Empirical Counterparts}

How does the model map to the available data from global Input-Output tables? Remember that a WIOT contains information on intermediate purchases by industry $s$ in country $j$ from sector $r$ in country $i$, which we denote by $Z_{i j}^{r s}$. It also contains information on the final-use expenditure in each country $j$ on goods/services originating from sector $r$ in country $i$, which we denote by $F_{i j}^{r}$. Finally, the values of country-industry gross output $Y_{j}^{s}$ and value-added $V_{j}^{s}$, as well as countryspecific trade deficits $D_{j}$, can all be computed from the WIOT. For clarity, we denote the observed values for these variables that come from the WIOT data with tildes (e.g., $\tilde{Z}_{i j}^{r s}$ ).

The main limitation of this framework as it stands is that it imposes the same market share of a given country $i$ in the sales of output of a given sector $r$ to a destination country $j$ regardless of whether that output is designated for final-use or for use as an intermediate by other industries. In particular, note that the model imposes:

$$
\pi_{i j}^{r}=\frac{\tilde{F}_{i j}^{r}}{\sum_{k=1}^{J} \tilde{F}_{k j}^{r}}=\frac{\tilde{Z}_{i j}^{r s}}{\sum_{k=1}^{J} \tilde{Z}_{k j}^{r s}} \text { for } j=1, \ldots, J .
$$

Prior to the WIOD, the standard proportionality assumptions used to infer these import shares from available data would have generated identical shares across both final-use and input purchases. One of the contributions of the WIOD was to bring additional information to bear to distinguish imports across different end-use categories (see Dietzenbacher et al., 2013, for details). In the WIOD data, the $J$ input shares on the right-end of equation (27) and the final-use shares in the middle term would thus differ from each other, except by extreme coincidence. Hence, the Caliendo and Parro (2015) model cannot exactly match all the entries of a generic WIOT. For certain applications, this mismatch may of course not be too important. But in using the WIOT to make sense of the positioning of a country in GVCs, it stands to reason that it would be important for the model to be able to fully account for all final-use and intermediate-use trade shares.

${ }^{32}$ Aggregating (25) across sectors, and using (26), one obtains after some manipulations:

$$
w_{j} L_{j}=\sum_{r=1}^{S}\left(1-\sum_{s=1}^{S} \gamma_{j}^{s r}\right) \sum_{i=1}^{J} \pi_{j i}^{r} X_{i}^{r}=\sum_{r=1}^{S}\left(1-\sum_{s=1}^{S} \gamma_{j}^{s r}\right) Y_{j}^{r} .
$$

In words, the total wage payments to labor in country $j$ are equal to total value-added across all sectors of $j$.

${ }^{33}$ Note that $(22)$ comprises $J \times(J-1) \times S$ independent equations, since the shares $\pi_{i j}^{s}$ need to sum to 1 for each $j$-s pair. Also, (23) and (24) each comprise $J \times S$ equations. The market-clearing condition (25) comprises $J \times S-1$ independent equations, since one of these is redundant by Walras' Law. Finally, there are $J$ trade balance conditions in (26). On the other hand, the equilibrium seeks to solve for the following objects: the shares $\pi_{i j}^{s}$ (of which there are $J \times(J-1) \times S$ independent shares), the unit production costs $c_{j}^{s}$ and price indices $P_{j}^{s}$ (of which there are $J \times S$ each), as well as the $J-1$ wage levels $w_{j}$ 's (with one country's wage chosen as the numéraire) and the $J \times S$ expenditure levels $X_{j}^{s}$ 's. Thus, we have as many equilibrium conditions as variables to be solved for. 


\subsection{A More Flexible Model}

We now present a more flexible version of the Caliendo and Parro (2015) model. In particular, we relax their assumption that iceberg trade $\operatorname{costs} \tau_{i j}^{s}$ are only country-pair and (selling) industry specific.

\subsubsection{New Assumptions and Equilibrium}

Instead of the previous formulation of trade costs, consider the case in which trade costs are denoted by $\tau_{i j}^{r s}$ when goods/services in sector $r$ from country $i$ are shipped to industry $s$ in country $j$. Similarly, denote by $\tau_{i j}^{r F}$ the trade costs incurred when goods/services in sector $r$ from country $i$ are shipped to final consumers in country $j$. This variation could reflect, for instance, underlying heterogeneity in the characteristics (weight, value, etc.) of the various inputs and final goods that are lumped together into a sector in the WIOD. Naturally, it might also be driven by heterogeneity in the man-made trade barriers applied to these various industry subcategories. To the extent that different sectors buy different types of inputs in a given sector in different proportions, they will effectively face different trade costs, with the same being true of purchasers of final varieties.

As noted in the Introduction (see footnote 6 in particular), the proportionality assumptions used to construct WIOTs would generate identical trade shares, $\pi_{i j}^{r}$, across all input-purchasing industries $s .{ }^{34}$ This suggests that an extension of the Caliendo and Parro (2015) framework that simply allowed for distinct trade costs for shipments of inputs and final-goods for a given country pair $i-j$ and selling sector $r$ would be sufficient to match all the entries of a WIOT. In practice, the WIOD used in our empirical analysis features minor deviations from these proportionality assumptions, so we develop here a model with more flexible input trade shares that vary depending on the identity of the purchasing industry. ${ }^{35}$ Although this added flexibility is likely to be of little quantitative importance for our exercise centered on the WIOD, there are good reasons to believe (see de Gortari, 2017) that trade shares do vary significantly in the real world depending on what the input is used for, and we expect future WIOTs to more effectively exploit firm-level import and export data to document larger departures from the commonly-used proportionality assumptions.

How does this more general formulation of trade costs affect the equilibrium conditions of the model developed above? Following the same exact steps as in our derivations in the CaliendoParro model, it is easy to verify that producers in industry $s$ in country $j$ now spend on inputs from different sectors $r$ and countries $i$ according to the input trade shares:

$$
\pi_{i j}^{r s}=\frac{T_{i}^{r}\left(c_{i}^{r} \tau_{i j}^{r s}\right)^{-\theta^{r}}}{\sum_{k=1}^{J} T_{k}^{r}\left(c_{k}^{r} \tau_{k j}^{r s}\right)^{-\theta^{r}}} .
$$

Meanwhile, consumers in $j$ spend a share $\pi_{i j}^{r F}$ of their sector- $r$ final consumption on varieties from

\footnotetext{
${ }^{34}$ In other words, given the identities of $i, j$ and $r, \tilde{Z}_{i j}^{r s} / \sum_{k=1}^{J} \tilde{Z}_{k j}^{r s}$ would be equal for all purchasing industries $s$.

${ }^{35}$ These deviations arise from adjustments made by the WIOD to reconcile the information contained on bilateral trade flows; see in particular Section 5 of Dietzenbacher et al. (2013).
} 
country $i$, where $\pi_{i j}^{r F}$ is given by:

$$
\pi_{i j}^{r F}=\frac{T_{i}^{r}\left(c_{i}^{r} \tau_{i j}^{r F}\right)^{-\theta^{r}}}{\sum_{k=1}^{J} T_{k}^{r}\left(c_{k}^{r} \tau_{k j}^{r F}\right)^{-\theta^{r}}}
$$

These expressions are analogous to equation $(22)$, but they now define $(S+1) \times J$ distinct trade shares, rather than only $J$.

On the cost side, we now have the following counterpart to equation (23):

$$
c_{j}^{s}=\Upsilon_{j}^{s} w_{j}^{1-\sum_{r=1}^{S} \gamma_{j}^{r s}} \prod_{r=1}^{S}\left(P_{j}^{r s}\right)^{\gamma_{j}^{r s}},
$$

where $\Upsilon_{j}^{s}$ is again a constant that depends only on the parameters $\gamma_{j}^{r s}$, but $P_{j}^{r s}$ is now the ideal price index of the sector- $r$ composite good in country $j$ when purchased by industry- $s$ producers. This price index is given by:

$$
P_{j}^{r s}=A^{r}\left[\sum_{i=1}^{J} T_{i}^{r}\left(c_{i}^{r} \tau_{i j}^{r s}\right)^{-\theta^{r}}\right]^{-1 / \theta^{r}}
$$

where $A^{r}$ is again a constant that depends only on $\sigma^{r}$ and $\theta^{r}$. The main difference relative to equation (24) is that this price index is now $r s$-specific, rather than just $r$-specific. For similar reasons, we now have to separately define the price index for final consumption for each sector in each country $j$ :

$$
P_{j}^{r F}=A^{r}\left[\sum_{i=1}^{J} T_{i}^{r}\left(c_{i}^{r} \tau_{i j}^{r F}\right)^{-\theta^{r}}\right]^{-1 / \theta^{r}} .
$$

Note that the price index for overall consumption is now given by:

$$
P_{j}^{F}=\prod_{s=1}^{S}\left(P_{j}^{s F} / \alpha_{j}^{s}\right)^{\alpha_{j}^{s}}
$$

Consider next the goods-market clearing conditions. As in the previous less flexible model, the equality of total expenditure of country $j$ on industry- $s$ varieties can still be expressed as the sum of total expenditure on inputs and on final consumption in that sector:

$$
X_{j}^{s}=\sum_{r=1}^{S} \gamma_{j}^{s r} Y_{j}^{r}+\alpha_{j}^{s}\left(w_{j} L_{j}+D_{j}\right)
$$

However, it is now not so straightforward to express $Y_{j}^{r}$ as a function of $X_{i}^{r}$ in other sectors and countries, as we did in equation (25). Instead, we need to consider final sales and intermediate input sales separately, which leads us to develop a linear system of equations in the gross output 
levels:

$$
Y_{j}^{s}=\underbrace{\sum_{k=1}^{J} \pi_{j k}^{s F} \alpha_{k}^{s}\left(w_{k} L_{k}+D_{k}\right)}_{\text {final-use sales }}+\underbrace{\sum_{r=1}^{S} \sum_{k=1}^{J} \pi_{j k}^{s r} \gamma_{k}^{s r} Y_{k}^{r}}_{\text {intermediate-input sales }} .
$$

In words, the gross output of sector $s$ in country $j$ is either used for final consumption in all countries around the world (the first term in (35)) or as an input by all industries in all countries (the second term in (35)).

We finally impose trade balance, equating a country $j$ 's imports to the sum of its exports and its trade deficit $D_{j}$. After some simplifications, this can be written as:

$$
\sum_{i=1}^{J} \sum_{r=1}^{S} \sum_{s=1}^{S} \pi_{i j}^{s r} \gamma_{j}^{s r} Y_{j}^{r}+w_{j} L_{j}=\sum_{i=1}^{J} \sum_{r=1}^{S} \sum_{s=1}^{S} \pi_{j i}^{s r} \gamma_{i}^{s r} Y_{i}^{r}+\sum_{s=1}^{S} \sum_{i=1}^{J} \pi_{j i}^{s F} \alpha_{i}^{s}\left(w_{i} L_{i}+D_{i}\right)
$$

One can show that this last equilibrium condition can again be written as (equipped) labor income being equal to value-added. ${ }^{36}$

The equilibrium is now defined by equations (28), (29), (30), (31), (32), (35), and (36). Note that (28) comprises $J \times(J-1) \times S \times S$ independent equations, since the shares $\pi_{i j}^{r s}$ need to sum to 1 for each $j$-rs pair; for a similar reason, (29) comprises $J \times(J-1) \times S$ independent equations. In turn, (30) and (32) comprise $J \times S$ equations each, while (31) comprises $J \times S \times S$ equations. Finally, the market-clearing conditions in (35) comprise $J \times S-1$ independent equations, since one of these is redundant by Walras' Law, and we also have $J$ trade balance conditions from (36). On the other hand, the equilibrium seeks to solve for the following objects: the $\pi_{i j}^{r s}$ 's (of which there are $J \times(J-1) \times S \times S$ independent shares); the $\pi_{i j}^{r F}$ 's (of which there are $J \times(J-1) \times S$ independent shares); the unit production $\operatorname{costs} c_{j}^{s}$, and price indices $P_{j}^{r s}$ and $P_{j}^{r F}$ (of which there are $J \times S, J \times S \times S$, and $J \times S$ terms respectively); the $J-1$ wage levels $w_{j}$ 's (with one country's wage picked as the numéraire); as well as the $J \times S$ gross output levels $Y_{j}^{s}$ 's. Thus, we have as many equilibrium conditions as variables to be solved for. With wages and the gross output levels, we can also easily solve for the expenditure levels $X_{j}^{s}$ using equation (34).

We shall not concern ourselves with proving the sufficient conditions for the existence and uniqueness of an equilibrium. Such a proof could be carried out following the approach in Alvarez and Lucas (2007). In discussing how our extended Caliendo-Parro model maps to a WIOT, we will however discuss issues that relate to the existence of an equilibrium.

\footnotetext{
${ }^{36}$ In particular, and just as in footnote 32, aggregating (25) across sectors, and using (26), one obtains after some manipulations:

$$
w_{j} L_{j}=\sum_{r=1}^{S}\left(1-\sum_{s=1}^{S} \gamma_{j}^{s r}\right) Y_{j}^{r}
$$
}




\subsubsection{Mapping to Empirical Counterparts}

We now turn to evaluate the ability of our model to match the type of data available in world InputOutput tables. Our main result will be that, via a suitable choice of parameter values for trade costs, our extended model will be able to match all entries of a WIOT that relate to intermediateuse and final-use expenditures. This will in turn allow us to provide a structural interpretation of a WIOT and of the measures of GVC positioning computed from its entries. We will also show in the next section, that one can perform interesting counterfactuals with information on only a small subset of the primitive parameters of the model, a subset that crucially does not include the complex matrix of trade costs that ensure a perfect fit of our model.

Before discussing the mapping between model and data, remember that a WIOT contains information on country-industry pair input flows $\left(Z_{i j}^{r s}\right)$, country-pair final-use trade flows by sector $\left(F_{i j}^{r}\right)$, country-sector-specific gross output $Y_{j}^{s}$ and value-added $V_{j}^{s}$, and country-specific trade deficits $D_{j}$. As before, we denote the observed values of these variables in the WIOT with tildes.

It is useful to begin by considering the mapping between the data and both the input share parameters $\gamma_{j}^{r s}$ and final expenditure share parameters $\alpha_{j}^{s}$. As in the benchmark Caliendo-Parro framework developed above, the Cobb-Douglas structure of the model allows us to easily recover all these parameters from observed trade flows. In particular, we have:

$$
\gamma_{j}^{r s}=\frac{\sum_{i=1}^{J} \tilde{Z}_{i j}^{r s}}{\tilde{Y}_{j}^{s}}
$$

and:

$$
\alpha_{j}^{s}=\frac{\sum_{i=1}^{J} \tilde{F}_{i j}^{s}}{\sum_{r=1}^{S} \widetilde{V A}_{j}^{r}+\tilde{D}_{j}} .
$$

Furthermore, the value-added share in sector $r$ can be recovered as $1-\sum_{r=1}^{S} \gamma_{j}^{r s}$.

Let us now turn to the ability of the model to replicate observed inter-industry and final-use flows, this being a limitation of the benchmark Caliendo-Parro model. With our more flexible trade cost formulation, we now have:

$$
Z_{i j}^{r s}=\pi_{i j}^{r s} \gamma_{j}^{r s} Y_{j}^{s}
$$

and:

$$
F_{i j}^{r}=\pi_{i j}^{r F} \alpha_{j}^{r}\left(\sum_{r=1}^{S} V A_{j}^{r}+D_{j}\right) .
$$

The key novelty is that the trade shares $\pi_{i j}^{r s}$ now vary both across buying and selling industries, and are also distinct from the trade shares for final consumption $\left(\pi_{i j}^{r F}\right)$. This feature in turn implies that, conditional on the observed values of gross output $\tilde{Y}_{j}^{s}$, value-added in all sectors $\widetilde{V A}_{j}^{r}$, and the trade deficits $\tilde{D}_{j}$, together with the recovered values of $\gamma_{j}^{r s}$ and $\alpha_{j}^{s}$ in (37) and (38), there exist values for the trade cost parameters $\tau_{i j}^{r s}$ and $\tau_{i j}^{r F}$ that lead the model to exactly match all the empirically observed values of $\tilde{Z}_{i j}^{r s}$ and $\tilde{F}_{i j}^{r}$.

To illustrate this result, focus first on the $\pi_{i j}^{r F}$ trade shares. Let us define: $b_{i}^{r}=T_{i}^{r}\left(c_{i}^{r}\right)^{-\theta^{r}}$ and 
$\rho_{i j}^{r s}=\left(\tau_{i j}^{r s}\right)^{-\theta^{r}}$. Combining equation (39) with the definition of the input trade shares $\pi_{i j}^{r s}$ in (28), we then obtain:

$$
\rho_{i j}^{r s}=\frac{\tilde{Z}_{i j}^{r s}}{\sum_{l=1}^{J} \tilde{Z}_{l j}^{r s}} \sum_{k=1}^{J} \frac{b_{k}^{r}}{b_{i}^{r}} \rho_{k j}^{r s} .
$$

For each destination country $j$ and each sector pair $r s$, equation (41) defines a system of $J$ linear equations in the power transformation of trade costs $\left(\rho_{1 j}^{r s}, \ldots, \rho_{i j}^{r s}, \ldots, \rho_{J j}^{r s}\right)$. Clearly, the system is linearly dependent: given a solution, if all the $\rho_{i j}^{r s}$ are multiplied by a common constant $\kappa_{j}^{r s}$, these alternative trade costs also solve the system. One can thus normalize one of the $J$ trade cost parameters to 1 , and it is natural to set the domestic trade cost to $\rho_{j j}^{r s}=1$ (i.e., $\tau_{j j}^{r s}=1$ ). Under weak invertibility conditions, the system in (41) with $\rho_{j j}^{r s}=1$ delivers a unique solution for the matrix of $\rho_{i j}^{r s}$ 's, given a vector of observed input flows $\tilde{Z}_{i j}^{r s}$ as well as values for the terms $b_{i}^{r}$.

Similarly, from equations (40) and (29), we obtain the following system of linear equations:

$$
\rho_{i j}^{r F}=\frac{\tilde{F}_{i j}^{r}}{\sum_{l=1}^{J} \tilde{F}_{l j}^{r}} \sum_{k=1}^{J} \frac{b_{k}^{r}}{b_{i}^{r}} \rho_{k j}^{r F},
$$

which also delivers, under weak invertibility conditions, a unique solution for the matrix of $\tau_{i j}^{r F}$ 's conditional on values for observed final-use flows $\tilde{F}_{i j}^{r}$ and the values of the terms $b_{i}^{r}$, after setting $\rho_{j j}^{r F}=1$ (i.e., $\tau_{j j}^{r F}=1$ ).

It is worth stressing that our results above are not sufficient to provide a method to recover a unique set of values of the trade cost parameters, $\tau_{i j}^{r s}$ and $\tau_{i j}^{r F}$, that ensure a perfect match between the trade shares in the model and in the data. More specifically, the trade cost parameters implicitly defined by (41) and (42) are a function of the terms $b_{i}^{r}$, which are in turn shaped by the unobserved technology parameters $T_{i}^{r}$ and by the (endogenous) unit cost variables $c_{i}^{r}$. Furthermore, transitioning from $\rho_{i j}^{r s}$ to $\tau_{i j}^{r s}$ requires knowledge of the trade elasticity parameters $\theta^{r}$.

For these reasons, backing out the values of $\tau_{i j}^{r s}$ and $\tau_{i j}^{r F}$ that ensure that the model perfectly matches the data is not straightforward. Fortunately, we will demonstrate in the next section that this does not preclude a structural interpretation of the data and the implementation of interesting counterfactuals. For our purposes, it will suffice to show that there exists at least one set of values for the trade cost parameters $\tau_{i j}^{r s}$ and $\tau_{i j}^{r F}$ such that the model exactly replicates the data. Our derivations above indicate that this is certainly the case (under weak invertibility conditions) conditional on the values of $b_{i}^{r}$. In the Appendix, we demonstrate that when allowing the values of $b_{i}^{r}$ to be determined by the technology parameters $T_{i}^{r}$ and by the general equilibrium of the model, this existence result persists. As long as the general equilibrium of the model exists (regardless of whether that equilibrium is unique or not), the equilibrium will deliver a well-defined vector of values for $b_{i}^{r}$, which also ensures that the model can exactly match the input and final-use trade shares, $\pi_{i j}^{r s}$ and $\pi_{i j}^{r F}$; it follows immediately that the model will also match the country-sector-specific gross output $Y_{j}^{s}$ and value-added $V_{j}^{s}$, and country-specific trade deficits $D_{j}$.

There is one additional issue with regard to mapping the model exactly to the data. The 
underlying Eaton-Kortum structure of the model implies that all of the trade shares, $\pi_{i j}^{r s}$ and $\pi_{i j}^{r F}$, are strictly positive. In particular, this means that the production of each good $s$ in country $j$ would source a positive amount of inputs from all sectors $r$ in all countries $i$. In the WIOD data, however, zero entries are relatively common. To address this, we have taken the pragmatic approach of replacing each zero input-purchase or final-use entry in the WIOD with a positive constant $\left(1 e^{-18}\right)$ that is less than the smallest positive entry seen in the WIOD. This naturally precludes us from evaluating interesting counterfactuals that pertain to how the extensive margin of sourcing would adjust. In what follows, we have therefore focused on counterfactual outcomes that pertain to the aggregate economy (rather than on the effects on specific entries in the WIOT).

\section{Counterfactuals}

We conclude the paper by illustrating how the theoretical results derived in the last section can be used to deliver quantitative insights related to where countries are positioned in GVCs. First, we will extend the "hat algebra" results in Dekle et al. (2008) and Caliendo and Parro (2015), to show that in order to perform various counterfactuals with the model, all that is required are: (i) the initial trade shares, $\pi_{i j}^{r s}$ and $\pi_{i j}^{r F}$, available from a WIOT; (ii) the demand and technological Cobb-Douglas parameters $\gamma_{j}^{r s}$ and $\alpha_{j}^{s}$, which we have also shown are easily recoverable from the same WIOT; and (iii) a vector of sectoral parameters $\theta^{r}$ shaping the elasticity of trade flows (across source countries) to trade barriers. In particular, although the existence of flexible trade $\operatorname{costs} \tau_{i j}^{r s}$ and $\tau_{i j}^{r F}$ is crucial to ensure that the model is able to fit the WIOT data exactly, knowledge of the precise values of these trade cost parameters is not necessary to conduct counterfactuals. Similarly, although the technological parameters $T_{i}^{r}$ certainly shape the values of the trade costs, $\tau_{i j}^{r s}$ and $\tau_{i j}^{r F}$, that would enable the model to fit the data, the specific values of $T_{i}^{r}$ are not essential for these counterfactuals. Having derived these sufficient statistics results, we then perform a series of counterfactual exercises, in order to shed light on the possible determinants of the evolution of our various GVC positioning measures over time.

\subsection{The Hat Algebra Approach}

We are interested in obtaining the values of the counterfactual entries of a WIOT following a shock to some of the parameters of the model. In practice, we will focus in our applications on changes in trade costs, $\tau_{i j}^{r s}$ and $\tau_{i j}^{r F}$, and in the final demand Cobb-Douglas parameters $\alpha_{j}^{r}$; our exposition below will therefore consider the case where only these parameters change in the model. ${ }^{37}$ For simplicity, we will also assume that deficits $D_{j}$ are held constant in the counterfactuals we will study. We denote the counterfactual value of a parameter or variable $X$ with a prime (e.g., $X^{\prime}$ ) and use hats to denote the relative change in these variables, i.e., $\hat{X}=X^{\prime} / X$.

\footnotetext{
${ }^{37}$ One could also easily use this approach to explore changes in the technology parameters $T_{i}^{r}$. It would also be interesting to explore shocks to the Cobb-Douglas technological parameters $\gamma_{j}^{r s}$, but the sufficient statistics results derived below do not easily generalize to this type of shocks.
} 
With this notation, and invoking equations (39) and (40), we can express the counterfactual input and final-use flows as:

$$
\left(Z_{i j}^{r s}\right)^{\prime}=\left(\pi_{i j}^{r s}\right)^{\prime} \gamma_{j}^{r s}\left(Y_{j}^{s}\right)^{\prime}
$$

and:

$$
\left(F_{i j}^{r}\right)^{\prime}=\left(\pi_{i j}^{r F}\right)^{\prime}\left(\alpha_{j}^{r}\right)^{\prime}\left(\sum_{r}\left(V A_{j}^{r}\right)^{\prime}+D_{j}\right) .
$$

Clearly, to obtain the specific counterfactual values of these entries, one needs to figure out how the trade shares $\pi_{i j}^{r s}$ and $\pi_{i j}^{r F}$, as well as gross output $Y_{j}^{s}$ and value-added levels $V A_{j}^{r}$, are affected by changes in trade costs or final-consumption shares.

Consider first trade shares. Using the hat algebra notation, it is easy to verify that (28) and (29) result in:

$$
\hat{\pi}_{i j}^{r s}=\left(\frac{\hat{c}_{i}^{r} \hat{\tau}_{i j}^{r s}}{\hat{P}_{j}^{r s}}\right)^{-\theta^{r}}
$$

and:

$$
\hat{\pi}_{i j}^{r F}=\left(\frac{\hat{c}_{i}^{r} \hat{\tau}_{i j}^{r F}}{\hat{P}_{j}^{r F}}\right)^{-\theta^{r}} .
$$

In words, the percentage response of trade shares is purely shaped by the trade elasticity parameters $\theta^{r}$ and by the percentage shifts of the various trade cost parameters, as well as the percentage responses of the unit $\operatorname{costs} c_{i}^{r}$, and the price indices $P_{j}^{r s}$ and $P_{j}^{r F}$. It is worth stressing that (45) and (46) are not approximations: they hold exactly for any shock to trade costs (or to final consumption shares), regardless of the size of the shock. Notice also, that the level of trade costs or the unobserved technological parameters $T_{i}^{r}$ do not appear directly in these equations.

The responses of the unit $\operatorname{costs} c_{i}^{r}$ and the price indices $P_{j}^{r s}$ and $P_{j}^{r F}$ to changes in the environment can be obtained from simple manipulations of equations (30), (31), and (32). More specifically, plugging in the expressions for the trade shares from (28) and (29), we obtain:

$$
\begin{gathered}
\hat{c}_{j}^{s}=\left(\hat{w}_{j}\right)^{1-\sum_{r=1}^{S} \gamma_{j}^{r s}} \prod_{r=1}^{S}\left(\hat{P}_{j}^{r s}\right)^{\gamma_{j}^{r s}}, \\
\hat{P}_{j}^{r s}=\left[\sum_{i=1}^{J} \pi_{i j}^{r s}\left(\hat{c}_{i}^{r} \hat{\tau}_{i j}^{r s}\right)^{-\theta^{r}}\right]^{-1 / \theta^{r}},
\end{gathered}
$$

and:

$$
\hat{P}_{j}^{r F}=\left[\sum_{i=1}^{J} \pi_{i j}^{r F}\left(\hat{c}_{i}^{r} \hat{\tau}_{i j}^{r F}\right)^{-\theta^{r}}\right]^{-1 / \theta^{r}} .
$$

There are two key features of these three sets of equations. First, the only variables in levels that appear in these equations are the trade shares prior to the shocks (which are obviously observable), the Cobb-Douglas technological parameters $\gamma_{j}^{r s}$ (which are retrievable from the data in a WIOT), and the trade elasticity parameters $\theta^{r}$. Second, it is clear from inspection that combining (47) and 
(48), one should be able to solve - albeit computationally - for $\hat{c}_{j}^{s}$ and $\hat{P}_{j}^{r s}$ as a function of these initial trade shares, as well as the percentage changes in wages $\left(\hat{w}_{j}\right)$ and input trade costs $\left(\hat{\tau}_{i j}^{r s}\right)$. Similarly, combining (47) and (49), we can obtain $\hat{P}_{j}^{r F}$ as a function of these same initial trade shares, as well as the percentage changes in wages $\left(\hat{w}_{j}\right)$ and final-use trade costs $\left(\hat{\tau}_{i j}^{r F}\right)$.

Plugging these resulting values of $\hat{c}_{j}^{s}, \hat{P}_{j}^{r s}$, and $\hat{P}_{j}^{r F}$ into (45) and (46), this then allows us to express the changes in trade shares as a function of observables $\left(\pi_{i j}^{r s}, \pi_{i j}^{r F}\right.$, and $\left.\gamma_{j}^{r s}\right)$, the trade elasticity parameters $\theta^{r}$, and the percentage changes in wages and trade costs.

We finally discuss how to trace the response of wages, as well as gross output and value-added, to the shocks. For that, we invoke the goods-market clearing conditions (35) and the trade balance conditions (36). In the counterfactual equilibrium, these can be re-written as:

$$
\left(Y_{j}^{s}\right)^{\prime}=\sum_{k=1}^{J}\left(\pi_{j k}^{s F}\right)^{\prime}\left(\alpha_{k}^{s}\right)^{\prime}\left(\hat{w}_{k} w_{k} L_{k}+D_{k}\right)+\sum_{r=1}^{S} \sum_{k=1}^{J}\left(\pi_{j k}^{s r}\right)^{\prime} \gamma_{k}^{s r}\left(Y_{k}^{r}\right)^{\prime}
$$

and:

$$
\begin{aligned}
\sum_{i=1}^{J} \sum_{r=1}^{S} \sum_{s=1}^{S}\left(\pi_{i j}^{s r}\right)^{\prime} \gamma_{j}^{s r}\left(Y_{j}^{r}\right)^{\prime}+\hat{w}_{j} w_{j} L_{j}= & \sum_{i=1}^{J} \sum_{r=1}^{S} \sum_{s=1}^{S}\left(\pi_{j i}^{s r}\right)^{\prime} \gamma_{i}^{s r}\left(Y_{i}^{r}\right)^{\prime} \\
& +\sum_{s=1}^{S} \sum_{i=1}^{J}\left(\pi_{j i}^{s F}\right)^{\prime}\left(\alpha_{i}^{s}\right)^{\prime}\left(\hat{w}_{i} w_{i} L_{i}+D_{i}\right)
\end{aligned}
$$

Noting that $\left(\pi_{i j}^{s r}\right)^{\prime}=\hat{\pi}_{i j}^{s r} \cdot \pi_{i j}^{s r}$, this system of equations delivers solutions for $\left(Y_{j}^{s}\right)^{\prime}=\hat{Y}_{i j}^{s} \cdot Y_{i j}^{s}$ and $\hat{w}_{j}$ as a function of the changes in trade costs and Cobb-Douglas demand parameters $\left(\hat{\tau}_{i j}^{r s}, \hat{\tau}_{i j}^{r F}\right.$, and $\hat{\alpha}_{j}^{s}$ ). Plugging these values into (39) and (40), and noting that $\left(V A_{j}^{r}\right)^{\prime}=\widehat{V A}_{j}^{r} \cdot V A_{j}^{r}=\hat{Y}_{j}^{r} \cdot V A_{j}^{r}$ (due to the Cobb-Douglas assumption in technology), this then allows us to obtain the counterfactual values of all the entries in a WIOT.

In sum, we have demonstrated that in order to perform counterfactual exercises that shock trade costs or the demand parameters $\alpha_{j}^{s}$ while holding all other parameters constant, all that is required is the initial values of a set of variables that are easily retrieved from a WIOT, as well as values for the trade elasticities $\theta^{r} .{ }^{38}$ We next turn to an application of this result to various counterfactual scenarios of interest.

\subsection{Applications}

We will perform two types of counterfactuals, using the system of equations in "hat algebra" form just laid out in (43)-(51). First, we will study how much changes in trade costs and changes in the $\alpha_{j}^{s}$ preference parameters can help explain the evolution of the GVC positioning of industries and countries over the period 1995-2011. More specifically, we will hold all other parameters of

\footnotetext{
${ }^{38}$ As pointed out by a referee, for the approach to work, it is important that the sectoral trade elasticities do not vary across importing countries.
} 
the model (including trade deficits) to their 1995 level, and allow first trade costs and then the parameters $\alpha_{j}^{s}$ to jump to their 2011 levels. This will shed light on the extent to which these factors might help in resolving the empirical puzzles identified in Section 3. We will later consider further counterfactual trade cost reductions and changes in demand parameters starting from their 2011 levels, to offer projections for the future positioning of countries in GVCs.

We should stress that the exercise here is not meant to be an exhaustive exploration of the forces that could account for the persistent correlations in the country-level GVC measures. The counterfactuals that we run here speak to the two candidate explanations posited earlier in Section 4, namely movements in trade costs and shifts in sectoral composition. Even so, we are unable to explore the effect of changes in the input purchase share parameters (the $\gamma_{j}^{r s}$ 's), though these have likely contributed too to the realignments in sectoral composition, as such shifts cannot be analyzed using the "hat algebra" techniques within the current model with Cobb-Douglas production functions. ${ }^{39}$ Likewise, we do not explore the possible role of changes in the fundamental technology levels (the $T_{i}^{r}$ 's), since these are harder to discipline empirically with available data. (Note that in the exercises below, we adopt $\theta^{r}=5$ throughout for simplicity.)

In Table 8 below, we explore the model's implications for shifts in country GVC positioning over the 1995-2011 period. Panel A reports several key moments and correlations related to the countrylevel GVC measures, including the values computed directly from the 1995 and 2011 WIOTs. Consider first the effect of a change in trade costs from 1995 to 2011 levels. Since we encounter a non-trivial number of zero entries in the WIOT in each year (which would inconveniently imply that the Head-Reis trade cost index is infinite for these entries), we opt to aggregate the industries in the WIOT into two broad sectors, namely goods versus services. We thus compute Head-Reis indices associated with trade in intermediates between any country-sector pair (based on the goods and services sectoral aggregates), as well as the Head-Reis indices associated with final-use trade between any country pair in goods and in services. ${ }^{40}$

What are the quantitative implications of the empirically observed reductions in trade costs? We argued in Section 4.1 that falling trade costs would tend to weaken the correlation between the final-use and value-added shares in gross output across countries, as production along GVCs becomes more fragmented across borders. Yet, in Section 4.2 we also put forth the view that the increased specialization in services and in goods production illustrated in Figure 8 - which tended to increase the correlation between $F / G O$ and $V A / G O$ - could also well be driven by trade cost reductions. Which of these forces dominated over the period 1995-2011? Our results in Table 8 indicate that, in isolation, trade costs would have led to a reduction in the correlation between $F / G O$ and $V A / G O$ from a value of 0.825 in the initial year to 0.612 by the end of the period.

\footnotetext{
${ }^{39}$ To accommodate changes in the $\gamma_{j}^{r s}$ 's, one would require a more flexible production specification, such as CES production functions in each industry.

${ }^{40}$ In other words, we calculate $(2 J)^{2}$ instead of $(J \times S)^{2}$ trade costs for intermediate inputs, and $2 J^{2}$ instead of $J^{2} \times S$ trade costs for final-use trade. We adopt $\theta=5$ when computing these Head-Reis indices. Even after aggregating to the broad sectoral level, there are still a number of zeros in the matrix. We therefore bottom-code $\hat{\tau}_{i j}^{r s}$ and $\hat{\tau}_{i j}^{r F}$ at their respective first percentile values if these proportional changes fall below this percentile threshold. Likewise, we top-code large values of $\hat{\tau}_{i j}^{r s}$ and $\hat{\tau}_{i j}^{r F}$ at their respective 99th percentile values.
} 
This contrasts against the fact that this correlation actually moved in the opposite direction in the data, and stood at 0.925 in 2011 . Along a similar vein, the changes in trade costs alone would have generated a drop in the correlation between the country-level production staging measures ( $U$ vs $D$ ), from 0.868 to 0.666 , whereas the WIOT data point to an increase in this correlation to 0.912 .

\section{[Table 8 here]}

We next consider the effects of holding trade costs constant while feeding into the model the observed change in the $\alpha_{j}^{s}$ preference parameters seen between 1995-2011. As reported under "Change expenditure shares" in Panel A, this generates a moderate increase in the correlation between $F / G O$ and $V A / G O$ to 0.857 , as well as in the correlation between $U$ and $D$ to 0.889 . As services have become more important in consumption relative to goods, the model implies that service industries would have expanded across most countries, which in turn would reinforce the aforementioned positive correlations among these country-level measures of GVC positioning. Note that quantitatively, the change in the $\alpha_{j}^{s}$ 's on their own brings us about a third to a half of the way towards bridging the gap between the correlations recorded in 1995 and in 2011.

However, when the changes in trade costs and the final-use expenditure shares are considered simultaneously, the effect of the trade cost declines dominates: The correlations of interest all weaken relative to 1995, although the extent of this decline is not as large compared to the first counterfactual where only trade cost movements were considered. This leaves us to conclude that other forces which we are not able to accommodate with the current framework - such as shifts in the use of inputs (the $\gamma_{j}^{r s}$ 's) towards services - would have had to be at play, in order to rationalize the rising correlation between the country-level GVC measures from 1995-2011.

A similar conclusion is reached if we look at Panel B of Table 8. There, we have re-run the same series of regressions as in Table 3, to estimate the partial correlation between the counterfactual GVC measures at the country-industry level (i.e., between $(F / G O)_{j}^{s}$ and $(V A / G O)_{j}^{s}$, as well as between $(U)_{j}^{s}$ and $\left.(D)_{j}^{s}\right)$. These regressions have been run in the pure cross-section with no fixed effects, with country fixed effects, and further including industry fixed effects. The simulations point to an increase in the slope coefficients across all columns, which is consistent with what we see in the actual evolution of the country-industry GVC measures between 1995 and 2011. That said, the combined effect of the trade costs and expenditure share shifts ("Both changes") is only able to partially account for the increase seen in the slope coefficients; in particular, these forces alone do not do particularly well in explaining the magnitude of the increase in the slope coefficient when both country and industry dummies are controlled for.

We turn to some forward projections in Table 9. For this exercise, we now calibrate the model to the 2011 WIOT as a starting point, and then ask what would happen to the country-level GVC measures if shifts in trade costs (and/or the final-use expenditure shares) were to persist for a further 16 years. We take guidance from the average rates of decline in trade costs estimated earlier in Tables 4 and 5 for intermediate and final-use trade, for goods and services separately. For example, we assume in these simulations that trade costs for goods shipped for intermediate use 
continue to decline at the rate of $1.81 \%$ per annum (based on the coefficient estimate in Column 3 , Table 4); the assumed rates of decline for trade in final-goods, as well as for trade in services are drawn from these tables in an analogous manner. ${ }^{41}$ For the projected changes in the expenditure shares, we likewise simulate the effects of a decrease in the $\alpha_{j}^{s}$ 's associated with goods industries of $1.27 \%$ per year (taking guidance from Column 3, Table 6), coupled with a rise in the $\alpha_{j}^{s}$ 's associated with services of $0.37 \%$ per year (Column 5, Table 6); the counterfactual $\alpha_{j}^{s}$ shares are re-scaled proportionally to ensure that they sum to 1 for each country.

\section{[Table 9 here]}

We once again find in Table 9 that a decline in trade costs alone would tend to reduce the country-level correlations between the final-use and value-added shares in gross output (from 0.925 to 0.840 ), as well as that between $U$ and $D$ (from 0.912 to 0.815 ). A more nuanced view emerges when we consider changes in the trade costs associated with shipping goods and shipping services separately. A hypothetical decline in trade costs for goods ("Goods only") would tend to reduce the cross-country correlations, as expected. However, a decline in trade costs for services ("Services only") instead sees the correlation between $U$ and $D$ rise to 0.908 , and that between $F / G O$ and $V A / G O$ rise to 0.914 . It thus appears that if trade costs for services were to fall relatively more than trade costs for goods, this would reinforce comparative advantage in services for those countries that were already initially specializing in those industries; this in turn would be sufficient to raise the cross-country correlation between the GVC measures. Thus, depending on whether trade costs declines are larger for goods versus services, there appears to be scope for trade cost movements to generate a between-industry shift in specialization patterns.

As in our counterfactuals in Table 8, the effects of an isolated shift in the final expenditure shares (continuing their 1995-2011 trajectory) would tend to increase the country-level correlations between the final-use and value-added shares in gross output. Even though the initial correlations are already very high, they increase even further to 0.934 (between $F / G O$ and $V A / G O$ ) and to 0.923 (between $U$ and $D$ ), respectively. When considered in conjunction with the trade cost movements, the shifts in the $\alpha_{j}^{s}$ 's act to moderate the decline in these key correlations induced when trade cost decreases are applied to both goods and services; the shift in consumption towards services is however not sufficiently large to fully undo or reverse the overall weakening in these correlations between the country GVC measures.

We round off this discussion of counterfactuals by taking a more detailed look at the projected shift in countries' GVC positioning should trade costs continue to decline. Figure 11 plots the changes in country-level upstreamness $(U)$ and downstreamness $(D)$ based on the "Change trade costs" simulation from Table 9. The figure points to interesting variation across countries in response to a continued fall in trade costs applied to both goods and services. China stands out as a country that records a large decrease in its production staging distance according to both

\footnotetext{
${ }^{41}$ Specifically, trade costs for goods shipped for final-use are assumed to decline at the rate of $2.31 \%$ per annum (Column 3, Table 5); trade costs for services shipped for intermediate use decline at $1.50 \%$ per annum (Column 5 , Table 4); and trade costs for services shipped for final-use decline at $1.96 \%$ per year (Column 5 , Table 5).
} 

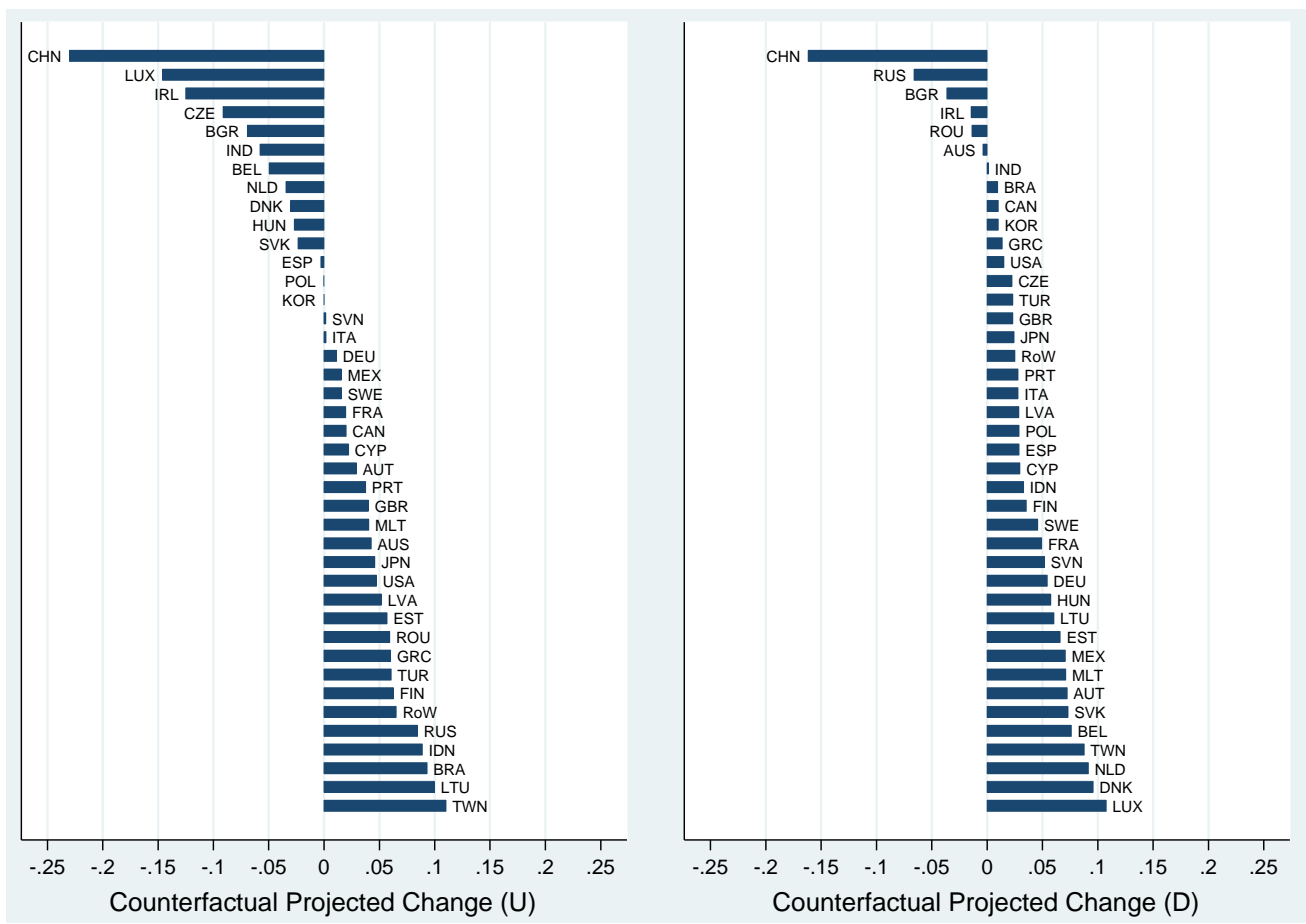

Figure 11: Further Declines in Trade Costs and Country GVC Position

$U$ and $D$. A closer look at the underlying sectoral shifts reveals that this is driven by a further decline in output in Mining and Quarrying (an industry with a particularly high value of $U$ ), as the fall in trade costs reinforces China's production patterns towards other goods and service industries in which it has stronger comparative advantage. On the other hand, economies like Taiwan, Finland, and Japan exhibit an increase in both $U$ and $D$, and thus appear to become more embedded in longer value chains that place them at a greater production staging distance from both end-consumers and primary factors.

\section{Conclusion}

This paper aims to contribute to our understanding of the positioning of countries and industries in GVCs. We have relied on data from the World Input-Output Database (WIOD) to document the evolution of the upstreamness and downstreamness of various countries and industries in GVCs during the period 1995-2011. We have emphasized, in particular, the presence of a puzzling positive correlation between several pairs of GVC measures at both the country and country-industry levels. More specifically, countries and country-industries far removed from final demand also tend to be far removed from the use of primary factors in production. We have explored potential explanations for this phenomenon and have assessed the quantitative role of two factors: a reduction in trade costs and an increase in the share of world spending on services. This quantitative evaluation is based on a theoretical model of GVCs that we have built, by extending the framework of Caliendo and Parro (2015) in a way that allows the model to match all the entries of a world Input-Output 
table. We have finally used the model to conjecture on the future evolution of the positioning of industries and countries in GVCs. By introducing considerations related to the positioning of countries and industries in GVCs into a general equilibrium model of trade with cross-sectoral linkages, we hope to contribute a useful bridge between two literatures: on the one hand, the body of empirical work on GVCs employing Input-Output analysis techniques, and on the other hand, the theoretical literature on quantitative trade models that facilitate a structural interpretation of input flows across countries (c.f., Costinot and Rodríguez-Clare 2014). We also hope that the modeling framework will in turn provide scope for future research, to arrive at a more complete decomposition of the forces that account for the evolution of GVC activity. In this regard, a potentially fruitful line of work would be to generalize the production setup to a constant elasticity of substitution (CES) specification, in order to assess the role of shifts in input-use shares (the $\gamma$ 's) in accounting for the observed trends in the measures of GVC positioning. 


\section{References}

Acemoglu, Daron, Vasco M. Carvalho, Asuman Ozdaglar, and Alireza Tahbaz-Salehi, (2012), "The Network Origins of Aggregate Fluctuations," Econometrica 80(5): 1977-2016.

Alexander, Patrick D., (2017), "Vertical Specialization and Gains from Trade," Bank of Canada Staff Working Paper 2017-17.

Alfaro, Laura, Pol Antràs, Davin Chor, and Paola Conconi, (2017), "Internalizing Global Value Chains: A Firm-Level Analysis," Journal of Political Economy, forthcoming.

Alvarez, Fernando, and Robert E. Lucas, (2007), "General Equilibrium Analysis of the Eaton-Kortum model of International Trade," Journal of Monetary Economics 54(6): 1726-1768.

Antràs, Pol, and Davin Chor, (2013), "Organizing the Global Value Chain," Econometrica 81(6): 21272204.

Antràs, Pol, Davin Chor, Thibault Fally, and Russell Hillberry, (2012), "Measuring the Upstreamness of Production and Trade Flows," American Economic Review Papers 83 Proceedings 102(3): 412-416.

Antràs, Pol, and Alonso de Gortari, (2017), "On the Geography of Global Value Chains," mimeo Harvard University.

Baldwin, Richard, and Tadashi Ito, (2014), "The Smile Curve: Evolving Sources of Value Added in Manufacturing," mimeo.

Baldwin, Richard, and Anthony Venables, (2013), "Spiders and Snakes: Offshoring and Agglomeration in the Global Economy," Journal of International Economics 90(2): 245-254.

Berlingieri, Giuseppe, (2014), "Outsourcing and the Rise in Services," CEP Discussion Paper No. 1199.

Caliendo, Lorenzo, and Fernando Parro, (2015), "Estimates of the Trade and Welfare Effects of NAFTA," Review of Economic Studies 82(1): 1-44.

Cameron, Colin, Jonah Gelbach, and Douglas Miller, (2011), "Robust Inference with Multi-way Clustering," Journal of Business and Economic Statistics 29(2): 238-249.

Costinot, Arnaud, and Andrés Rodríguez-Clare, (2014), "Trade Theory with Numbers: Quantifying the Consequences of Globalization," in Handbook of International Economics, vol. 4: pp.197-261.

Costinot, Arnaud, Jonathan Vogel, and Su Wang, (2013), "An Elementary Theory of Global Supply Chains," Review of Economic Studies 80(1): 109-144.

de Gortari, Alonso, (2017), "Disentangling Global Value Chains," mimeo Harvard University.

Dekle, Robert, Jonathan Eaton, and Samuel Kortum, (2008), "Global Rebalancing with Gravity: Measuring the Burden of Adjustment," IMF Economic Review 55(3): 511-540. 
Dietzenbacher, Erik, Bart Los, Robert Stehrer, Marcel Timmer, and Gaaitzen J. de Vries, (2013), "The Construction of World Input-Output Tables in the WIOD Project," Economic Systems Research 25(1): 71-98.

Dixit, Avinash, and Gene Grossman, (1982), "Trade and Protection with Multistage Production," Review of Economic Studies 49(4): 583-594.

Eaton, Jonathan, and Samuel Kortum, (2002), "Technology, Geography, and Trade," Econometrica 70(5): 1741-1779.

Fally, Thibault, (2012), "Production Staging: Measurement and Facts," mimeo UC Berkeley.

Fally, Thibault, and Russell Hillberry, (2015), "A Coasian Model of International Production Chains," mimeo UC Berkeley.

Harms, Philipp, Oliver Lorz, and Dieter Urban, (2012), "Offshoring along the Production Chain," Canadian Journal of Economics 45(1): 93-106.

Head, Keith, and John Ries, (2001), "Increasing Returns Versus National Product Differentiation as an Explanation for the Pattern of U.S.-Canada Trade," American Economic Review 91(4): 858-876.

Johnson, Robert C., (2014), "Five Facts about Value-Added Exports and Implications for Macroeconomics and Trade Research," Journal of Economic Perspectives 28(2): 119-142.

Johnson, Robert C., (2017), "Measuring Global Value Chains," NBER Working Paper 24027.

Johnson, Robert C., and Guillermo Noguera, (2012), "Accounting for Intermediates: Production Sharing and Trade in Value Added," Journal of International Economics 86(2): 224-236.

Kikuchi, Tomoo, Kazuo Nishimura, and John Stachurski, (2017), "Span of Control, Transaction Costs and the Structure of Production Chains," Theoretical Economics, forthcoming.

Kohler, Wilhelm, (2004), "International Outsourcing and Factor Prices with Multistage Production," Economic Journal 114(494): C166-C185.

Koopman, Robert, Zhi Wang, and Shang-Jin Wei, (2014), "Tracing Value-Added and Double Counting in Gross Exports," American Economic Review 104(2): 459-494.

Kremer, Michael, (1993), "The O-Ring Theory of Economic Development," Quarterly Journal of Economics 108(3): 551-575.

Mas-Colell, Andreu, Michael Whinston, and Jerry Green, (1995), Microeconomic Theory, Oxford University Press.

Miller, Ronald E., and Umed Temurshoev, (2017), "Output Upstreamness and Input Downstreamness of Industries/Countries in World Production," International Regional Science Review 40(5): 443-475. 
Sanyal, Kalyan K., and Ronald W. Jones, (1982), "The Theory of Trade in Middle Products," American Economic Review 72(1): 16-31.

Timmer, Marcel P., Abdul Azeez Erumban, Bart Los, Robert Stehrer, and Gaaitzen J. de Vries, (2014), "Slicing Up Global Value Chains," Journal of Economic Perspectives 28(2): 99-118.

Timmer, Marcel P., Eric Dietzenbacher, Bart Los, Robert Stehrer, and Gaaitzen J. de Vries, (2015), "An Illustrated User Guide to the World Input-Output Database: the Case of Global Automotive Production," Review of International Economics 23(3): 575-605.

Tyazhelnikov, Vladimir, (2017), "Production Clustering and Offshoring," mimeo UC Davis.

Wang, Zhi, Shang-Jin Wei, Xinding Yu, and Kunfu Zhu, (2017), "Measures of Participation in Global Value Chains and Global Business Cycles," NBER Working Paper 23222.

Yi, Kei-Mu, (2003), "Can Vertical Specialization Explain the Growth of World Trade?" Journal of Political Economy 111(1): 52-102.

Yi, Kei-Mu, (2010), "Can Multistage Production Explain the Home Bias in Trade?" American Economic Review 100(1): 364-393. 


\section{A Appendix}

In this Appendix, we first outline the main steps involved in proving the existence of equilibrium in our extension of the Caliendo and Parro (2015) model. We also expand our discussion from the main text regarding the ability of the model to match all the entries of a WIOT.

Let us first tackle the issue of existence of equilibrium. The key equations characterizing such an equilibrium are (28), (29), (30), (31), (32), (35), and (36). We begin by noting that the system of equations in (31), after plugging in (30), can be written as

$$
\left(P_{j}^{r s}\right)^{-\theta^{r}}=\left(A^{r}\right)^{-\theta^{r}} \sum_{i=1}^{J} T_{i}^{r}\left(\tau_{i j}^{r s}\right)^{-\theta^{r}}\left(\Upsilon_{i}^{r} w_{i}^{1-\sum_{t=1}^{S} \gamma_{i}^{t r}} \prod_{t=1}^{S}\left(P_{i}^{t r}\right)^{\gamma_{i}^{t r}}\right)^{-\theta^{r}}
$$

Following the same approach as in Alvarez and Lucas (2007) or Antràs and de Gortari (2017), one can verify that as long as trade costs are bounded and $\sum_{t=1}^{S} \gamma_{i}^{t r}<1$ for all $i$ and $r$, the system above delivers a unique mapping between the vector of wages $\mathbf{w}=\left\{w_{j}\right\}_{j=1}^{J}$ and the matrix of price indices $P_{j}^{r s}$. From equation (30), this in turn implies that, under the same conditions, there exists a unique matrix of unit $\operatorname{costs} c_{i}^{r}$ given a vector of wages $\mathbf{w}$.

The proof of the existence of a vector of wages is more involved, and we shall not develop it in full detail here, but such a proof would proceed as follows. First, notice that the system of equations defined in (35) can be inverted - under weak invertibility conditions - to express the matrix of gross output levels as a function of the equilibrium vector of wages $\mathbf{w}$. In doing so, one would invoke that trade shares are only a function of wages and parameters once plugging in the values of $c_{i}^{r}$ as a function of the same vector of wages. With this result in hand, the last step is to simply plug trade shares - in (28) and (29) - and gross output levels - in (35) - into the trade balance condition (36) to obtain a system of $J$ equations in the $J$ equilibrium wages w. Following Alvarez and Lucas (2007) or Antràs and de Gortari (2017), one would then define an excess demand function $Z(\mathbf{w})$ and show that it satisfies the conditions in Propositions 17.C.1 in Mas-Colell et al. (1995, p.585), namely continuity, homogeneity of degree 0 in wages, Walras' Law, the existence of a lower bound, and a limit condition.

The existence of an equilibrium does not of course guarantee that it is unique. In fact, even in the simpler one-sector Eaton and Kortum (2002) model, uniqueness has only been demonstrated under certain (suficient) conditions on the matrix of trade costs (see Alvarez and Lucas, 2007). To derive the analogous sufficient conditions, one would need to verify the restrictions on trade costs that guarantee that the excess demand function $Z(\mathbf{w})$ has the gross substitutes property in $\mathbf{w}$ (see Proposition 17.F.3 in Mas-Colell et al., 1995, p.613).

Let us now return to the issue of whether our more flexible formulation of trade costs allows our model to match all the entries of a WIOT, no matter their values. A first obvious observation is that, if an equilibrium of the model exists, then given matrices of input and final-use trade costs, there exists equilibrium commodity flows $Z_{i j}^{r s}$ and $F_{i j}^{r}$ across sectors and industries, as well as country-sector-specific gross output $Y_{j}^{s}$ and valueadded $V A_{j}^{s}$ levels. In other words, the model produces values for all the entries of a WIOT.

Now suppose that we begin with the empirical entries of an actual WIOT. Suppose you fix the vector of equipped labor $\mathbf{L}=\left\{L_{j}\right\}_{j=1}^{J}$ to some arbitrary values (e.g., the labor force in each country). Given $\mathbf{L}$ 
and the vector of aggregate value-added in each country, we obtain a vector of empirical wages $\tilde{\mathbf{w}}$, where we again use tildes to denote empirical values. It is clear that plugging the empirically observed trade shares $\tilde{\pi}_{i j}^{s r}$ and $\tilde{\pi}_{j i}^{s F}$, and gross output and deficit levels $\tilde{Y}_{j}^{r}$ and $\tilde{D}_{j}$, as well as the easily recoverable parameters $\gamma_{j}^{s r}$ and $\alpha_{i}^{s}$ (see (37) and (38)), the goods-market and trade balance conditions (35) and (36) will hold as identities.

As demonstrated in the main text, defining $b_{i}^{r}=T_{i}^{r}\left(c_{i}^{r}\right)^{-\theta^{r}}$ and $\rho_{i j}^{r s}=\left(\tau_{i j}^{r s}\right)^{-\theta^{r}}$, we can write equations (28) and (29) as:

$$
\rho_{i j}^{r s}=\tilde{\pi}_{i j}^{r s} \sum_{k=1}^{J} \frac{b_{k}^{r}}{b_{i}^{r}} \rho_{k j}^{r s}
$$

and:

$$
\rho_{i j}^{r F}=\tilde{\pi}_{i j}^{r F} \sum_{k=1}^{J} \frac{b_{k}^{r}}{b_{i}^{r}} \rho_{k j}^{r F} .
$$

We now further note that the values of (transformed) trade costs $\rho_{i j}^{r s}$ and the term $b_{i}^{r}$ need also satisfy the two remaining equilibrium conditions (30) and (31), which further imposes:

$$
\left(b_{j}^{s}\right)^{-1 / \theta^{s}}=\Psi_{j}^{s}\left(\tilde{w}_{j}\right)^{1-\sum_{r=1}^{S} \gamma_{j}^{r s}} \prod_{r=1}^{S}\left[\sum_{i=1}^{J} b_{i}^{r} \rho_{i j}^{r s}\right]^{-\gamma_{j}^{r s} / \theta^{r}},
$$

where the constant $\Psi_{j}^{s}$ is given by $\Psi_{j}^{s}=T_{j}^{s} \Upsilon_{j}^{s}\left(A^{r}\right)^{\gamma_{j}^{r s}}{ }^{42}$ Fixing the parameters $T_{j}^{s}$, as well as $\sigma^{r}$ and $\theta^{r}$ (shaping $A^{r}$ ), the system provides a second set of equilibrium conditions relating trade $\operatorname{costs} \rho_{i j}^{r s}$ and the term $b_{i}^{r}$ (while involving other parameters and "observables"). Combining (A.1) and (A.3) one should, under the necessary invertibility conditions solve for the matrix of values for $b_{j}^{s}$ consistent with the observables in the WIOT and the general equilibrium of the model. With those in hand, it just suffices to plug them back into (A.1) and (A.2) to obtain the matrices of trade $\operatorname{costs} \rho_{i j}^{r s}$ and $\rho_{i j}^{r F}$ that make the model replicate all the entries of a WIOT exactly. Although it should be clear from our proof, obtaining those parameters requires however fixing the other unobserved (and not easily retrieved) parameters $L_{j}, T_{j}^{s}, \sigma^{r}$ and $\theta^{r}$.

\footnotetext{
${ }^{42}$ Strictly speaking, one should also be concerned with the model satisfying the equilibrium condition (32), which solves for the matrix of final-use price indices $P_{j}^{r F}$. These price indices are however not directly observable in a WIOT, so this condition is not relevant for the purposes of the result we are proving.
} 
Table 1

Country-Level GVC Position by Rank (Top and Bottom Five)

\begin{tabular}{|c|c|c|c|c|c|c|c|c|c|}
\hline \multirow{2}{*}{$\begin{array}{r}\text { Rank: } \\
1 .\end{array}$} & \multicolumn{2}{|c|}{$\underline{\text { F/GO (1995) }}$} & \multicolumn{2}{|c|}{$\underline{F / G O}(2011)$} & \multirow{2}{*}{$\begin{array}{r}\text { Rank: } \\
1 .\end{array}$} & \multicolumn{2}{|c|}{$\underline{\text { VA/GO (1995) }}$} & \multicolumn{2}{|c|}{$\underline{\text { VA/GO }}(2011)$} \\
\hline & China & 0.384 & Luxembourg & 0.296 & & China & 0.373 & China & 0.325 \\
\hline 2. & Luxembourg & 0.388 & China & 0.340 & 2. & Czech Rep. & 0.403 & Luxembourg & 0.362 \\
\hline 3. & Slovakia & 0.394 & Korea & 0.377 & 3. & Slovakia & 0.416 & Korea & 0.372 \\
\hline 4. & Czech Rep. & 0.408 & Taiwan & 0.396 & 4. & Estonia & 0.430 & Czech Rep. & 0.383 \\
\hline 5. & Russia & 0.444 & Czech Rep. & 0.401 & 5. & Romania & 0.454 & Bulgaria & 0.401 \\
\hline 37. & Denmark & 0.558 & Brazil & 0.557 & 37. & Austria & 0.563 & Brazil & 0.561 \\
\hline 38. & Brazil & 0.572 & USA & 0.569 & 38. & Turkey & 0.575 & USA & 0.562 \\
\hline 39. & Turkey & 0.605 & Mexico & 0.586 & 39. & Brazil & 0.575 & Mexico & 0.581 \\
\hline 40. & Greece & 0.625 & Cyprus & 0.637 & 40. & Greece & 0.576 & Cyprus & 0.586 \\
\hline 41. & Cyprus & 0.709 & Greece & 0.668 & 41. & Cyprus & 0.625 & Greece & 0.628 \\
\hline Rank: & \multicolumn{2}{|c|}{$\underline{U}(1995)$} & \multicolumn{2}{|c|}{$\underline{U}(2011)$} & Rank: & \multicolumn{2}{|c|}{$\underline{\mathrm{D}}(1995)$} & \multicolumn{2}{|c|}{$\underline{\mathrm{D}}(2011)$} \\
\hline 1. & Cyprus & 1.451 & Greece & 1.546 & 1. & Cyprus & 1.662 & Greece & 1.657 \\
\hline 2. & Greece & 1.611 & Cyprus & 1.617 & 2. & Brazil & 1.748 & Cyprus & 1.763 \\
\hline 3. & Turkey & 1.666 & Mexico & 1.737 & 3. & Turkey & 1.758 & Mexico & 1.779 \\
\hline 4. & Brazil & 1.755 & USA & 1.786 & 4. & Greece & 1.759 & Brazil & 1.806 \\
\hline 5. & Denmark & 1.810 & Brazil & 1.824 & 5. & Austria & 1.800 & USA & 1.808 \\
\hline 37. & Russia & 2.185 & Czech Rep. & 2.358 & 37. & Romania & 2.155 & Luxembourg & 2.348 \\
\hline 38. & Luxembourg & 2.242 & Taiwan & 2.463 & 38. & Estonia & 2.209 & Bulgaria & 2.370 \\
\hline 39. & Czech Rep. & 2.331 & Korea & 2.544 & 39. & Slovakia & 2.306 & Czech Rep. & 2.444 \\
\hline 40. & Slovakia & 2.389 & Luxembourg & 2.581 & 40. & Czech Rep. & 2.344 & Korea & 2.534 \\
\hline 41. & China & 2.535 & China & 2.819 & 41. & China & 2.591 & China & 2.900 \\
\hline
\end{tabular}

Notes: Rank order based on the respective GVC measures computed at the country-level, i.e., based on the WIOD aggregated to a country-by-country panel of Input-Output tables. The top and bottom five countries in the rank order are reported, for both 1995 and 2011. 
Table 2

Evolution of GVC Measures within Country-Industries over Time

\begin{tabular}{|c|c|c|c|c|c|c|c|c|}
\hline Dependent variable: & $\begin{array}{c}F / G_{j, t}{ }^{S} \\
(1)\end{array}$ & $\begin{array}{c}\mathrm{F} / \mathrm{GO}_{\mathrm{j}, \mathrm{t}}^{\mathrm{S}} \\
(2)\end{array}$ & $\begin{array}{c}\mathrm{VA} / \mathrm{GO}_{\mathrm{j}, \mathrm{t}}^{\mathrm{s}} \\
(3)\end{array}$ & $\begin{array}{c}\mathrm{VA} / \mathrm{GO}_{\mathrm{j}, \mathrm{t}}{ }^{\mathrm{s}} \\
(4)\end{array}$ & $\begin{array}{c}(U)_{j, t}{ }^{s} \\
(5)\end{array}$ & $\begin{array}{c}(U)_{j, t}{ }^{s} \\
(6)\end{array}$ & $\begin{array}{c}(D)_{\mathrm{j}, \mathrm{t}}^{\mathrm{s}} \\
(7)\end{array}$ & $\begin{array}{c}(D)_{j, t}{ }^{s} \\
(8)\end{array}$ \\
\hline Year & $\begin{array}{l}-0.0009^{*} \\
{[0.0004]}\end{array}$ & & $\begin{array}{c}-0.0017^{\star \star \star} \\
{[0.0005]}\end{array}$ & & $\begin{array}{c}0.0064^{\star \star \star} \\
{[0.0015]}\end{array}$ & & $\begin{array}{c}0.0084^{\star \star *} \\
{[0.0017]}\end{array}$ & \\
\hline (Dum: Year=1996) & & $\begin{array}{c}-0.0002 \\
{[0.0025]}\end{array}$ & & $\begin{array}{l}-0.0012 \\
{[0.0026]}\end{array}$ & & $\begin{array}{c}-0.0060 \\
{[0.0083]}\end{array}$ & & $\begin{array}{c}0.0019 \\
{[0.0079]}\end{array}$ \\
\hline (Dum: Year=1997) & & $\begin{array}{l}-0.0015 \\
{[0.0020]}\end{array}$ & & $\begin{array}{l}-0.0024 \\
{[0.0020]}\end{array}$ & & $\begin{array}{c}0.0026 \\
{[0.0068]}\end{array}$ & & $\begin{array}{c}0.0061 \\
{[0.0062]}\end{array}$ \\
\hline (Dum: Year=1998) & & $\begin{array}{l}0.0026^{\star *} \\
{[0.0010]}\end{array}$ & & $\begin{array}{c}0.0002 \\
{[0.0015]}\end{array}$ & & $\begin{array}{c}-0.0129 * * * \\
{[0.0032]}\end{array}$ & & $\begin{array}{l}-0.0085^{\star} \\
{[0.0043]}\end{array}$ \\
\hline (Dum: Year=1999) & & $\begin{array}{l}0.0029 * * * \\
{[0.0004]}\end{array}$ & & $\begin{array}{l}-0.0005 \\
{[0.0005]}\end{array}$ & & $\begin{array}{c}-0.0086^{\star \star *} \\
{[0.0010]}\end{array}$ & & $\begin{array}{c}-0.0073^{\star \star \star} \\
{[0.0025]}\end{array}$ \\
\hline (Dum: Year=2000) & & $\begin{array}{l}-0.0015 \\
{[0.0014]}\end{array}$ & & $\begin{array}{c}-0.0094^{\star \star *} \\
{[0.0016]}\end{array}$ & & $\begin{array}{c}0.0140^{\star \star *} \\
{[0.0045]}\end{array}$ & & $\begin{array}{c}0.0311^{\star \star *} \\
{[0.0044]}\end{array}$ \\
\hline (Dum: Year=2001) & & $\begin{array}{c}-0.0022 \\
{[0.0020]}\end{array}$ & & $\begin{array}{c}-0.0122 * \star * \\
{[0.0021]}\end{array}$ & & $\begin{array}{l}0.0182^{\star \star} \\
{[0.0065]}\end{array}$ & & $\begin{array}{c}0.0394^{\star \star \star} \\
{[0.0053]}\end{array}$ \\
\hline (Dum: Year=2002) & & $\begin{array}{c}-0.0010 \\
{[0.0024]}\end{array}$ & & $\begin{array}{c}-0.0091^{* * *} \\
{[0.0022]}\end{array}$ & & $\begin{array}{c}0.0069 \\
{[0.0069]}\end{array}$ & & $\begin{array}{c}0.0218^{\star \star \star} \\
{[0.0054]}\end{array}$ \\
\hline (Dum: Year=2003) & & $\begin{array}{c}-0.0033 \\
{[0.0027]}\end{array}$ & & $\begin{array}{c}-0.0102^{\star * *} \\
{[0.0022]}\end{array}$ & & $\begin{array}{l}0.0204^{* *} \\
{[0.0082]}\end{array}$ & & $\begin{array}{c}0.0334^{\star \star *} \\
{[0.0059]}\end{array}$ \\
\hline (Dum: Year=2004) & & $\begin{array}{c}-0.0052 \\
{[0.0030]}\end{array}$ & & $\begin{array}{c}-0.0135^{\star \star *} \\
{[0.0025]}\end{array}$ & & $\begin{array}{c}0.0346^{\star \star *} \\
{[0.0100]}\end{array}$ & & $\begin{array}{c}0.0490^{\star \star *} \\
{[0.0079]}\end{array}$ \\
\hline (Dum: Year=2005) & & $\begin{array}{l}-0.0061^{*} \\
{[0.0031]}\end{array}$ & & $\begin{array}{c}-0.0153^{\star * *} \\
{[0.0032]}\end{array}$ & & $\begin{array}{c}0.0421^{\star \star *} \\
{[0.0099]}\end{array}$ & & $\begin{array}{c}0.0657^{\star * *} \\
{[0.0101]}\end{array}$ \\
\hline (Dum: Year=2006) & & $\begin{array}{c}-0.0084^{\star *} \\
{[0.0033]}\end{array}$ & & $\begin{array}{c}-0.0208^{\star \star *} \\
{[0.0036]}\end{array}$ & & $\begin{array}{c}0.0598^{\star \star \star} \\
{[0.0117]}\end{array}$ & & $\begin{array}{c}0.0919 * \star \star \\
{[0.0115]}\end{array}$ \\
\hline (Dum: Year=2007) & & $\begin{array}{c}-0.0119 * \star \star \\
{[0.0038]}\end{array}$ & & $\begin{array}{c}-0.0237^{\star \star \star} \\
{[0.0039]}\end{array}$ & & $\begin{array}{c}0.0797^{\star \star \star} \\
{[0.0137]}\end{array}$ & & $\begin{array}{c}0.1103^{\star \star \star} \\
{[0.0133]}\end{array}$ \\
\hline (Dum: Year=2008) & & $\begin{array}{c}-0.0130^{\star \star *} \\
{[0.0044]}\end{array}$ & & $\begin{array}{c}-0.0287^{\star \star *} \\
{[0.0048]}\end{array}$ & & $\begin{array}{c}0.0894^{\star \star *} \\
{[0.0159]}\end{array}$ & & $\begin{array}{c}0.1333^{\star \star \star} \\
{[0.0154]}\end{array}$ \\
\hline (Dum: Year=2009) & & $\begin{array}{l}-0.0075 \\
{[0.0052]}\end{array}$ & & $\begin{array}{c}-0.0164^{\star * *} \\
{[0.0052]}\end{array}$ & & $\begin{array}{c}0.0562 * \star * \\
{[0.0171]}\end{array}$ & & $\begin{array}{c}0.0746^{\star \star \star} \\
{[0.0150]}\end{array}$ \\
\hline (Dum: Year=2010) & & $\begin{array}{l}-0.0102^{*} \\
{[0.0055]}\end{array}$ & & $\begin{array}{c}-0.0211^{* * *} \\
{[0.0053]}\end{array}$ & & $\begin{array}{c}0.0738^{\star * *} \\
{[0.0180]}\end{array}$ & & $\begin{array}{c}0.1027^{\star * *} \\
{[0.0167]}\end{array}$ \\
\hline (Dum: Year=2011) & & $\begin{array}{l}-0.0111^{*} \\
{[0.0055]}\end{array}$ & & $\begin{array}{c}-0.0226^{\star * *} \\
{[0.0054]}\end{array}$ & & $\begin{array}{c}0.0822^{\star * *} \\
{[0.0179]}\end{array}$ & & $\begin{array}{c}0.1110^{\star \star \star} \\
{[0.0168]}\end{array}$ \\
\hline Country-Industry FE? & $\mathrm{Y}$ & $\mathrm{Y}$ & $\mathrm{Y}$ & Y & Y & Y & Y & Y \\
\hline Observations & 24,076 & 24,076 & 24,395 & 24,395 & 24,395 & 24,395 & 24,395 & 24,395 \\
\hline $\mathrm{R}^{2}$ & 0.9709 & 0.9709 & 0.9491 & 0.9495 & 0.9632 & 0.9636 & 0.9444 & 0.9460 \\
\hline
\end{tabular}

Notes: The sample comprises all countries (41), industries (35), and years (17) in the WIOD. Standard errors are multi-way clustered by country, industry, and year; ${ }^{* *}, * \star$, and * denote significance at the $1 \%, 5 \%$, and $10 \%$ levels respectively. The dependent variables are respectively the GVC measures computed at the country-industry level for each year. All columns control for country-industry (i.e., j-s) pair fixed effects; columns (2), (4), (6) and (8) further include year fixed effects, with the omitted category being the dummy for 1995. 
Table 3

Correlation between Country-Industry GVC Measures (1995 and 2011)

\begin{tabular}{|c|c|c|c|c|c|c|}
\hline Dependent variable: & $\begin{array}{c}{\mathrm{F} / G O_{\mathrm{j}, \mathrm{t}}^{\mathrm{s}}}^{\mathrm{s}} \\
1995 \\
(1)\end{array}$ & $\begin{array}{c}\mathrm{F} \mathrm{GO}_{\mathrm{j}, \mathrm{t}}^{\mathrm{s}} \\
1995 \\
(2)\end{array}$ & $\begin{array}{c}\mathrm{F} / \mathrm{GO}_{\mathrm{j}, \mathrm{t}}{ }^{\mathrm{s}} \\
1995 \\
(3)\end{array}$ & $\begin{array}{c}{\mathrm{F} / G O_{\mathrm{j}, \mathrm{t}} \mathrm{s}}^{\mathrm{s}} \\
2011 \\
(4)\end{array}$ & $\begin{array}{c}F / G_{j, t}{ }^{s} \\
2011 \\
(5)\end{array}$ & $\begin{array}{c}{\mathrm{F} / G O_{j, \mathrm{t}}{ }^{\mathrm{S}}} 2011 \\
(6)\end{array}$ \\
\hline $\mathrm{VA} / \mathrm{GO}_{\mathrm{j}, \mathrm{t}}^{\mathrm{s}}$ & $\begin{array}{c}0.5438^{\star \star \star} \\
{[0.1815]}\end{array}$ & $\begin{array}{l}0.5196^{\star \star} \\
{[0.1924]}\end{array}$ & $\begin{array}{c}0.0775 \\
{[0.0543]}\end{array}$ & $\begin{array}{c}0.6543^{\star \star \star} \\
{[0.1647]}\end{array}$ & $\begin{array}{c}0.6373^{\star \star \star} \\
{[0.1740]}\end{array}$ & $\begin{array}{r}0.2647^{* \star *} \\
{[0.0527]}\end{array}$ \\
\hline $\begin{array}{l}\text { Country FE? } \\
\text { Industry FE? }\end{array}$ & $\begin{array}{l}\mathrm{N} \\
\mathrm{N}\end{array}$ & $\begin{array}{l}\mathrm{Y} \\
\mathrm{N}\end{array}$ & $\begin{array}{l}Y \\
Y\end{array}$ & $\begin{array}{l}N \\
N\end{array}$ & $\begin{array}{l}\mathrm{Y} \\
\mathrm{N}\end{array}$ & $\begin{array}{l}Y \\
Y\end{array}$ \\
\hline $\begin{array}{l}\text { Observations } \\
\mathrm{R}^{2}\end{array}$ & $\begin{array}{c}1,417 \\
0.1285\end{array}$ & $\begin{array}{l}1,417 \\
0.1488\end{array}$ & $\begin{array}{l}1,417 \\
0.8392\end{array}$ & $\begin{array}{c}1,414 \\
0.1927\end{array}$ & $\begin{array}{c}1,414 \\
0.2033\end{array}$ & $\begin{array}{c}1,414 \\
0.8479\end{array}$ \\
\hline Dependent variable: & $\begin{array}{c}\mathrm{U}_{\mathrm{j}, \mathrm{t}}^{\mathrm{s}} \\
1995 \\
(7)\end{array}$ & $\begin{array}{c}U_{j, t}^{s} \\
1995 \\
(8)\end{array}$ & $\begin{array}{c}\mathrm{U}_{\mathrm{j}, \mathrm{t}}^{\mathrm{s}} \\
1995 \\
(9)\end{array}$ & $\begin{array}{c}\mathrm{U}_{\mathrm{j}, \mathrm{t}}^{\mathrm{s}} \\
2011 \\
(10)\end{array}$ & $\begin{array}{c}U_{j, t}{ }^{s} \\
2011 \\
(11)\end{array}$ & $\begin{array}{c}\mathrm{U}_{\mathrm{j}, \mathrm{t}}^{\mathrm{s}} \\
2011 \\
(12)\end{array}$ \\
\hline$D_{\mathrm{j}, \mathrm{t}}{ }^{\mathrm{o}}$ & $\begin{array}{c}0.5308^{\star \star \star} \\
{[0.1640]}\end{array}$ & $\begin{array}{l}0.4820 * * \\
{[0.1902]}\end{array}$ & $\begin{array}{c}0.2413^{\star \star \star} \\
{[0.0604]}\end{array}$ & $\begin{array}{c}0.6213^{\star \star \star} \\
{[0.1454]}\end{array}$ & $\begin{array}{c}0.5707^{\star \star *} \\
{[0.1698]}\end{array}$ & $\begin{array}{c}0.3772^{\star * *} \\
{[0.0617]}\end{array}$ \\
\hline $\begin{array}{l}\text { Country FE? } \\
\text { Industry FE? }\end{array}$ & $\begin{array}{l}\mathrm{N} \\
\mathrm{N}\end{array}$ & $\begin{array}{l}\mathrm{Y} \\
\mathrm{N}\end{array}$ & $\begin{array}{l}Y \\
Y\end{array}$ & $\begin{array}{l}N \\
N\end{array}$ & $\begin{array}{l}\mathrm{Y} \\
\mathrm{N}\end{array}$ & $\begin{array}{l}Y \\
Y\end{array}$ \\
\hline $\begin{array}{l}\text { Observations } \\
\mathrm{R}^{2}\end{array}$ & $\begin{array}{c}1,435 \\
0.1350\end{array}$ & $\begin{array}{c}1,435 \\
0.1742\end{array}$ & $\begin{array}{c}1,435 \\
0.8264\end{array}$ & $\begin{array}{c}1,435 \\
0.1946\end{array}$ & $\begin{array}{c}1,435 \\
0.2232\end{array}$ & $\begin{array}{c}1,435 \\
0.8325\end{array}$ \\
\hline
\end{tabular}

Notes: The sample comprises all countries (41), industries (35), and years (17) in the WIOD. Standard errors are multi-way clustered by country and industry; ${ }^{\star \star \star},{ }^{* \star}$, and * denote significance at the $1 \%, 5 \%$, and $10 \%$ levels respectively. The dependent variables are GVC measures computed at the country-industry level for each year. The upper row reports regressions of F/GO against VA/GO, while the lower row reports regressions of $U$ against $D$. Regressions are run for both 1995 and 2011; for each year, three specificatons are reported: (i) with no fixed effects; (ii) with country fixed effects; and (iii) with country and industry fixed effects. 
Table 4

Head-Reis Trade Costs for Intermediate Inputs over Time

\begin{tabular}{|c|c|c|c|c|c|c|}
\hline \multirow[t]{2}{*}{ Dependent variable: } & \multicolumn{6}{|c|}{ log Trade Costs for Intermediate Inputs } \\
\hline & (1) & (2) & (3) & (4) & (3) & (4) \\
\hline Industries: & All & All & Goods & Goods & Services & Services \\
\hline Year & $\begin{array}{c}-0.0164^{\star \star *} \\
{[0.0022]}\end{array}$ & & $\begin{array}{c}-0.0181 * \star * \\
{[0.0024]}\end{array}$ & & $\begin{array}{c}-0.0150 \star \star \star \\
{[0.0026]}\end{array}$ & \\
\hline Dum: Year=1996 & & $\begin{array}{l}-0.0052 \\
{[0.0093]}\end{array}$ & & $\begin{array}{l}-0.0211^{\star} \\
{[0.0108]}\end{array}$ & & $\begin{array}{c}0.0085 \\
{[0.0142]}\end{array}$ \\
\hline Dum: Year=1997 & & $\begin{array}{c}-0.0782^{\star \star *} \\
{[0.0048]}\end{array}$ & & $\begin{array}{c}-0.0982^{\star * \star} \\
{[0.0075]}\end{array}$ & & $\begin{array}{c}-0.0609 * \star \star \\
{[0.0061]}\end{array}$ \\
\hline Dum: Year=1998 & & $\begin{array}{c}-0.1108 * \star \star \\
{[0.0039]}\end{array}$ & & $\begin{array}{c}-0.1503^{\star * *} \\
{[0.0077]}\end{array}$ & & $\begin{array}{c}-0.0768 * \star * \\
{[0.0055]}\end{array}$ \\
\hline Dum: Year=1999 & & $\begin{array}{c}-0.1129 * * \star \\
{[0.0048]}\end{array}$ & & $\begin{array}{c}-0.1598^{\star * *} \\
{[0.0074]}\end{array}$ & & $\begin{array}{c}-0.0725^{\star \star *} \\
{[0.0063]}\end{array}$ \\
\hline Dum: Year=2000 & & $\begin{array}{c}-0.1562^{\star \star \star} \\
{[0.0056]}\end{array}$ & & $\begin{array}{c}-0.1850^{\star * \star} \\
{[0.0079]}\end{array}$ & & $\begin{array}{c}-0.1313^{\star \star \star} \\
{[0.0086]}\end{array}$ \\
\hline Dum: Year=2001 & & $\begin{array}{c}-0.1653^{\star \star \star} \\
{[0.0067]}\end{array}$ & & $\begin{array}{c}-0.2021^{\star * *} \\
{[0.0093]}\end{array}$ & & $\begin{array}{c}-0.1336 * \star \\
{[0.0099]}\end{array}$ \\
\hline Dum: Year=2002 & & $\begin{array}{c}-0.1594^{\star \star \star} \\
{[0.0064]}\end{array}$ & & $\begin{array}{c}-0.1936 * \star \star \\
{[0.0079]}\end{array}$ & & $\begin{array}{c}-0.1299 * \star \star \\
{[0.0107]}\end{array}$ \\
\hline Dum: Year=2003 & & $\begin{array}{c}-0.1778^{\star * \star} \\
{[0.0100]}\end{array}$ & & $\begin{array}{c}-0.2141 * * * \\
{[0.0123]}\end{array}$ & & $\begin{array}{c}-0.1465^{\star \star \star} \\
{[0.0154]}\end{array}$ \\
\hline Dum: Year=2004 & & $\begin{array}{c}-0.2019 \star \star \star \\
{[0.0097]}\end{array}$ & & $\begin{array}{c}-0.2219 * * * \\
{[0.0115]}\end{array}$ & & $\begin{array}{c}-0.1846 \text { *** } \\
{[0.0155]}\end{array}$ \\
\hline Dum: Year=2005 & & $\begin{array}{c}-0.2239 * \star \star \\
{[0.0109]}\end{array}$ & & $\begin{array}{c}-0.2558^{\star \star \star} \\
{[0.0147]}\end{array}$ & & $\begin{array}{c}-0.1965^{\star \star \star} \\
{[0.0159]}\end{array}$ \\
\hline Dum: Year=2006 & & $\begin{array}{c}-0.2491^{* \star \star} \\
{[0.0107]}\end{array}$ & & $\begin{array}{c}-0.2781^{\star * *} \\
{[0.0154]}\end{array}$ & & $\begin{array}{c}-0.2241^{\star \star \star} \\
{[0.0152]}\end{array}$ \\
\hline Dum: Year=2007 & & $\begin{array}{c}-0.2629 * \star \star \\
{[0.0108]}\end{array}$ & & $\begin{array}{c}-0.2895^{\star \star \star} \\
{[0.0153]}\end{array}$ & & $\begin{array}{c}-0.2400^{\star \star \star} \\
{[0.0157]}\end{array}$ \\
\hline Dum: Year=2008 & & $\begin{array}{c}-0.2697^{\star * \star} \\
{[0.0122]}\end{array}$ & & $\begin{array}{c}-0.3055^{\star \star \star} \\
{[0.0158]}\end{array}$ & & $\begin{array}{c}-0.2387^{\star \star \star *} \\
{[0.0182]}\end{array}$ \\
\hline Dum: Year=2009 & & $\begin{array}{c}-0.2727^{\star \star \star} \\
{[0.0123]}\end{array}$ & & $\begin{array}{c}-0.2991 * * * \\
{[0.0146]}\end{array}$ & & $\begin{array}{c}-0.2499 * \star * \\
{[0.0188]}\end{array}$ \\
\hline Dum: Year=2010 & & $\begin{array}{c}-0.2425^{\star \star \star} \\
{[0.0124]}\end{array}$ & & $\begin{array}{c}-0.2989 * * \star \\
{[0.0146]}\end{array}$ & & $\begin{array}{c}-0.1939 \star * \star \star \\
{[0.0188]}\end{array}$ \\
\hline Dum: Year=2011 & & $\begin{array}{c}-0.2544^{\star \star *} \\
{[0.0125]}\end{array}$ & & $\begin{array}{c}-0.3157^{\star \star \star *} \\
{[0.0148]}\end{array}$ & & $\begin{array}{c}-0.20166^{\star \star \star} \\
{[0.0190]}\end{array}$ \\
\hline $\begin{array}{l}\text { Input Country-Industry by } \\
\text { Destination Country-Industry } \\
\text { Pair FE? }\end{array}$ & Y & $\mathrm{Y}$ & $\mathrm{Y}$ & $\mathrm{Y}$ & $\mathrm{Y}$ & $\mathrm{Y}$ \\
\hline Observations & $17,491,215$ & $17,491,215$ & $8,101,928$ & $8,101,928$ & $9,389,287$ & $9,389,287$ \\
\hline $\mathrm{R}^{2}$ & 0.8602 & 0.8604 & 0.7408 & 0.7414 & 0.8806 & 0.8808 \\
\hline
\end{tabular}

Notes: The left-hand side variable is the Head-Reis index (computed with $\Theta=5$ ) associated with trade costs for intermediate inputs, from industry $r$ in country i purchased by industry $s$ in country $\mathrm{j}$, for trade costs that correspond to input purchases that lie above the main diagonal of the WIOT in each year. Standard errors are multi-way clustered by source country-industry (i,r), destination country-industry $(\mathrm{j}, \mathrm{s})$, and year; ${ }^{* * *},{ }^{* *}$, and * denote significance at the $1 \%, 5 \%$, and $10 \%$ levels respectively. All columns control for source countryindustry by destination country-industry fixed effects. Columns (3)-(4) restrict to the subsample of trade costs where the industry $r$ is from the goods sectors, while Columns (5)-(6) restrict to the subsample where the industry $r$ is from the services sectors. 
Table 5

Head-Reis Trade Costs for Final-Use over Time

\begin{tabular}{|c|c|c|c|c|c|c|}
\hline \multirow{3}{*}{$\begin{array}{r}\text { Dependent variable: } \\
\text { Industries: }\end{array}$} & \multicolumn{6}{|c|}{ log Trade Costs for Final Goods/Services } \\
\hline & (1) & $(2)$ & (3) & (4) & (3) & (4) \\
\hline & All & All & Goods & Goods & Services & Services \\
\hline Year & $\begin{array}{l}-0.0212^{\star \star *} \\
{[0.0039]}\end{array}$ & & $\begin{array}{l}-0.0231 * \star * \\
{[0.0041]}\end{array}$ & & $\begin{array}{l}-0.0196^{\star \star *} \\
{[0.0051]}\end{array}$ & \\
\hline Dum: Year=1996 & & $\begin{array}{c}-0.0217 \\
{[0.0332]}\end{array}$ & & $\begin{array}{c}-0.0510^{\star} \\
{[0.0278]}\end{array}$ & & $\begin{array}{c}0.0029 \\
{[0.0550]}\end{array}$ \\
\hline Dum: Year=1997 & & $\begin{array}{c}-0.1123^{\star \star \star} \\
{[0.0104]}\end{array}$ & & $\begin{array}{c}-0.1306^{\star \star \star} \\
{[0.0146]}\end{array}$ & & $\begin{array}{r}-0.0968^{* * *} \\
{[0.0115]}\end{array}$ \\
\hline Dum: Year=1998 & & $\begin{array}{c}-0.1588^{\star \star \star} \\
{[0.0099]}\end{array}$ & & $\begin{array}{c}-0.2095^{\star \star \star} \\
{[0.0116]}\end{array}$ & & $\begin{array}{r}-0.1161^{\star * *} \\
{[0.0168]}\end{array}$ \\
\hline Dum: Year=1999 & & $\begin{array}{c}-0.1479 \star \star \star \\
{[0.0193]}\end{array}$ & & $\begin{array}{c}-0.1910^{\star \star \star} \\
{[0.0090]}\end{array}$ & & $\begin{array}{r}-0.1115^{\star \star} \\
{[0.0441]}\end{array}$ \\
\hline Dum: Year=2000 & & $\begin{array}{l}-0.2001^{\star \star \star} \\
{[0.0257]}\end{array}$ & & $\begin{array}{l}-0.2445^{\star \star \star} \\
{[0.0162]}\end{array}$ & & $\begin{array}{r}-0.1628^{\star \star \star} \\
{[0.0456]}\end{array}$ \\
\hline Dum: Year=2001 & & $\begin{array}{c}-0.2370^{\star \star \star} \\
{[0.0233]}\end{array}$ & & $\begin{array}{c}-0.2708^{\star \star \star} \\
{[0.0245]}\end{array}$ & & $\begin{array}{r}-0.2084^{\star \star \star} \\
{[0.0360]}\end{array}$ \\
\hline Dum: Year=2002 & & $\begin{array}{c}-0.2295^{\star \star \star} \\
{[0.0179]}\end{array}$ & & $\begin{array}{c}-0.2589 * \star \star \\
{[0.0238]}\end{array}$ & & $\begin{array}{r}-0.2047^{\star * \star} \\
{[0.0359]}\end{array}$ \\
\hline Dum: Year=2003 & & $\begin{array}{c}-0.2500^{\star \star \star} \\
{[0.0251]}\end{array}$ & & $\begin{array}{c}-0.2825^{\star \star \star} \\
{[0.0251]}\end{array}$ & & $\begin{array}{r}-0.2225^{\star \star \star} \\
{[0.0423]}\end{array}$ \\
\hline Dum: Year=2004 & & $\begin{array}{c}-0.2814^{\star \star \star} \\
{[0.0304]}\end{array}$ & & $\begin{array}{c}-0.2951^{\star \star \star} \\
{[0.0303]}\end{array}$ & & $\begin{array}{r}-0.2699 * * \star \\
{[0.0435]}\end{array}$ \\
\hline Dum: Year=2005 & & $\begin{array}{l}-0.3024^{\star \star \star} \\
{[0.0323]}\end{array}$ & & $\begin{array}{l}-0.3417^{\star \star \star} \\
{[0.0372]}\end{array}$ & & $\begin{array}{r}-0.2693^{\star \star \star} \\
{[0.0435]}\end{array}$ \\
\hline Dum: Year=2006 & & $\begin{array}{c}-0.3260 \star \star \star \\
{[0.0307]}\end{array}$ & & $\begin{array}{c}-0.3652^{\star \star \star} \\
{[0.0372]}\end{array}$ & & $\begin{array}{r}-0.2930 \star \star \star \star \\
{[0.0425]}\end{array}$ \\
\hline Dum: Year=2007 & & $\begin{array}{l}-0.3470^{\star \star \star *} \\
{[0.0317]}\end{array}$ & & $\begin{array}{l}-0.3764^{\star \star \star} \\
{[0.0399]}\end{array}$ & & $\begin{array}{r}-0.3223^{\star \star \star} \\
{[0.0429]}\end{array}$ \\
\hline Dum: Year=2008 & & $\begin{array}{c}-0.3524^{\star \star \star} \\
{[0.0391]}\end{array}$ & & $\begin{array}{c}-0.3858^{\star \star \star} \\
{[0.0386]}\end{array}$ & & $\begin{array}{r}-0.3244^{\star * \star} \\
{[0.0555]}\end{array}$ \\
\hline Dum: Year=2009 & & $\begin{array}{c}-0.3588^{\star \star \star} \\
{[0.0392]}\end{array}$ & & $\begin{array}{c}-0.3964^{\star \star *} \\
{[0.0397]}\end{array}$ & & $\begin{array}{r}-0.3272^{\star * \star} \\
{[0.0547]}\end{array}$ \\
\hline Dum: Year=2010 & & $\begin{array}{c}-0.3250^{\star \star \star} \\
{[0.0413]}\end{array}$ & & $\begin{array}{c}-0.3899 * \star \star \\
{[0.0380]}\end{array}$ & & $\begin{array}{r}-0.2704^{\star * \star} \\
{[0.0576]}\end{array}$ \\
\hline Dum: Year=2011 & & $\begin{array}{l}-0.3421^{\star \star \star} \\
{[0.0421]}\end{array}$ & & $\begin{array}{l}-0.4137^{\star \star \star *} \\
{[0.0437]}\end{array}$ & & $\begin{array}{r}-0.2818^{\star \star \star+} \\
{[0.0585]}\end{array}$ \\
\hline $\begin{array}{l}\text { Source Country-Industry by } \\
\text { Destination Country FE? }\end{array}$ & $\mathrm{Y}$ & $\mathrm{Y}$ & $\mathrm{Y}$ & $\mathrm{Y}$ & $\mathrm{Y}$ & $\mathrm{Y}$ \\
\hline Observations & 487,900 & 487,900 & 223,040 & 223,040 & 264,860 & 264,860 \\
\hline $\mathrm{R}^{2}$ & 0.9002 & 0.9005 & 0.7109 & 0.7119 & 0.9140 & 0.9143 \\
\hline
\end{tabular}

Notes: The left-hand side variable is the Head-Reis index (computed with $\theta=5$ ) associated with trade costs for final-use sales, from industry $r$ in country i purchased by country $j$, for all $i<j$. Standard errors are multi-way clustered by source country-industry $(i, r)$, destination country (j), and year; ${ }^{\star * *},{ }^{\star *}$, and ${ }^{*}$ denote significance at the $1 \%, 5 \%$, and $10 \%$ levels respectively. All columns control for source country-industry by destination country fixed effects. Columns (3)-(4) restrict to the subsample of trade costs where the industry $r$ is from the goods sectors, while Columns (5)-(6) restrict to the subsample where the industry $r$ is from the services sectors. 
Table 6

Final-Use Expenditure Shares over Time

\begin{tabular}{|c|c|c|c|c|c|c|}
\hline \multirow[t]{2}{*}{ Dependent variable: } & \multicolumn{6}{|c|}{ log Expenditure Shares, $\alpha_{j}^{s}$} \\
\hline & (1) & (2) & (3) & (4) & (5) & (6) \\
\hline Industries: & All & All & Goods & Goods & Services & Services \\
\hline Year & $\begin{array}{c}-0.0038 \\
{[0.0025]}\end{array}$ & & $\begin{array}{c}-0.0127^{\star \star \star} \\
{[0.0037]}\end{array}$ & & $\begin{array}{c}0.0037 \\
{[0.0025]}\end{array}$ & \\
\hline Dum: Year=1996 & & $\begin{array}{c}0.0016 \\
{[0.0148]}\end{array}$ & & $\begin{array}{l}-0.0087 \\
{[0.0183]}\end{array}$ & & $\begin{array}{c}0.0104 \\
{[0.0200]}\end{array}$ \\
\hline Dum: Year=1997 & & $\begin{array}{l}-0.0078 \\
{[0.0117]}\end{array}$ & & $\begin{array}{l}-0.0230^{\star} \\
{[0.0127]}\end{array}$ & & $\begin{array}{c}0.0050 \\
{[0.0137]}\end{array}$ \\
\hline Dum: Year=1998 & & $\begin{array}{l}-0.0139 \\
{[0.0081]}\end{array}$ & & $\begin{array}{c}-0.0493^{\star \star \star} \\
{[0.0158]}\end{array}$ & & $\begin{array}{l}0.0160 * * \\
{[0.0059]}\end{array}$ \\
\hline Dum: Year=1999 & & $\begin{array}{c}-0.0070^{* * *} \\
{[0.0022]}\end{array}$ & & $\begin{array}{c}-0.0633^{\star \star \star} \\
{[0.0077]}\end{array}$ & & $\begin{array}{c}0.0405^{\star * *} \\
{[0.0036]}\end{array}$ \\
\hline Dum: Year=2000 & & $\begin{array}{c}0.0028 \\
{[0.0060]}\end{array}$ & & $\begin{array}{c}-0.0497^{\star \star \star} \\
{[0.0130]}\end{array}$ & & $\begin{array}{c}0.0470 * * * \\
{[0.0086]}\end{array}$ \\
\hline Dum: Year=2001 & & $\begin{array}{l}-0.0013 \\
{[0.0099]}\end{array}$ & & $\begin{array}{c}-0.0718^{\star \star \star} \\
{[0.0119]}\end{array}$ & & $\begin{array}{c}0.0582^{\star \star *} \\
{[0.0155]}\end{array}$ \\
\hline Dum: Year=2002 & & $\begin{array}{l}-0.0123 \\
{[0.0144]}\end{array}$ & & $\begin{array}{c}-0.0991 * * \star \\
{[0.0104]}\end{array}$ & & $\begin{array}{l}0.0609 * \star \\
{[0.0231]}\end{array}$ \\
\hline Dum: Year=2003 & & $\begin{array}{l}-0.0192 \\
{[0.0159]}\end{array}$ & & $\begin{array}{c}-0.1171^{\star \star \star} \\
{[0.0134]}\end{array}$ & & $\begin{array}{l}0.0633^{\star \star} \\
{[0.0222]}\end{array}$ \\
\hline Dum: Year=2004 & & $\begin{array}{l}-0.0165 \\
{[0.0185]}\end{array}$ & & $\begin{array}{c}-0.1130 \star \star \star \\
{[0.0250]}\end{array}$ & & $\begin{array}{c}0.0648^{\star \star \star} \\
{[0.0212]}\end{array}$ \\
\hline Dum: Year=2005 & & $\begin{array}{l}-0.0136 \\
{[0.0216]}\end{array}$ & & $\begin{array}{c}-0.1123^{\star \star *} \\
{[0.0344]}\end{array}$ & & $\begin{array}{c}0.0697^{\star \star *} \\
{[0.0232]}\end{array}$ \\
\hline Dum: Year=2006 & & $\begin{array}{l}-0.0207 \\
{[0.0234]}\end{array}$ & & $\begin{array}{c}-0.1164^{\star *} \\
{[0.0396]}\end{array}$ & & $\begin{array}{l}0.0601^{\star *} \\
{[0.0245]}\end{array}$ \\
\hline Dum: Year=2007 & & $\begin{array}{l}-0.0226 \\
{[0.0235]}\end{array}$ & & $\begin{array}{c}-0.1188^{\star \star} \\
{[0.0405]}\end{array}$ & & $\begin{array}{l}0.0584^{\star \star} \\
{[0.0247]}\end{array}$ \\
\hline Dum: Year=2008 & & $\begin{array}{l}-0.0315 \\
{[0.0256]}\end{array}$ & & $\begin{array}{c}-0.1409 * * * \\
{[0.0440]}\end{array}$ & & $\begin{array}{l}0.0607^{\star *} \\
{[0.0225]}\end{array}$ \\
\hline Dum: Year=2009 & & $\begin{array}{c}-0.0687^{\star *} \\
{[0.0303]}\end{array}$ & & $\begin{array}{c}-0.2297^{\star \star \star} \\
{[0.0345]}\end{array}$ & & $\begin{array}{l}0.0670 * * \\
{[0.0311]}\end{array}$ \\
\hline Dum: Year=2010 & & $\begin{array}{c}-0.0645^{\star *} \\
{[0.0294]}\end{array}$ & & $\begin{array}{c}-0.2103^{\star \star \star} \\
{[0.0373]}\end{array}$ & & $\begin{array}{c}0.0583^{\star} \\
{[0.0297]}\end{array}$ \\
\hline Dum: Year=2011 & & $\begin{array}{l}-0.0579 * \\
{[0.0292]}\end{array}$ & & $\begin{array}{c}-0.1938^{\star \star *} \\
{[0.0403]}\end{array}$ & & $\begin{array}{l}0.0567 * \\
{[0.0293]}\end{array}$ \\
\hline $\begin{array}{l}\text { Input Industry by Purchasing } \\
\text { Country FE? }\end{array}$ & $\mathrm{Y}$ & $\mathrm{Y}$ & $\mathrm{Y}$ & $\mathrm{Y}$ & $\mathrm{Y}$ & $\mathrm{Y}$ \\
\hline Observations & 24,392 & 24,392 & 11,152 & 11,152 & 13,240 & 13,240 \\
\hline $\mathrm{R}^{2}$ & 0.9833 & 0.9834 & 0.9713 & 0.9715 & 0.9872 & 0.9872 \\
\hline
\end{tabular}

Notes: The sample comprises all countries (41), industries (35), and years (17) in the WIOD. Standard errors are multi-way clustered by country, industry, and year; ${ }^{* *},{ }^{*}$, and * denote significance at the $1 \%, 5 \%$, and $10 \%$ levels respectively. The dependent variable is the log expenditure share in country j on final-use purchases from industry s. All columns control for country-industry (i.e., j-s) pair fixed effects; columns (2), (4), and (6) further include year fixed effects, with the omitted category being the year dummy for 1995. Columns (1)(2) run the regression on all observations; columns (3)-(4) restrict to expenditure shares for purchases from goods industries; while columns (5)-(6) restrict to expenditure shares for purchases from services industries. 
Table 7

Input-Use Shares over Time

\begin{tabular}{|c|c|c|c|c|c|c|}
\hline \multirow[t]{2}{*}{ Dependent variable: } & \multicolumn{6}{|c|}{ log Input-Use Shares, $y_{j}^{r s}$} \\
\hline & (1) & (2) & (3) & (4) & (5) & (6) \\
\hline Industries: & All & All & Goods & Goods & Services & Services \\
\hline Year & $\begin{array}{c}0.0000 \\
{[0.0031]}\end{array}$ & & $\begin{array}{c}-0.0113^{\star \star} \\
{[0.0043]}\end{array}$ & & $\begin{array}{c}0.0097^{\star \star *} \\
{[0.0031]}\end{array}$ & \\
\hline Dum: Year=1996 & & $\begin{array}{c}0.0098 \\
{[0.0160]}\end{array}$ & & $\begin{array}{l}-0.0050 \\
{[0.0186]}\end{array}$ & & $\begin{array}{c}0.0227 \\
{[0.0142]}\end{array}$ \\
\hline Dum: Year=1997 & & $\begin{array}{c}0.0093 \\
{[0.0134]}\end{array}$ & & $\begin{array}{l}-0.0209 \\
{[0.0167]}\end{array}$ & & $\begin{array}{l}0.0351^{\star *} \\
{[0.0131]}\end{array}$ \\
\hline Dum: Year=1998 & & $\begin{array}{l}-0.0031 \\
{[0.0110]}\end{array}$ & & $\begin{array}{c}-0.0580 * * \star \\
{[0.0186]}\end{array}$ & & $\begin{array}{c}0.0437^{\star * *} \\
{[0.0130]}\end{array}$ \\
\hline Dum: Year=1999 & & $\begin{array}{c}0.0013 \\
{[0.0043]}\end{array}$ & & $\begin{array}{l}-0.0728^{\star \star \star} \\
{[0.0087]}\end{array}$ & & $\begin{array}{c}0.0643^{* * *} \\
{[0.0087]}\end{array}$ \\
\hline Dum: Year=2000 & & $\begin{array}{c}0.0204^{* \star *} \\
{[0.0032]}\end{array}$ & & $\begin{array}{l}-0.0544^{\star \star *} \\
{[0.0091]}\end{array}$ & & $\begin{array}{c}0.0840^{* \star *} \\
{[0.0062]}\end{array}$ \\
\hline Dum: Year=2001 & & $\begin{array}{c}0.0450 * \star \star \\
{[0.0119]}\end{array}$ & & $\begin{array}{c}-0.0660 * \star \star \\
{[0.0103]}\end{array}$ & & $\begin{array}{c}0.1391^{\star \star \star} \\
{[0.0157]}\end{array}$ \\
\hline Dum: Year=2002 & & $\begin{array}{l}0.0335^{\star *} \\
{[0.0154]}\end{array}$ & & $\begin{array}{c}-0.0894^{\star \star \star} \\
{[0.0116]}\end{array}$ & & $\begin{array}{c}0.1377^{\star \star * *} \\
{[0.0193]}\end{array}$ \\
\hline Dum: Year=2003 & & $\begin{array}{c}0.0234 \\
{[0.0183]}\end{array}$ & & $\begin{array}{c}-0.1068^{\star \star \star} \\
{[0.0166]}\end{array}$ & & $\begin{array}{c}0.1337^{\star \star *} \\
{[0.0209]}\end{array}$ \\
\hline Dum: Year=2004 & & $\begin{array}{c}0.0353 \\
{[0.0230]}\end{array}$ & & $\begin{array}{c}-0.1028^{\star \star \star} \\
{[0.0276]}\end{array}$ & & $\begin{array}{c}0.1524^{\star \star *} \\
{[0.0242]}\end{array}$ \\
\hline Dum: Year=2005 & & $\begin{array}{c}0.0353 \\
{[0.0260]}\end{array}$ & & $\begin{array}{c}-0.1032^{\star *} \\
{[0.0372]}\end{array}$ & & $\begin{array}{c}0.1526^{\star \star *} \\
{[0.0250]}\end{array}$ \\
\hline Dum: Year=2006 & & $\begin{array}{c}0.0300 \\
{[0.0269]}\end{array}$ & & $\begin{array}{l}-0.1072^{* *} \\
{[0.0415]}\end{array}$ & & $\begin{array}{l}0.1462^{\star * *} \\
{[0.0235]}\end{array}$ \\
\hline Dum: Year=2007 & & $\begin{array}{c}0.0309 \\
{[0.0292]}\end{array}$ & & $\begin{array}{l}-0.1154^{\star *} \\
{[0.0437]}\end{array}$ & & $\begin{array}{l}0.1549 * * * \\
{[0.0254]}\end{array}$ \\
\hline Dum: Year=2008 & & $\begin{array}{c}0.0226 \\
{[0.0318]}\end{array}$ & & $\begin{array}{l}-0.1298^{\star *} \\
{[0.0494]}\end{array}$ & & $\begin{array}{c}0.1518^{\star * *} \\
{[0.0264]}\end{array}$ \\
\hline Dum: Year=2009 & & $\begin{array}{l}-0.0112 \\
{[0.0363]}\end{array}$ & & $\begin{array}{c}-0.2111^{\star \star \star} \\
{[0.0440]}\end{array}$ & & $\begin{array}{c}0.1581^{\star \star \star} \\
{[0.0298]}\end{array}$ \\
\hline Dum: Year=2010 & & $\begin{array}{l}-0.0044 \\
{[0.0352]}\end{array}$ & & $\begin{array}{l}-0.1891^{\star \star \star} \\
{[0.0460]}\end{array}$ & & $\begin{array}{c}0.1520 * \star \star \\
{[0.0297]}\end{array}$ \\
\hline Dum: Year=2011 & & $\begin{array}{l}-0.0021 \\
{[0.0350]}\end{array}$ & & $\begin{array}{c}-0.1773^{\star \star \star} \\
{[0.0486]}\end{array}$ & & $\begin{array}{c}0.1463^{\star \star \star} \\
{[0.0300]}\end{array}$ \\
\hline $\begin{array}{l}\text { Input industry by Purchasing } \\
\text { country-industry FE? }\end{array}$ & $\mathrm{Y}$ & $\mathrm{Y}$ & $\mathrm{Y}$ & $\mathrm{Y}$ & $\mathrm{Y}$ & $\mathrm{Y}$ \\
\hline Observations & 826,130 & 826,130 & 378,258 & 378,258 & 447,872 & 447,872 \\
\hline $\mathrm{R}^{2}$ & 0.9622 & 0.9623 & 0.9543 & 0.9543 & 0.9662 & 0.9662 \\
\hline
\end{tabular}

Notes: The sample comprises all input industries (35), purchasing country-industry pairs $(41 \times 35)$, and years (17) in the WIOD. Standard errors are multi-way clustered by input industry, purchasing country-industry, and year; ***, **, and * denote significance at the $1 \%, 5 \%$, and $10 \%$ levels respectively. The dependent variable is the log share of purchases on inputs from industry $r$ by industry $s$ in country $j$. All columns control for country by industry-pair fixed effects; columns (2), (4), and (6) further include year fixed effects, with the omitted category being the year dummy for 1995. Columns (1)-(2) run the regression on all observations; columns (3)-(4) restrict to input shares for purchases from goods industries; while columns (5)-(6) restrict to input shares for purchases from services industries. 
Table 8

Evaluating the Role of Changes in Trade Costs and Expenditure Shares

\begin{tabular}{|c|c|c|c|c|c|c|c|}
\hline A: Country-level GVC measures & $\begin{array}{l}\text { Mean } \\
\text { FIGO }\end{array}$ & $\begin{array}{l}\text { Mean } \\
\text { VA/GO }\end{array}$ & $\begin{array}{l}\text { Correlation } \\
\text { FIGO, VA/GO }\end{array}$ & $\begin{array}{c}\text { Mean } \\
\mathbf{U}\end{array}$ & $\begin{array}{l}\text { Mean } \\
\text { D }\end{array}$ & $\begin{array}{c}\text { Correlation } \\
\text { U, D }\end{array}$ & $\begin{array}{l}\text { Real wage change } \\
\text { (Min, Mean, Max) }\end{array}$ \\
\hline 1995 baseline (from data) & 0.507 & 0.503 & 0.825 & 1.976 & 1.987 & 0.868 & --- \\
\hline 2011 baseline (from data) & 0.484 & 0.487 & 0.925 & 2.085 & 2.070 & 0.912 & --- \\
\hline \multicolumn{8}{|l|}{1995 to 2011 Shifts } \\
\hline Change trade costs & 0.518 & 0.502 & 0.612 & 1.940 & 1.984 & 0.666 & $(1.003,1.104,1.512)$ \\
\hline Change expenditure shares & 0.516 & 0.513 & 0.857 & 1.945 & 1.953 & 0.889 & $(0.993,1.001,1.017)$ \\
\hline Both changes & 0.525 & 0.511 & 0.660 & 1.917 & 1.952 & 0.705 & $(1.002,1.093,1.434)$ \\
\hline B: Country-industry GVC measures & \multicolumn{3}{|c|}{$\begin{array}{c}\text { Regress F/GO }{ }_{j, t}{ }^{s} \text { on } V A / G O_{j, t}{ }^{s} \\
\left(_{\left.\text {Coefficient on } V A / G O_{j, t}{ }^{s}\right)}\right.\end{array}$} & \multicolumn{3}{|c|}{$\begin{array}{l}\text { Regress } U_{j, t} s \text { on } D_{j, t} s \\
\left.\text { (Coefficient on } D_{j, t} s\right)\end{array}$} & \\
\hline 1995 baseline (from data) & $0.5434^{\star \star \star}$ & $0.5184^{\star \star}$ & 0.0851 & $0.5337^{\star \star \star}$ & $0.4839 * *$ & $0.2564^{\star \star \star}$ & --- \\
\hline 2011 baseline (from data) & $0.6543^{\star \star \star}$ & $0.6373^{\star \star *}$ & $0.2647^{\star * \star}$ & $0.6286^{\star \star \star}$ & $0.5785^{\star \star \star}$ & $0.4156^{\star \star \star}$ & --- \\
\hline \multicolumn{8}{|l|}{1995 to 2011 Shifts } \\
\hline Change trade costs & 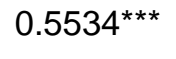 & $0.5321^{\star \star \star}$ & $0.1101^{\star}$ & $0.5270^{\star \star \star}$ & $0.4844^{\star \star}$ & $0.2474^{\star \star \star}$ & --- \\
\hline Change expenditure shares & $0.5942^{\star \star \star}$ & $0.5760 * \star \star$ & $0.1029 *$ & $0.5930^{\star \star \star}$ & $0.5540^{\star \star \star}$ & $0.2753^{\star \star \star}$ & --- \\
\hline Both changes & $0.6009 * \star \star$ & $0.5854^{\star * \star}$ & $0.1193^{\star \star}$ & $0.5856^{\star \star \star}$ & $0.5512^{\star \star \star}$ & $0.2609 * \star \star$ & --- \\
\hline Country FE? & $\mathrm{N}$ & Y & $\mathrm{Y}$ & $\mathrm{N}$ & $\mathrm{Y}$ & Y & --- \\
\hline Industry FE? & $\mathrm{N}$ & $\mathrm{N}$ & $\mathrm{Y}$ & $\mathrm{N}$ & $\mathrm{N}$ & $\mathrm{Y}$ & --- \\
\hline
\end{tabular}

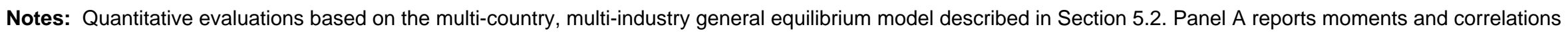

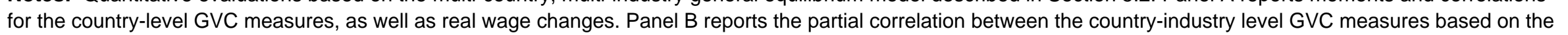
regression specifications in Table 3; standard errors are multi-way clustered by country and industry; ${ }^{* *}$, **, and * denote significance at the $1 \%, 5 \%$, and $10 \%$ levels

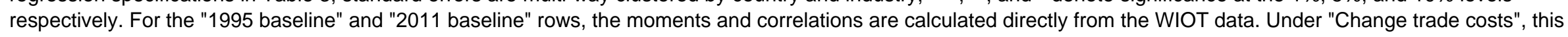
simulates the effect of the observed change between 1995 and 2011 in the Head-Reis trade cost indices computed at the country-sector level after aggregating the industries up to broad sectoral aggregates (i.e., Goods vs Services). The trade costs indices are computed separately for intermediate-use and final-use shipments; for each of these categories, changes in trade costs that fall below the 1st percentile (respectively, above the 99th percentile) are bottom-coded (respectively, top-coded).

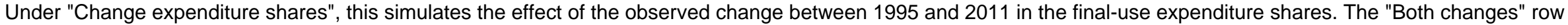
simulates the combined effect of both the above changes in trade costs and final-use expenditure shares. 
Table 9

Counterfactual Projections

\begin{tabular}{|c|c|c|c|c|c|c|c|}
\hline Country-level measures & $\begin{array}{l}\text { Mean } \\
\text { FIGO }\end{array}$ & $\begin{array}{l}\text { Mean } \\
\text { VA/GO }\end{array}$ & $\begin{array}{l}\text { Correlation } \\
\text { FIGO, VA/GO }\end{array}$ & $\begin{array}{l}\text { Mean } \\
\mathbf{U}\end{array}$ & $\begin{array}{l}\text { Mean } \\
\text { D }\end{array}$ & $\begin{array}{l}\text { Correlation } \\
\text { U, D }\end{array}$ & $\begin{array}{l}\text { Real wage change } \\
\text { (Min, Mean, Max) }\end{array}$ \\
\hline 2011 baseline (from data) & 0.484 & 0.487 & 0.925 & 2.085 & 2.070 & 0.912 & --- \\
\hline \multicolumn{8}{|l|}{1995 to 2011 Shifts } \\
\hline Change trade costs & 0.482 & 0.476 & 0.840 & 2.095 & 2.101 & 0.815 & $(1.070,1.207,1.485)$ \\
\hline Change trade costs (Goods only) & 0.483 & 0.480 & 0.836 & 2.089 & 2.091 & 0.811 & $(1.058,1.151,1.269)$ \\
\hline Change trade costs (Services only) & 0.486 & 0.485 & 0.914 & 2.081 & 2.073 & 0.908 & $(1.010,1.048,1.286)$ \\
\hline Change expenditure shares & 0.492 & 0.494 & 0.934 & 2.054 & 2.042 & 0.923 & $(0.997,1.000,1.006)$ \\
\hline $\begin{array}{l}\text { Change trade costs (goods \& services) } \\
\text { and expenditure shares }\end{array}$ & 0.489 & 0.483 & 0.867 & 2.066 & 2.072 & 0.849 & $(1.064,1.189,1.456)$ \\
\hline
\end{tabular}

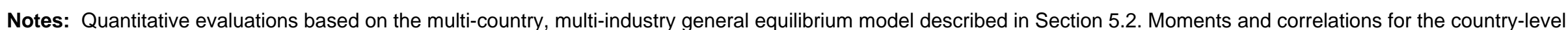

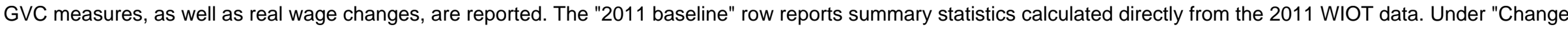

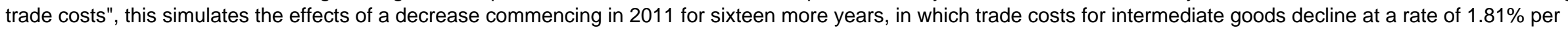

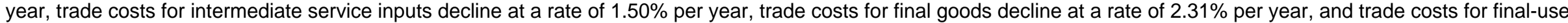

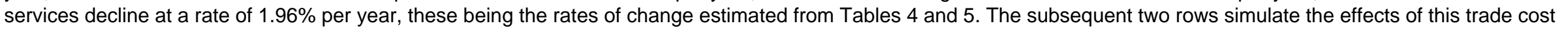
decrease, but applying the decrease to Goods (respectively, Services) industries only. Under "Change expenditure shares", this simulates the effects of a decrease

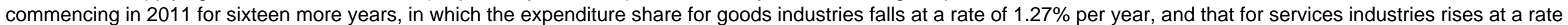

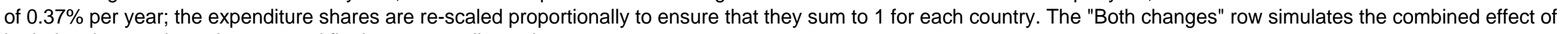
both the changes in trade costs and final-use expenditure shares. 
Table A.1

Summary Statistics: Country-Industry GVC Measures

\begin{tabular}{l|ccc|ccc}
\hline \hline & 10th & Median & 90th & Mean & Std Dev & N \\
\hline \hline F/GO & & & & & & \\
All industries & & & & & & \\
Goods industries only & 0.125 & 0.444 & 0.901 & 0.473 & 0.271 & 24,076 \\
Service industries only & 0.076 & 0.373 & 0.700 & 0.379 & 0.240 & 11,105 \\
& 0.216 & 0.496 & 0.956 & 0.553 & 0.270 & 12,971 \\
VA/GO & & & & & & \\
All industries & & & & & & \\
Goods industries only & 0.279 & 0.456 & 0.738 & 0.489 & 0.186 & 24,395 \\
Service industries only & 0.247 & 0.360 & 0.499 & 0.371 & 0.118 & 11,152 \\
& 0.378 & 0.575 & 0.812 & 0.589 & 0.175 & 13,243 \\
$\underline{\mathbf{U}}$ & & & & & & \\
All industries & & & & & & \\
Goods industries only & 1.153 & 2.126 & 2.914 & 2.098 & 0.649 & 24,395 \\
Service industries only & 1.523 & 2.298 & 3.048 & 2.291 & 0.605 & 11,152 \\
& 1.055 & 1.982 & 2.771 & 1.936 & 0.640 & 13,243 \\
D & & & & & & \\
All industries & & & & & & \\
Goods industries only & 2.033 & 2.381 & 2.728 & 2.376 & 0.316 & 11,152 \\
Service industries only & 1.356 & 1.846 & 2.363 & 1.852 & 0.404 & 13,243 \\
\hline \hline
\end{tabular}

Notes: Based on the country-industry GVC measures calculated from the WIOD for 1995-2011; the sample comprises all 41 countries, 35 industries, and 17 years. Goods industries are defined as primary and manufacturing industries, namely industries 1-16 in the WIOD classification. The service industries are industries 17-35 in the WIOD classification. 